\title{
Breaking the chain: How arrests reduce the probability of near repeat crimes ${ }^{*}$
}

Andrew P. Wheeler ${ }^{1, * *}$, Jordan R. Riddell ${ }^{1}$, Cory P. Haberman ${ }^{2}$

*Data and code to replicate the findings can be obtained from

https://www.dropbox.com/sh/72q0i7wm60ndqve/AABgFB8zwGHG6xjExvaD01EGa?dl=0

**Corresponding author, email: apwheele@gmail.com

1. School of Economic, Political, and Policy Sciences - Program in Criminology \& Criminal Justice

The University of Texas at Dallas

800 West Campbell Road, Mail Station GR 31

Richardson, Texas 75080-3021

2. University of Cincinnati, School of Criminal Justice 


\section{Breaking the chain: How arrests reduce the probability of near repeat crimes}

Objectives: Near repeat patterns have been identified for a host of different crimes, but effective strategies to reduce near repeats have had more variable results. This study identifies near repeat crime patterns in Dallas, Texas and examines the effects of an arrest on reducing the probability of future crime.

Method: Using open source crime data from the Dallas Police Department from July 2014 through June 2018, we identified near repeat patterns for shootings, interpersonal robberies, residential burglaries, and thefts from motor vehicles. Logistic regression models were used to test the effect of an arrest on reducing near repeat crimes; controls for geographic, demographic, and temporal factors were included in each model.

Results: Near repeat calculations suggest violent crime clustered closely in time and space, with property crime dispersed over larger spatial and temporal dimensions. Across all four crime types, findings suggest arrests resulted in $20 \%$ to $40 \%$ reductions in a near repeat follow up crime.

Conclusions: In line with past research on shootings, arrests reduced the likelihood of subsequent crimes. This suggests policing strategies to increase arrests may be a fruitful way to reduce near repeat crime patterns.

Keywords: near repeat, arrests, spatial-analysis, crime-analysis

Link to code to replicate the analysis can be found at:

https://www.dropbox.com/sh/72q0i7wm60ndqve/AABgFB8zwGHG6xjExvaD01EGa?dl=0. 


\section{Introduction}

The fact that crimes cluster in short space time windows, near repeats, is a well established criminological finding for many different types of crimes (Johnson et al., 2007; Ratcliffe \& Rengert, 2008; Youstin et al., 2011). But, policing strategies to reduce the probability of near repeat crimes are much more variable in their effectiveness (Elffers et al., 2018; Groff \& Taniguchi, 2019; Santos \& Santos, 2016; Stokes \& Clare, 2019). Here we focus on if arresting individuals reduces the probability of a near repeat crime.

We build on prior work in two particular ways. Prior analyses of shooting data have established that arrests reduce the probability of near repeat patterns (Wyant et al., 2012). In this work, we establish whether this relationship also holds true for not only shootings in another sample, but also for other instrumental crime types of residential burglaries, interpersonal robberies, and thefts from motor vehicles. If near repeat patterns are largely a function of the same individuals committing multiple offenses in a short spree (Johnson, Summers, \& Pease, 2009), it may be the incapacitation or deterrent effects of an arrest are larger for instrumental crimes than for shootings, which are theoretically driven by retaliatory violence (Loftin, 1986; Ratcliffe \& Rengert, 2008).

Given that macro level evidence of the effectiveness of arrests in reducing future crime are more equivocal (Bursik, Grasmick, \& Chamlin, 1990; Chamlin et al., 1992; Levitt, 1998), examining very small space and time windows provides a more direct test of the efficacy of arrest based strategies that are less influenced by potential endogeneity problems. If arrests provide subsequent reductions in near repeat offending, it can provide the foundation for assessing the benefits of increasing arrest rates in reference to reduced crime rates.

Second, a variety of more recent work has established different predictive factors that correlate with the probability of a near repeat crime (Garnier, Caplan, \& Kennedy, 2018; Moreto, Piza, \& Caplan, 2014; Piza \& Carter, 2018). In addition to formulating a regression model incorporating these demographic and facility factors to account for additional confounds not present in prior work, we also include a factor for the historical density of crimes. Given that hot spots of crime tend to be temporally stable (Curman, Andresen, \& Brantingham, 2014; Weisburd et al., 2004; Wheeler, Worden, \& McLean, 2016), not accounting for the underlying density can result in confounds in predicting which crimes are likely to result in a near repeat offense.

A large sample of four years of open data on crime incidents and arrests from Dallas, Texas was used for this study. Compared to prior work on shootings, we find that arrests tended to have similar effectiveness in reducing the probability of a near repeat offense for all the crimes types examined (Wyant et al., 2012), typically ranging from a reduction of $20 \%$ to $40 \%$ near repeats across different space and time windows. Given the low arrest rates for many of the crime types under study, prioritizing events that have a higher probability of a near repeat crime may be a reasonable strategy for police departments to tackle near repeat crimes.

\section{Literature Review}

\section{Overview of Near Repeat Crime Patterns}

Near repeat crime patterns occur when two or more crimes occur in a short spatialtemporal window. For example, a house is burglarized on a Monday, and the next door neighbor is burglarized the following Wednesday. While most work on near repeat crime patterns has been focused on burglary (Townsley, Homel, \& Chaseling, 2003; Johnson et al., 2007), it has 
been shown to extend to a variety of different crime types: robbery, shootings, theft from motor vehicles, thefts of motor vehicles, arson, assault, economic crimes, piracy, and terroristic events (Behlendorf, LaFree, \& Legault, 2012; Block \& Fujita, 2013; Braithwaite \& Johnson, 2012; Haberman \& Ratcliffe, 2012; Marchione \& Johnson, 2013; Powell, Grubb, \& Nobles, 2018; Sturup et al., 2018; Townsley, Johnson, \& Ratcliffe, 2008; Turchan et al., 2018; Wells, Wu, \& Ye, 2012; Youstin et al., 2011; Zhang et al., 2015).

Two phenomena may explain near repeat patterns: (1) risk heterogeneity (or the flag hypothesis) and (2) state dependence (or the boost hypothesis) (Farrell \& Pease, 1993; Short et al., 2009). Risk heterogeneity is simply the hypothesis that certain areas have a higher overall propensity for crime - hot spots (Weisburd, 2015). Different characteristics of targets/areas can explain that propensity (e.g. see Bowers \& Johnson, 2005). Nonetheless, near repeats in space and time occur simply due to chance due to crimes being more common in those small areas. For example, if a street segment tends to have an average of 10 robberies per year, and those robberies are distributed according to a Poisson distribution, and the probability of a near repeat crime happening within a week on that same street segment is over 17\% (Park \& Eck, 2013).

The second potential explanation of near repeat patterns is state dependence or boost hypothesis. State dependence occurs when the risk of crime over time is not constant, but increases due to a previous victimization. A shooting can increase the risk of a future shooting, due to retaliatory violence (Loftin, 1986; Ratcliffe \& Rengert, 2008). A burglary can increase the risk of a future burglary because a burglar learned an effective way to enter similarly built homes in an area (Bowers \& Johnson, 2004). Another example is that the same offender can victimize multiple targets within a short spree (e.g. stealing from many open cars in the same parking lot in a short time period), or in a more serial nature (e.g. burglarizing a new house every day of the week) (Wheeler, 2016). In the former case, offenders are restricted to a short spatial window due to not being able to travel far in a particular time period (Ratcliffe, 2006). The latter can potentially be within a larger spatial area, but due to offenders limited awareness space of potential victimizable targets (Brantingham \& Brantingham, 1993) they often forage in a smaller, known areas for potential victims (Jacobs, 2010). ${ }^{1}$ Several studies have confirmed (using arrest data), that near repeat crimes are more likely to have been committed by the same offender (Bernasco, 2008; Davies \& Marchione, 2015; Johnson, 2013; Johnson et al., 2009). One study even found that the probability of a near repeat in space and time is higher for networked offenders, suggesting that offenders may vicariously share information on potential targets (Lantz \& Ruback, 2017).

Recently, researchers have attempted to identify the spatial characteristics that predict whether a crime is likely to result in a near repeat. Broadly, these involve either identifying micro place characteristics of the built environment (Garnier et al., 2018; Moreto et al., 2014; Piza \& Carter, 2018) or neighborhood demographic characteristics (Bowers \& Johnson, 2005; Johnson, Bowers, \& Hirschfield, 1997; Nobles, Ward, \& Tillyer, 2016).

Studies that focus on micro places tend to measure nearby facilities and land uses that increase the probability of a near repeat event. For just one example of a facility, both Moreto et al. (2014) and Garnier et al. (2018) examined whether places nearby pawnshops increased the chance of a near repeat burglary or robbery victimization (respectively) in Newark, New Jersey. Piza \& Carter (2018), examining burglary and motor vehicle thefts in Indianapolis, classified

\footnotetext{
${ }^{1}$ One conflicting finding to this is in Wheeler (2012), who finds that future offending locations tend to be quite far apart, on average over 1.5 kilometers. But, he does also find though that events closer in time tend to be closer together in space.
} 
crimes into either isolated events, initiator events, or near repeat events. They then used multinomial models based on local land use factors and a neighborhood measure of social disorganization to identify whether those characteristics are more likely to predict initiator events.

Studies that examine greater neighborhood characteristics often find that areas with higher levels of concentrated disadvantage have more near repeats (Bowers \& Johnson, 2005; Johnson et al., 1997; Nobles et al., 2016). While this makes sense, in that those areas also tend to be higher crime, others have found wide spatial variations in near repeats (Groff and Taniguchi, 2018; 2019), or that near repeat patterns spatially shift over time (Johnson \& Bowers, 2004). One additional explanation for more near repeats in disadvantaged neighborhoods (beyond they are typically higher crime) is that individuals in low-income areas lack the capital to fund physical security measures (Johnson, et al., 1997; Bowers \& Johnson, 2005; Nobles et al., 2016).

Understanding spatial variations in near repeat risk can help identify efficient strategies to allocate resources to mitigate future risk. Contrary to one's intuition, Chainey et al. (2018) find that most near repeats occur outside of hot spots, and so police strategies to address near repeats are not as simple as chasing the dots on the map following a crime that may result in a near repeat event (also see Haberman \& Ratcliffe, 2012).

\section{Crime Prevention Based on Near Repeats}

Crime prevention undertaken by policing agencies in response to near repeat patterns can be broadly classified under three types: (1) victim focused strategies (i.e. target hardening), (2) proactive policing strategies (e.g. more patrols in the area of the near repeat crimes), and (3) arrest based strategies.

Victim focused strategies have been applied towards preventing near repeat burglary victimization. Such interventions have included publicly funded target-hardening installations (Hirschfield, Newton, \& Rogerson, 2010), contacting the victims of burglary and providing informational pamphlets to them and neighbors (Stokes \& Clare, 2019), and conducting security audits to reduce the likelihood of a future residential burglary (Groff \& Taniguchi, 2019). Target hardening approaches can focus on area based characteristics or at-risk targets, but Hirschfield et al. (2010) suggest a combined approach. Hirschfield et al. (2010) and Stokes and Clare (2019) find publicly funded prevention investments were not cost effective solutions and repeat burglary risk did not decrease in the respective studies. Results from Groff and Taniguchi's (2019) study also indicate no significant difference between control and treatment zones where a target hardening strategy was implemented.

Proactive policing strategies are those that devote extra patrol resources in response to near repeat events. Fielding \& Jones (2012) find that deploying extra patrols in Trafford, England in response to near repeat burglaries over an extended period of time resulted in a $27 \%$ reduction of burglaries over a 12 month period. Although not specifically focused on responding to near repeat patterns, Wells \& Wu (2011) do not find evidence that a specialized gun crime unit in Houston reduced near repeat shootings. In a predictive policing study of proactive patrol (in which targeted locations are both based on historical patterns, as well as elevated risk due to near repeats), Mohler et al. (2015) find slight reductions in overall crime. Finally, Elffers et al. (2018) examination of foot patrols in the area surrounding a burglary location found no difference in burglary crime rates after comparing the treatment and control groups.

Additionally, Santos and Santos published a series of articles using data collected by the Port St. Lucie Police Department on proactive policing in micro-time hot spots. Micro-time hot 
spots effectively represent near repeat patterns. Four studies demonstrated the effectiveness of directed police patrols in reducing residential burglaries and thefts from motor vehicles (Santos \& Santos, 2016). Immediate, directed patrol and increases in police response reduced residential burglaries and thefts from motor vehicles in micro-time hotspots (Santos \& Santos, 2015a; Santos \& Santos, 2015b; Santos \& Santos, 2015c).

Finally, two studies have examined the impact of arrest strategies on subsequent gun crimes (Wu \& Wells, 2016; Wyant et al., 2012). In a study of over 5,000 firearm arrests and shootings in Philadelphia, Wyant et al. (2012) demonstrated using a modified bivariate Knox-test that following an arrest, firearm shootings within 800 feet and 4 days were lowered by about 28\%. In a replication study in Houston, Wu and Well's (2016) find more mixed results, although they do detect fewer shootings than expected at 400 feet and four days after the arrest.

Given the mixed results of victimization and proactive policing strategies, reducing near repeat victimization via arrests may be a fruitful approach. There are two theoretical mechanisms through which arrests can subsequently reduce future offending: (1) deterrence and (2) specific incapacitation. Arrests are hypothesized to decrease crime by signaling to would-be offenders that the risk of apprehension is high (Wilson \& Boland 1978; Sampson \& Cohen, 1988). In short, offenders may observe an arrest and increase their risk perceptions, or hear about an arrest from others (Parker \& Grasmick, 1979; Stafford \& Warr, 1993; Wyant et al., 2012; Lantz \& Ruback, 2017).

Alternatively, offenders who are arrested and subsequently incarcerated will be specifically incapacitated as they will not have the capability to commit another offense. Even if offenders are then subsequently released within a short window (such as on bail), presumably their internal estimate of the probability of being caught in the future should be increased (Anwar \& Loughran, 2011; Piquero et al., 2011). If near repeat victimization is driven by high-risk offenders repeatedly committing crimes, then arrests should be particularly effective at reducing the likelihood of a near repeat incident.

Although past analyses of firearm arrests and shootings have shown fleeting effects, shootings are one type of near repeat pattern that is not theoretically explained by the same offender committing multiple offenses in a short time period, but by retaliatory violence. So it seems likely that specific deterrence or incapacitation due to an arrest is likely to have a much larger effect reducing near repeats for instrumental crimes, such as burglaries, robberies, and thefts from motor vehicles. Thus, this analysis extends prior work examining the micro spatial patterns of shootings and firearm arrests to examine the impact of arrests on near repeat patterns of more crime types.

Based on this prior literature, we subsequently test two hypotheses in this work:

Hypothesis 1: An arrest will reduce the probability of a near repeat burglaries, robberies, shootings, and thefts from motor vehicles.

Hypothesis 2: An arrest will reduce the probability of a near repeat shooting, but will have a smaller effect compared to instrumental crimes. 


\section{Data and Methods}

Data

Dallas, Texas is the study site. Data were collected from [number] sources. First, crime incident and arrest data from July 2014 through June 2018 were provided by the Dallas Police Department The specific crime types included were shootings, interpersonal robberies, residential burglaries, and thefts from motor vehicles. Second, data for control variables capturing the locations of potentially criminogenic facilities and land use were taken from different open data sources, such as the street index database (Cortright \& Mahmoudi, 2016), Dallas county parcel data, and commercial databases such as Lexis Nexis and Reference USA. Third, sociodemographic control variables were developed using the 2014 five year American Community Survey estimates at the block group level.

\section{Dependent Variable}

Recall the present study tests if arrests reduce the probability of a near repeat crime incident in the future. The dependent variable is a dichotomous measure of whether or not a subsequent crime incident occurs within a specific spatial-temporal window of each crime. For every crime event, we conduct a search of whether a future crime occurred within a particular distance and time threshold, and label that a "1". All crimes that did not result in a near repeat were then coded "0". So instead of the approach in Piza and Carter (2018) which classifies crimes into isolates, initiator, or near repeat crimes, here each crime incident is a unit of analysis and has the potential to be an initiator event. This is key because recent research has demonstrated that an incident that is a near repeat to a previous originator may later become an originator (i.e., near repeat chains; see Haberman \& Ratcliffe, 2012), which is accounted for in the present approach. For simplicity in the main analysis, we focus on identifying near repeat crime events within 1,000 feet and 7 days. This is based on past research on typical sizes of near repeat patterns, along with our estimates of significant near repeats in this sample tend to always be significant among the different crime types given that window. But, given selecting spacetime thresholds is arbitrary (Ratcliffe \& Rengert, 2008), sensitivity analyses to examine the deterrent effect of an arrest over different time and space thresholds are also shown. ${ }^{2}$

\section{Independent Variables}

The main independent variable of interest in this analysis is whether a crime event resulted in an arrest. Events which are recorded as having an arrest are then coded as a "1", and events without an associated arrest are coded as a " 0 " in the subsequently regression models. We do not count case clearances via other means (e.g. "exceptional clearance"), only those cases specifically mentioning an arrest occurred are coded as " 1 ".

Statistics for the number of crimes and the proportion of near repeats within 1,000 feet and 7 days are broken down by whether an arrest occurred and are included in Table 1. From this, one can surmise that arrests have a small effect, around a $10 \%$ reduction in near repeat

\footnotetext{
${ }^{2}$ Because we examine crimes up to a month into the future in the sensitivity analyses, only initial events occurring through May 2018 are included in the search for a future crime event.
} 
crimes for shootings and interpersonal robberies and a $20 \%$ reduction for burglaries. However, thefts from motor vehicles increase slightly. Arrest rates for each crime type vary inversely with their severity and frequency; shootings have the highest overall arrest rate (26\%), followed by robberies $(12 \%)$, burglaries $(4 \%)$, and thefts from motor vehicles $(3 \%)$.

\section{[INSERT TABLE 1 HERE]}

As previously mentioned, the probability of a near repeat is greatly influenced by the baseline density at which the crime occurs (Park \& Eck, 2013). More simply, long term hot spots will have more near repeats due to them being hot spots. As such, it is important to take this prior crime density factor into account. To do this, we use historical crime data that was provided directly by the Dallas PD from 2010 through June $30^{\text {th }} 2014$ to measure the historical crime density for each specific crime type. We use historical data is to prevent the measure from being endogenous with the near repeat outcome measure, which is examined using data from July $1^{\text {st }}$ 2014 through June $30^{\text {th }}$ 2018. Given that hot spots of crime tend to be quite temporally stable over time (Andresen, Curman, \& Linning, 2017; Curman et al., 2014; Weisburd et al., 2004; Wheeler, Worden, \& McLean, 2016), these historical measures are suitable to control for that historical crime density, while providing a measure that is not endogenous with the current crime data being predicted.

For a simplified example of our analysis, say a theft from a motor vehicle occurred at the coordinates $[0,0]$ on $1 / 1 / 2016$, and we are interested in examining near repeats within 7 days and 1,000 feet. If another theft from a motor vehicle occurred at coordinates $[100,100]$ on $1 / 4 / 2016$, we would classify that origin event as having a near repeat " 1 " for the outcome. Additionally, if an arrest did not occur for that origin event, it would receive " 0 " for the arrest indicator. As some places have many more crimes than others, we also include a term of all thefts from motor vehicles that occurred within 1,000 feet of the [0,0] coordinate in the historical crime data (from $1 / 1 / 2010$ through 6/30/2014). To illustrate how this would potentially impact the results, imagine two scenarios: one in which there were a total of 50 crimes within 1,000 feet of $[0,0]$ in the historical data, versus 300 crimes within 1,000 feet in the historical data, which equal a density of approximately 0.2 and 1.3 crimes on a per 7 day basis respectively. For the lower density estimate under a Poisson process, it would be expected to have a near repeat crime $20 \%$ of the time within 7 days simply by chance. Whereas for the higher density estimate it would be expected to have a near repeat $73 \%$ of the time.

Because the prior crime density can have such a large impact on the resulting probabilities of a near repeat crime, it is not only important to include as a potential covariate in the analysis, but we also examine its interaction with whether an arrest reduces the probability of a near repeat crime. In areas that have a very low probability of a near repeat, it may be that arrests are not as effective in preventing a future crime (a floor effect). It also may be the case in areas where crimes are very common (so have a very high probability of a near repeat) arrests additionally do not appear to be effective (a ceiling effect). The latter may especially be the case if a place is very heterogeneous in who commits a crime there, and so many near repeats are not a function of the same offender(s) committing multiple crimes. The ability to model different effects in a regression framework are one reason we use a regression modelling approach, as opposed to the modified Knox test approach as used in Wyant et al. (2012).

Given prior work showing that near repeat patterns are influenced by different facilities, we have included these additional factors into our model (Garnier et al., 2018; Moreto et al., 
2014; Piza \& Carter, 2018). We include a total of eighteen different crime generator factors. Each of these crime generators are encoded as distance from a crime to the nearest crime generator. Given these are control variables and are not the main interest of the analysis, we do not spend substantial time examining these factors in the subsequent models. Wheeler and Steenbeek (2019) provide a more detailed description of the data sources and how they are relevant in predicting micro level crime patterns, which similarly extends to predicting near repeat crime patterns (Garnier et al., 2018; Piza \& Carter, 2018).

These particular crime generator factors include commercial establishments: (1) large business retailers (e.g. Walmart, The Home Depot, CVS), (2) smaller food and clothing stores, (3) gasoline stations, (4) eating and drinking places, (5) liquor stores, (6) large entertainment areas (e.g. movie theaters, concert halls), (7) smaller entertainment areas (e.g. gyms, bowling alleys) and hair salons, (8) motels, (9) hotels, (10) shopping malls, (11) banks, and (12) check cashing stores. We also included non-commercial land use factors of (13) libraries, (14) middle and high schools, (15) public railway stations (DART Stations), (16) apartment complexes, (17) hospitals, (18) mobile home parks.

We also include a set of covariates based on the residential census demographics, again similar to that in Piza and Carter (2018). These measures are taken from the 2017 five year American Community Survey estimates. These measures include: (1) the percent of families in poverty, (2) the percent of individuals unemployed (of those over 16 and in the workforce), (3) the percent of individuals receiving some type of government assistance, (4) the percent of female headed households with children under eighteen, (5) the percent of the population that is Hispanic, (6) the percent of the population that is Asian, (7) the percent of the total population that is non-Hispanic black, (8) the proportion of families that have moved in the prior year, and (9) the total number of the population under 17. These are similar to measures that have been used in prior near repeat analyses (Piza \& Carter, 2018; Ratcliffe, Taylor, \& Perezin, 2016), and represent typically well established factors that proxy social disorganization theories of crime (Pratt \& Cullen, 2005; Sampson, Raudenbush, \& Earls, 1997; Shaw \& McKay, 1969).

The final set of factors are temporal controls. We include a set of dummy variables for the month of the incident and a linear time trend (as crimes have overall been slightly decreasing in Dallas over the examined period). These should take into account potential seasonal or overall time trend effects, which may result in particular periods having a higher or lower probability of a near repeat crime in space and time (Piza \& Carter, 2018). Table 2 provides descriptive statistics for the other variables used in the analysis, aggregated across each crime type.

\section{[INSERT TABLE 2 HERE]}

\section{Methods}

To test whether an arrest results in a reduced probability of a near repeat event, we use logistic regression analysis. In this model we include whether the current crime resulted in an arrest, the prior crime density per week (based on the same threshold distance for crimes occurring from 2010 through June 2014), an interaction between the two, and the remaining crime generator, and demographic and temporal control variables as have been used in prior research. The logistic regression model can then be formally written as: 


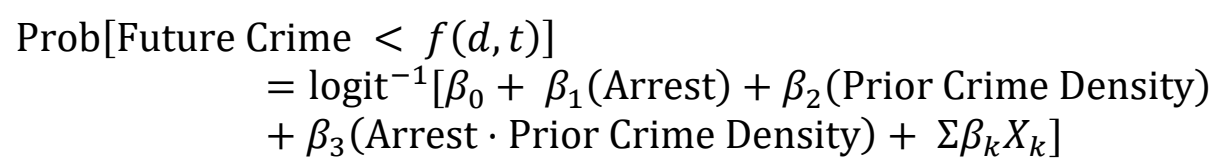

Where we predict the probability that a future crime occurs within a threshold distance $d$ and time $t$. Hypothesis 1 is that $\beta_{1}$, the coefficient for whether an arrest occurred, is negative and so reduces the probability of a near repeat. Given that we also estimate an interaction between arrests and prior crime density (i.e. arrests may be more or less effective in high crime areas), we assess this effect using marginal effect estimates over the domain of prior crime densities, holding all other variables at their means (Mize, 2019). The remaining control variables are then represented as $\beta_{k} X_{k}$.

This model is estimated for individual crime types of thefts from motor vehicles, interpersonal robberies, residential burglaries, and shootings. Hypothesis 2 is that while we expect that the arrest effect for shooting incidents is negative (Wyant et al., 2012), it is closer in absolute magnitude towards zero than the other instrumental crimes.

\section{Results}

\section{Near Repeat Analysis}

Knox ratios and accompanying p-values for each of the four crime types were generated for 30 spatial bins (100 feet each) and 30 temporal bins (1 day each), using 99 permutations to assess statistical randomness in the results (Tables listed in Appendix B due to their size). Results from the near repeat calculations suggest the day after an instigator event carries the highest risk for a repeat or near repeat event for each of the four crime types, but overall patterns in time and space deviate between crime types. Shootings were found to cluster closely in time and space, with the highest level of risk for a repeat shooting occurring in the first day and within 300 feet of the instigator incident. Near repeat interpersonal robberies showed a larger spatial and temporal distribution than shootings, with an increased risk to the surrounding area (0-300, $500-700,1900-2200,2400-2700$ feet) during the day after a robbery. The risk to the 3000 feet around the initial robbery decreases as time passes. This is true for residential burglaries and thefts from motor vehicles but to a lesser extent.

For a month after a burglary or vehicle break in, the offense location carries a higher risk of near repeat offenses. Up to a week after the instigator event, near repeat burglaries and vehicle break-ins follow the pattern of a series of crimes occurring closer to the initial offense location within the week and then spreading in distance as time continues. These findings are consistent with prior research finding near repeat patterns are more likely than by chance, and that those patterns fade for further spatial and time distances, but it is difficult to make specific rules for how far away in space or time near repeat patterns are likely to occur across crime types.

\section{Regression Model Results}

Table 3 displays the results of logistic regression models predicting the likelihood of a future crime for each crime type based on a series of spatial, temporal, and population characteristics, the historical crime density (number of crimes per week from 1/1/2010 - 
6/30/2014), and if there was an arrest for each offense. The tables are limited to coefficients for arrests and prior crime density. Appendix A contains a full set of the coefficients for the models.

The presence of an arrest reduces the likelihood of future interpersonal robberies (at pvalue 0.09), but all other direct effects of arrests across the crime types are not statistically significant. Considering the interaction effects, as the historical crime density increases, the effect of an arrest gets smaller for both thefts from motor vehicles and burglaries, although the pvalues for those interaction effects are above 0.05 . This provides evidence that arrests have a larger deterrent effect in high crime areas for those two crimes. The interaction effects for robberies and shootings are positive, suggesting that arrests have a larger deterrent effect in low crime areas, but again have p-values above 0.05 . Overall these results suggest that arrests have little impact on the probability of a near repeat event, but we graph the estimated reduction in the probability of arrest conditional on the historical crime density, as the interaction effects are difficult to intuitively understand.

\section{[INSERT TABLE 3 HERE]}

Each of the following four figures contain two graphs; the left hand side of Figures 1-4 illustrates the effect of historical crime density on the probability of a future crime depending on the presence of an arrest, holding all other control variables at their means, for each of the crime types under examination. The right hand side graph shows a confidence interval of the difference between those two predicted probability lines, and a pairwise $95 \%$ confidence interval of that difference in probabilities.

\section{[INSERT FIGURE 1, 2, 3, AND 4 HERE]}

In Figure 1, showing the probability of a future robbery within 1,000 feet and 7 days, one can see arrests decrease the probability of a future crime at low historical crime densities, and then predict a higher probability of a future offenses and higher historical crime densities. Examining the difference between these probabilities shows that the confidence interval of the difference in those probabilities covers 0 for the entire line. Figure 2 for burglaries appears to be more promising - even though each individual coefficient was not statistically significant at the 0.05 level, the predicted reduction in future burglaries appears to be much larger when taking into account the interaction effect. At areas with the highest historical crime density in the data, an arrest results in over a $20 \%$ reduction in a future near repeat burglary occurring. Figure 3 (shootings), shows very little difference in the estimated predictions. Thefts from motor vehicles (Figure 4) shows reductions in higher crime areas, but the confidence interval of the difference tends to always cover 0 .

The prior analysis focused on the crime reduction effects given a specific distance and time threshold, 1000 feet and 7 days specifically. Given that these thresholds are arbitrary, we have conducted additional analyses to examine the crime reduction effect of arrests at the distance thresholds of 500 to 3000 feet (in increments of 500 feet), as well as the time thresholds of $3,7,14,21$, and 28 days. Note these are cumulative thresholds, and so an event with a near repeat in 500 feet and 3 days will also count as a near repeat within 2000 feet and 14 days. We fit the same models as previously, controlling for the characteristics of the built environment, demographic factors, as well as the prior crime density (within the corresponding distance 
buffer). While we also include the interaction effect of the arrest and prior crime density in these models (same as before), here we focus on the direct effects of arrests for simplicity.

Figure 5 plots the linear coefficient of the effect that an arrest has on the probability of a future crime, illustrating the varying effects over different distance (the $\mathrm{X}$ axis) and day (different lines) near repeat events for each crime type under examination. For ease in interpretation, standard errors are not included on the chart, but coefficients with a p-value of less than 0.05 have an additional point superimposed on the line. The general patterns for each crime type show that larger temporal bands (grey to green) tend to show greater crime reduction effects, and the shorter temporal bands of 3 and 7 days (brown), tend to hover close to the null of zero crime reductions. Robberies at shorter distances of 500 to 1500 feet tend to show the largest crime reductions, but for the other crime types larger distances of 2000 to 3000 feet tend to have the largest reductions in near repeats. The main analysis examining the near repeat reduction effects at 7 days and 1000 feet then appear to be conservative estimates across all of the different crime types.

\section{[INSERT FIGURE 5 AND FIGURE 6 HERE]}

Thefts from motor vehicles actually show a statistically significant increase in the probability of a near repeat at the shortest distance and time interval examined (500 feet and 3 days). A potential explanation for this is that the current analysis does not take into account the timing of when the arrest occurred (that is not available in the open dataset), and so multiple events in a short period (e.g. someone breaking into five different cars in the same parking lot over a short time period in a single spree) will result in a near repeat event, but one that is unactionable from the police departments perspective (Groff \& Taniguchi, 2018). If those runs of many crimes are more likely to result in increased police scrutiny and a subsequent higher probability of an arrest, our estimate of the reduction of near repeat events outside of the initial string will be biased upwards. To account for this given the data that is accessible, like Groff and Taniguchi (2019) we eliminate near repeat events that occur within 24 hours of the initial event and re-run the same analyses. Those results are displayed in Figure 6.

The results when eliminating near repeat events within 24 hours of the initiating event generally show that arrests have a larger effect of reducing the probability of a near repeat crime. The exception to this is burglaries, which show near equivalent patterns to the original results. Robberies now show the strongest effects at 3 or 7 days and 1500 feet, but have similar effects at larger time bins and shorter distance bins. Thefts from motor vehicles tend to again show greater deterrent effects at larger distance and temporal bins, as do shootings. Of those statistically significant effects, they tend to hover in between coefficients of -0.2 and -0.5 for all crime types, which when exponentiated correspond to odds ratios of 0.82 and 0.61 respectively. This suggests a fairly consistent estimate of the reduction of a near repeat crime on the magnitude of $20 \%$ to $40 \%$ following an arrest, albeit at varying distance and temporal thresholds for each crime type examined here.

In reference to hypothesis 2 , that shootings will have a smaller near repeat reduction following an arrest, this does not appear to be the case for any of these analyses at varying distance and time thresholds. Consistent with the prior analysis focusing on 1000 feet and 7 days, if anything there is weak evidence that arrests following a shooting result in a larger reduction of a near repeat event than the other instrumental crime types examined. Given the size of the standard errors, conducting an actual test of the differences in coefficients, the contrasts would 
rarely show a statistically significant difference between the effects for different crime types over the majority of the different space and time thresholds. Thus there is no evidence here that arrests for instrumental crimes result in larger reductions of near repeat crimes than shootings.

\section{Discussion}

To recap the findings, we find mixed evidence of the reduction in near repeat crimes following an arrest across different instrumental and expressive crime types. While the space and time distances at which reductions were observed varied across the different crime types, in total the largest reductions tended to be around 20\% to $40 \%$ for each crime type. This replicates the findings of prior work only examining shootings and arrests by Wyant et al. (2012), who found in Philadelphia that an arrest reduced the probability of a near repeat crime by approximately $30 \%$ to $50 \%$. Unlike the findings in Wyant et al. (2012) though, the space-time distance of those effects were observed at larger distance and temporal bins across the crime types, more frequently at 2,000 feet and 21 days or more, compared to only around 1,000 feet and a few days for Wyant et al. (2012). This is also counter to the findings in Wu and Wells (2016), who only find evidence of a deterrent effect on shootings for arrests in a smaller space-time window.

In reference to the importance of the findings towards theory, prior evaluations of macro and neighborhood level patterns of arrests and subsequent crime declines have tended to produce mixed findings (Bursik et al., 1990; Chamlin et al. 1992; Levitt, 1998). Examining the reduction in near repeat crimes provides a way to show a relationship between arrests and subsequent crime in a more precise way than is possible when examining aggregate level statistics. It is still the case that one cannot identify the difference between specific incapacitation as opposed to general deterrent effects with this limited administrative data, but given that we know many crimes are committed by a few individuals (Ratcliffe \& Kikuchi, 2019), focusing on solving near repeat crimes seems a fruitful tactic for police departments to attempt to improve on.

Unlike hypothesized, we do not find evidence that the arrest effect is larger for instrumental crimes relative to an arrest for shootings. This is an important finding that not only replicates prior findings for the deterrent effect of arrests following shootings (Wyant et al., 2012), but provides evidence that solving violent crimes results in a lower probability of retaliation (Leovy, 2015). Improving clearance rates for serious violence is not impossible (Braga \& Dusseault, 2018) and is also expected to have downstream effects of improving perceptions of police as well (Braga, Brunson, \& Drakulich, 2019). These estimates of crime reductions can potentially be used to justify increased detective resources, especially given the costs associated with serious violence (Hunt, Saunders, \& Kilmer, 2019). Beyond policing, it is possible that community outreach violence interrupters also reduce the probability of retaliatory violence (Butts et al., 2015), and their effectiveness could be determined in a similar manner to the analysis we have conducted here.

The same rationale could be applied to devoting more investigatory resources towards solving instrumental crimes of theft from motor vehicles and burglary, but those crimes tend to have a much lower cost to the police (Hunt et al., 2019). As prior work suggests police departments already take quite seriously shootings and near repeat robberies (Haberman \& Ratcliffe, 2012; Wyant, 2014), it may be the case that other cost-effective strategies will be needed to improve arrest rates to prevent near repeat crimes. Technological solutions can be potentially used to increase arrest clearances, such as CCTV (Piza, Caplan, \& Kennedy, 2014; Ratcliffe et al., 2019) or street lighting (Chalfin et al., 2019). It may be feasible to move such 
cameras or lights in response to an emerging chain of near repeats, as opposed to relying on permanent locations for either.

It may also be the case that police can differentially devote resources to cases that have a higher probability of a near repeat offense. One way to do this is to identify cases in which there is a higher probability of a near repeat crime (Garnier et al., 2018; Moreto et al., 2014; Piza \& Carter, 2018), and then devote more detective resources to those events (or prevent them from being triaged). Another may be to use other automated detection processes to identify if a particular crime is linked to other crimes (Chohlas-Wood \& Levine, 2019; Porter, 2016). Again, those criminal events within a linked chain should then get higher priority from detectives, as those individuals have established a prior history that suggests they will commit a future crime.

The findings that arrests reduce near repeats within the range of 20 to 40 percent should also be taken in light of evidence of the mixed findings of target hardening approaches (Groff \& Taniguchi, 2019; Stokes \& Clare, 2019). It is also true that traditional police responses, such as increased patrol or street stops, may be a mechanism for police to reduce near repeat crime events (Santos \& Santos 2015c; Santos \& Santos, 2016; Wooditch \& Weisburd, 2016). While individuals typically have positive perceptions of police undertaking such target hardening responses to burglaries (Antrobus \& Pilotto, 2016; Groff \& Taniguchi, 2019), the lack of consistent evidence showing crime reduction effects undermines their overall utility. It may be those resources are better spent on general patrol or detective resources to solve crimes.

The findings should be interpreted in light of several limitations for the analysis. A major limitation of the work is that this is an observational research design. It is possible that arrests are confounded with other factors that explain their correlation with subsequent reductions in near repeat crimes. One example in which this could occur would be if less professional individuals are more likely to be arrested following a crime, and those same individuals are also less likely to commit another crime in the near future. This would result in a bias that concludes arrests have a larger deterrent effect on near repeat crimes than they do in reality. We attempt to take into account potential biases by including covariates for the historical crime density at places, as well as a host of other crime generator and demographic characteristics (Piza \& Carter, 2018). But absent an experiment or stronger quasi-experimental design this will always be a threat to the validity of the findings.

The bias could work the other way as well, in that if an individual commits multiple crimes in a short period, those strings of crimes are likely to gather more police attention (Haberman \& Ratcliffe, 2012), and subsequently have a higher rate of being solved. So arrests are associated with more crimes in the short term. This is partially solved in the analysis by only counting near repeats that occur 24 hours post the initial event (Groff \& Taniguchi, 2018), and the evidence indicates this bias occurs for robberies, thefts from motor vehicles, and shootings given the results, but not for burglaries. Future work could distinguish between the exact temporal timing of arrests associated with the criminal event. Only particular configurations of near repeats in which associated events are outside of a certain range are actionable from a police department's perspective (Davies \& Marchione, 2015).

A second limitation is that given the unknown potential space-time window of where we should observe a deterrent effect conditional on arrest, we test the deterrent effect given different space and time thresholds. While here this illustrates that larger deterrent effects are seen at larger space time windows, it also brings up the possibility that multiple comparisons are a reasonable explanation for the findings. Despite the large sample sizes, tests of crime reductions tended to only show a statistically significant crime reduction effect by a small margin. One 
potential way to account for this in future research is to estimate the decay effect directly, such as by decomposing the offspring effect in a Hawkes model into two components, crimes with and without arrests (Achab et al., 2018; Mohler, Carter, \& Raje, 2018; Reinhart \& Greenhouse, 2018).

The findings here will ultimately need to be tested in the field to prove their worth. As such, future research should focus on experimental or quasi experimental designs which attempt to improve arrest rates following crimes. Identifying cases that have a higher probability of resulting in a near repeat offense and devoting more investigative resources is one way in which that can be accomplished (Garnier et al., 2018). Another is identifying chains of near repeats and increasing investigative resources in response (Haberman \& Ratcliffe, 2012). In either case the results here are promising that such initiatives have excellent potential to reduce near repeat crimes. 


\section{References}

Achab, M., Bacry, E., Gaïffas, S., Mastromatteo, I., \& Muzy, J.F. (2018). Uncovering causality from multivariate Hawkes integrated cumulants. Journal of Machine Learning Research 18(192), 1-28.

Andresen, M.A., Curman, A.S., \& Linning, S.J. (2017). The trajectories of crime at places: Understanding the patterns of disaggregated crime types. Journal of Quantitative Criminology 33(3), 427-449.

Antrobus, E., \& Pilotto, A. (2016). Improving forensic responses to residential burglaries: Results of a randomized controlled field trial. Journal of Experimental Criminology 12(3), 319-345.

Anwar, S., \& Loughran, T.A. (2011). Testing a Bayesian learning theory of deterrence among serious juvenile offenders. Criminology 49(3), 667-698.

Behlendorf, B., LaFree, G., \& Legault, R. (2012). Microcycles of violence: Evidence from terrorist attacks by ETA and the FMLN. Journal of Quantitative Criminology 28(1), 4975.

Bernasco, W. (2008). Them again? Same-offender involvement in repeat and near repeat burglaries. European Journal of Criminology 5(4), 411-431.

Block, S., \& Fujita, S. (2013). Patterns of near repeat temporary and permanent motor vehicle thefts. Crime Prevention and Community Safety 15(2), 151-167.

Bowers, K. J. and Johnson, S. D. (2004). 'Who Commits Near Repeats? A Test of the Boost Explanation.' Western Criminology Review 5(3): 12-24.

Bowers, K.J. \& Johnson, S.D. (2005). Domestic burglary repeats and space-time clusters: The dimensions of risk. European Journal of Criminology, 2(1), 67-92.

Braga, A.A., Brunson, R.K., \& Drakulich, K.M. (2019). Race, place, and effective policing. Annual Review of Sociology 45.

Braga, A.A., \& Dusseault, D. (2018). Can homicide detectives improve homicide clearance rates? Crime \& Delinquency 64(3), 288-315.

Braithwaite, A., \& Johnson, S.D. (2012). Space-time modeling of insurgency and counterinsurgency in Iraq. Journal of Quantitative Criminology 28(1), 31-48.

Brantingham, P.L., \& Brantingham, P.J. (1993). Nodes, paths, and edges: Considerations on the complexity of crime and the physical environment. Journal of Environmental Pyschology $13(1), 3-28$. 
Bursik, R.J., Grasmick, H.G., \& Chamlin, M.B. (1990). The effect of longitudinal arrest patterns on the development of robbery trends at the neighborhood level. Criminology 28(3), 431450 .

Butts, J.A., Roman, C.G., Bostwick, L., \& Porter, J.R. (2015). Cure violence: A public health model to reduce gun violence. Annual Review of Public Health 36, 39-53.

Chainey, S.P., Curtis-Ham, S.J., Evans, R.M., \& Burns, G.J. (2018). Examining the extent to which repeat and near repeat patterns can prevent crime. Policing: An International Journal, 41(5), 608-622.

Chalfin, A., Hansen, B., Lerner, J., \& Larker, L. (2019). Reducing crime through environmental design: Evidence from a randomized experiment of street lighting in New York City. National Bureau of Economic Research Working Paper, https://www.nber.org/papers/w25798.

Chamlin, M.B., Grasmick, H.G., Bursik, R.J., \& Cochran, J.K. (1992). Time aggregation and time lag in macro-level deterrence research. Criminology 30(3), 377-396.

Cholas-Wood, A, \& Levine, E.S. (2019). A recommendation engine to aid in identifying crime patterns. Informs Journal on Applied Analytics 49(2), 154-166.

Curman, A.S., Andresen, M.A., \& Brantingham, P.J. (2014) Crime and place: A longitudinal examination of street segments patterns in Vancouver, BC. Journal of Quantitative Criminology, 31(1), 127-147.

Davies, T., \& Marchione, E. (2015). Event networks and the identification of crime pattern motifs. PLOS ONE, 10(11), e0143638.

Elffers, H., Peeters, M., van der Kemp, J., \& Beijers, G. (2018). Quasi-experimental evaluation of near repeat patrolling: the Amestelveen experiment. Netherlands Institute for the Study of Crime and Law Enforcement.

Farrell, G. \& Pease, K. (1993). Once bitten, twice bitten: Repeat victimisation and its implications for crime prevention. Police Research Group. Paper no 46. London: Home Office.

Fielding, M., \& Jones, V. (2012). 'Disrupting the optimal forager': Predictive risk mapping and domestic burglary reduction in Trafford, Greater Manchester. International Journal of Police Science \& Management, 14(1), 30-41.

Garnier, S., Caplan, J.M., \& Kennedy, L.W. (2018). Predicting dynamical crime distribution from environmental and social influences. Frontiers in Applied Mathematics and Statistics 4, 13. 
Groff, E.R., \& Taniguchi, T.A. (2018). Micro-level policing for preventing near repeat residential burglary. Washington, D.C.: Police Foundation.

Groff, E.R., \& Taniguchi, T.A. (2019). Using citizen notification to interrupt near repeat residential burglary patterns: The micro-level near repeat experiment. Journal of Experimental Criminology, Online First.

Haberman, C., \& Ratcliffe, J. (2012). The predictive policing challenges of near repeat armed street robberies. Policing 6(2), 151-166.

Hirschfield, A., Newton, A., \& Rogerson, M. (2010). Linking burglary and target hardening at the property level: New insights into victimization and burglary protection. Criminal Justice Policy Review 21(3), 319-337.

Hunt, P.E., Saunders, J., \& Kilmer, B. (2019). Estimates of law enforcement costs by crime type for benefit-cost analyses. Journal of Benefit-Cost Analysis 10(1), 95-123.

Jacobs, B. (2010). Serendipity in robbery target selection. The British Journal of Criminology 50(3), 514-529.

Johnson, D. (2013). The space/time behaviour of dwelling burglars: Finding near repeat patterns in serial offender data. Applied Geography 41(July), 139-146.

Johnson, S.D., Bernasco, W., Bowers, K.J., Elffers, H., Ratcliffe, J., Rengert, G., \& Townsley, M. (2007). Space-time patterns of risk: A cross national assessment of residential burglary victimization. Journal of Quantitative Criminology 23(3), 201-219.

Johnson, S.D. \& Bowers, K.J. (2004). The stability of space-time clusters of burglary. British Journal of Criminology 44(1), 55-65.

Johnson, S.D., Bowers, K., \& Hirschfield, A. (1997). New insights into the spatial and temporal distribution of repeat victimization. British Journal of Criminology 37(2), 224-241.

Johnson, S.D., Summers, L., \& Pease, K. (2009). Offender as forager: A direct test of the boost account of victimization. Journal of Quantitative Criminology 25(2), 181-200.

Lantz, B., \& Ruback, R.B. (2017). A networked boost: Burglary co-offending and repeat victimization using a network approach. Crime \& Delinquency 63(9), 1066-1090.

Leovy, J. (2015). Ghettoside: A true story of murder in America. New York: Random House.

Levitt, S.D. (1998). Why do increased arrest rates appear to reduce crime: Deterrence, incapacitation, or measurement error? Economic Inquiry 36(3), 353-372.

Loftin, C. (1986). Assaultive violence as a contagious social process. Bulletin of the New York Academy of Medicine, 62(5), 550-555. 
Marchione, E. \& Johnson, S.D. (2013). Spatial, temporal, and spatio-temporal patterns of maritime piracy. Journal of Research in Crime \& Delinquency 50(4), 504-524.

Mize, T.D. (2019). Best practices for estimating, interpreting, and presenting nonlinear interaction effects. Sociological Science 6(4), 81-117.

Mohler, G.O., Carter, J.C., \& Raje, R. (2018). Improving social harm indices with a modulated Hawkes process. International Journal of Forecasting 34(3), 431-439.

Mohler, G.O., Short, M.B., Malinowski, S., Johnson, M., Tita, G.E., Bertozzi, A.L., \& Brantingham, P.J. (2015). Randomized controlled field trials of predictive policing. Journal of the American Statistical Association 110(512), 1399-1411.

Moreto, W.D., Piza, E.L., \& Caplan, J.M. (2014). “A plague on both your houses?”: Risk, repeats and reconsiderations of urban residential burglary. Justice Quarterly 31(6), 11021126.

Nobles, M.R., Ward, J.T., \& Tillyer, R. (2016). The impact of neighborhood context on spatiotemporal patterns of burglary. Journal of Research in Crime \& Delinquency 53(5), 711-740.

Park, S.M., \& Eck, J.E. (2013). Understanding the random effect on victimization distributions: A statistical analysis of random repeat victimizations. Victims \& Offenders: An International Journal of Evidence-based Research, Policy, and Practice 8(4), 399-415.

Parker, J., \& Grasmick, H.G. (1979). Linking actual and perceived certainty of punishment: An exploratory study of an untested proposition in deterrence theory. Criminology 17(3), 366-379.

Piquero, A. R., Paternoster, R., Pogarsky, G., \& Loughran, T. (2011). Elaborating the individual difference component in deterrence theory. Annual Review of Law and Social Science 7, 335-360.

Piza, E., Caplan, J.M., \& Kennedy, L.W. (2014). Is the punishment more certain? An analysis of CCTV detections and enforcement. Justice Quarterly 31(6), 1015-1043.

Piza, E., \& Carter, J.G. (2018). Predicting initiator and near repeat events in spatio-temporal crime patterns: An analysis of residential burglary and motor vehicle theft. Justice Quarterly 35(5), 842-870.

Porter, M.D. (2016). A statistical approach to crime linkage. The American Statistician 70(2), 152-165.

Powell, Z.A., Grubb, J.A., \& Nobles, M.R. (2018). A near repeat examination of economic crimes. Crime \& Delinquency, Online First. 
Pratt, T.C., \& Cullen, F.T. (2005). Assessing macro-level predictors and theories of crime: A meta-analysis. Crime and Justice 32, 373-450.

Ratcliffe, J.H. (2006). A temporal constraint theory to explain opportunity-based spatial offending patterns. Journal of Research in Crime \& Delinquency 43(3), 261-291.

Ratcliffe, J.H., \& Kikuchi, G. (2019). Harm-focused offender triage and prioritization: A Philadelphia case study. Policing: An International Journal 42(1), 59-73.

Ratcliffe, J.H., Lattanzio, M., Kikuchi, G., \& Thomas, K. (2019). A partially randomized field experiment on the effect of an acoustic gunshot detection system on police incident reports. Journal of Experimental Criminology 15(1), 67-76.

Ratcliffe, J.H., \& Rengert, G.F. (2008). Near repeat Patterns in Philadelphia Shootings. Security Journal 21(1-2), 58-76.

Ratcliffe, J.H., Taylor, R.B., \& Perenzin, A. (2016). Predictive modeling combining short and long-term crime risk potential. Final Report. U.S. Department of Justice Washington, D.C.: National Institute of Justice.

Reinhart, A. \& Greenhouse, J. (2018). Self-exciting point processes with spatial covariates: Modelling the dynamics of crime. Journal of the Royal Statistical Society: Series C 67(5), 1305-1329.

Sampson, R.J., \& Cohen, J. (1988). Deterrent effects of police on crime: A replication and theoretical extension. Law \& Society Review 22(1), 163-190.

Sampson, R.J., Raudenbush, S.W., \& Earls, F. (1997). Neighborhoods and violent crime: A multilevel study of collective efficacy. Science 277(5328), 918-924.

Santos, R.B. \& Santos, R.G. (2016). Offender-focused police intervention in residential burglary and theft from vehicle hot spots: A partially blocked randomized control trial. Journal of Experimental Criminology 12(3), 373-402.

Santos, R.G. \& Santos, R.B. (2015c). Practice-based research: Ex post facto evaluation of evidence-based police practices implemented in residential burglary micro-time hot spots. Evaluation Review 39(5), 451-479.

Santos, R.G. \& Santos, R.B. (2015b). An ex post facto evaluation of tactical police response in residential theft from vehicle micro-time hot spots. Journal of Quantitative Criminology 31(4), 679-698.

Santos, R.B. \& Santos, R.G. (2015a). Examination of police dosage in residential burglary and residential theft from vehicle micro-time hot spots. Crime Science 4(27), 1-12. 
Shaw, C.R., \& McKay, H.D. (1969). Juvenile delinquency and urban areas: A study of rates of delinquency in relation to differential characteristics of local communities in American cities. Revised Edition. Chicago, IL: University of Chicago Press.

Short, M.B., D’Orsogna, M.R., Brantingham, P.J., \& Tita, G.E. (2009). Measuring and modeling repeat and near repeat burglary effects. Journal of Quantitative Criminology 25(3), 325339.

Stafford, M.C., \& Warr M. (1993). A reconceptualization of general and specific deterrence. Journal of Research in Crime \& Delinquency 30(2), 123-135.

Stokes, N., \& Clare, J. (2019). Preventing near repeat residential burglary through cocooning: Post hoc evaluation of a targeted police-led pilot intervention. Security Journal, Online First.

Sturup, J., Rostami, A., Gerell, M., \& Sandholm, A. (2018). Near repeat shootings in contemporary Sweden 2011 to 2015. Security Journal 31(1), 73-92.

Turchan, B., Grubb, J.A., Pizarro, J.M., \& McGarrell, E.F. (2018). Arson in an urban setting: A multi-event near repeat chain analysis in Flint, Michigan. Security Journal, Online First.

Townsley, M., Homel, R., \& Chaseling, J. (2003). Infectious burglaries: A test of the near repeat hypothesis. British Journal of Criminology 43(3), 615-633.

Townsley, M., Johnson, S.D., \& Ratcliffe, J.H. (2008). Space time dynamics of insurgent activity in Iraq. Security Journal 21(1), 139-146.

Youstin, T.J., Nobles, M.R., Ward, J.T., \& Cook, C.L. (2011). Assessing the generalizability of the near repeat phenomenon. Criminal Justice and Behavior 38(10), 1042-1063.

Weisburd, D. (2015). The law of crime concentration and the criminology of place. Criminology 53(2), 133-157.

Weisburd, D., Bushway, S.D., Lum, C., \& Yang, S.M. (2004). Trajectories of crime at places: A longitudinal study of street segments in the city of Seattle. Criminology 42(2), 283-322.

Wells, W., \& Wu, L. (2011). Proactive policing effects on repeat and near repeat shootings in Houston. Police Quarterly 14(3), 298-319.

Wells, W., Wu, L., \& Ye, X. (2012). Patterns of near repeat gun assaults in Houston. Journal of Research in Crime \& Delinquency 49(2), 186-212.

Wheeler, A.P. (2012). The moving home effect: A quasi experiment assessing effect of home location on the offence location. Journal of Quantitative Criminology 28(4), 587-606. 
Wheeler, A.P. (2016). Testing serial crime events for randomness in day-of-week patterns with small samples. Journal of Investigative Psychology and Offender Profiling 13(2), 148165.

Wheeler, A.P., \& Steenbeek, W. (2019). Mapping the risk terrain for crime using machine learning. Working paper.

Wheeler, A.P., Worden, R.E., \& McLean, S.J. (2016). Replicating group-based trajectory models of crime at micro-places in Albany, NY. Journal of Quantitative Criminology 32(4), 589612.

Wilson, J.Q., \& Boland, B. (1978). The effect of police on crime. Law \& Society Review 12(3), 367-390.

Wooditch, A. \& Weisburd, D. (2016). Using space-time analysis to evaluate criminal justice programs: An application to stop-question-frisk practices. Journal of Quantitative Criminology 32(2), 191-213.

Wu, L., \& Wells, W. (2016). A micro-level analysis of firearm arrests' effects on gun violence in Houston, Texas. GeoJournal 81(6), 891-905.

Wyant, B.R. (2014). Policing firearm violence: Examining space-time associations between shootings and firearm arrests to gauge police responsiveness. Policing: An International Journal of Police Strategies \& Management 37(1), 70-86.

Wyant, B.R., Taylor, R.B., Ratcliffe, J.H., \& Wood, J. (2012). Deterrence, firearm arrests, and subsequent shootings: A micro-level spatio-temporal analysis. Justice Quarterly 29(4), 524-545.

Zhang, Y., Zhao, J., Ren, L., \& Hoover, L. (2015). Space-time clustering of crime events and neighborhood characteristics in Houston. Criminal Justice Review 40(3), 340-360. 
Table 1: Descriptive statistics for different crime types. Future crime is based on a future crime occurring within 1,000 feet and 7 days of the initial crime

\begin{tabular}{|lrrrr|}
\hline & \multicolumn{2}{c}{ No Arrest } & \multicolumn{2}{c|}{ Arrest } \\
Crime Type & Total N & $\%$ Future Crime & Total N & $\%$ Future Crime \\
Shooting & 2,948 & $5.2 \%$ & 1,048 & $4.7 \%$ \\
Interpersonal Robbery & 10,206 & $14.0 \%$ & 1,351 & $12.7 \%$ \\
Residential Burglary & 25,157 & $20.6 \%$ & 983 & $16.1 \%$ \\
Theft From Motor Vehicles & 55,354 & $27.7 \%$ & 1,531 & $30.7 \%$ \\
\hline
\end{tabular}


Table 2: Descriptive Statistics for Main Independent Variables (excludes linear time trend and monthly dummy variable counts)

\begin{tabular}{|lrrrrr|}
\hline & Mean & Std. Deviation & Minimum & Median & Maximum \\
Historical Crimes within 1,000 ft & 65.65 & 67.42 & 0.00 & 42.00 & 552.00 \\
Distance in Feet to Crime Generators/Attractors & & & & & \\
Larger Business Retailers & $1,989.10$ & $1,663.73$ & 0.82 & $1,596.92$ & $14,850.78$ \\
Smaller food, clothing, drug and item stores & $1,385.14$ & $1,281.92$ & 1.06 & $1,082.36$ & $15,442.71$ \\
Gasoline Stations & $1,802.77$ & $1,414.35$ & 0.08 & $1,574.32$ & $28,943.31$ \\
Eating and drinking places & $1,692.12$ & $1,434.27$ & 0.60 & $1,351.26$ & $16,389.59$ \\
liquor stores & $4,890.93$ & $5,458.58$ & 0.15 & $3,031.69$ & $36,362.80$ \\
Movie theaters, amusement and entertainment & $3,301.54$ & $2,354.03$ & 3.80 & $2,714.40$ & $19,692.86$ \\
gyms and hair salons & $2,142.60$ & $1,638.31$ & 0.79 & $1,737.23$ & $16,427.69$ \\
Motel & $5,769.69$ & $3,980.69$ & 38.63 & $5,009.86$ & $21,960.28$ \\
Hotel & $7,626.74$ & $5,143.24$ & 30.86 & $6,644.16$ & $23,212.31$ \\
Shopping Mall & $18,949.42$ & $10,201.69$ & 199.92 & $19,127.76$ & $56,449.71$ \\
Bank & $4,369.18$ & $3,242.08$ & 23.45 & $3,593.17$ & $22,219.07$ \\
Check Cashing & $4,111.79$ & $4,236.79$ & 0.06 & $2,945.24$ & $31,607.41$ \\
Libraries & $7,062.23$ & $3,442.22$ & 75.24 & $6,888.93$ & $40,419.50$ \\
Middle or High School & $4,601.27$ & $2,479.66$ & 19.16 & $4,390.73$ & $19,651.62$ \\
Dart Stations & $14,363.29$ & $11,959.10$ & 42.74 & $10,502.28$ & $69,234.24$ \\
Apartment & $1,568.55$ & $1,790.90$ & 11.39 & 844.21 & $14,095.16$ \\
Hospital & $10,349.39$ & $6,450.78$ & 42.00 & $9,542.01$ & $42,686.42$ \\
Mobile Home Park & $16,998.82$ & $11,573.16$ & 21.41 & $14,197.65$ & $51,154.96$ \\
Demographic Factors & & & & & \\
Prop. Non-Hispanic White Population & 0.27 & 0.27 & 0.00 & 0.17 & 1.00 \\
Prop. Black Population & 0.29 & 0.28 & 0.00 & 0.20 & 1.00 \\
Prop. Hispanic & 0.31 & 0.25 & 0.00 & 0.23 & 1.00 \\
Prop. Asian & 0.03 & 0.06 & 0.00 & 0.01 & 0.67 \\
Total number of population under 17 years old & 449.26 & 361.68 & 0.00 & 370.00 & $2,275.00$ \\
Prop. Moved in the last year & 0.21 & 0.16 & 0.00 & 0.17 & 1.00 \\
Prop. in Poverty & 0.22 & 0.15 & 0.00 & 0.20 & 1.00 \\
Prop. of Female Headed Households with Children & 0.18 & 0.15 & 0.00 & 0.16 & 0.88 \\
Prop. Unemployed & 0.07 & 0.06 & 0.00 & 0.05 & 0.64 \\
Prop. with some type of govt assistance & 0.19 & 0.16 & 0.00 & 0.17 & 0.89 \\
\hline
\end{tabular}


Table 3: Logistic regression model predicting whether a future crime occurs within 1,000 feet and 7 days across different crime types

\begin{tabular}{lrrrrr} 
& Coefficient & $\begin{array}{r}\text { Std } \\
\text { Error }\end{array}$ & $\begin{array}{r}\text { P- } \\
\text { Value }\end{array}$ & $\begin{array}{r}\text { Low } \\
\text { OR }\end{array}$ & $\begin{array}{r}\text { High } \\
\text { OR }\end{array}$ \\
\hline Interpersonal Robbery & & & & & \\
Arrest & -0.24 & 0.14 & 0.09 & -0.53 & 0.04 \\
Crime Density & 4.13 & 0.25 & 0.00 & 3.64 & 4.62 \\
Arrest*Crime Density & 0.95 & 0.59 & 0.10 & -0.20 & 2.10 \\
Theft From MV & & & & & \\
Arrest & 0.13 & 0.10 & 0.19 & -0.06 & 0.31 \\
Crime Density & 1.95 & 0.04 & 0.00 & 1.87 & 2.04 \\
Arrest*Crime Density & -0.25 & 0.17 & 0.13 & -0.58 & 0.08 \\
Residential Burglary & & & & & \\
Arrest & -0.03 & -0.27 & 0.79 & -0.27 & 0.21 \\
Crime Density & 1.46 & 24.79 & 0.00 & 1.34 & 1.57 \\
Arrest*Crime Density & -0.50 & -1.83 & 0.07 & -1.04 & 0.04 \\
Shooting & & & & & \\
Arrest & -0.17 & 0.26 & 0.51 & -0.67 & 0.33 \\
Crime Density & 9.68 & 1.78 & 0.00 & 6.19 & 13.16 \\
Arrest*Crime Density & 0.72 & 2.51 & 0.77 & -4.20 & 5.64 \\
\hline
\end{tabular}

Note: Logit models include control variables for distance to 18 types of crime generators, demographic characteristics, a linear time trend, and monthly dummy variables. Confidence intervals for the odds ratios are $95 \%$. 

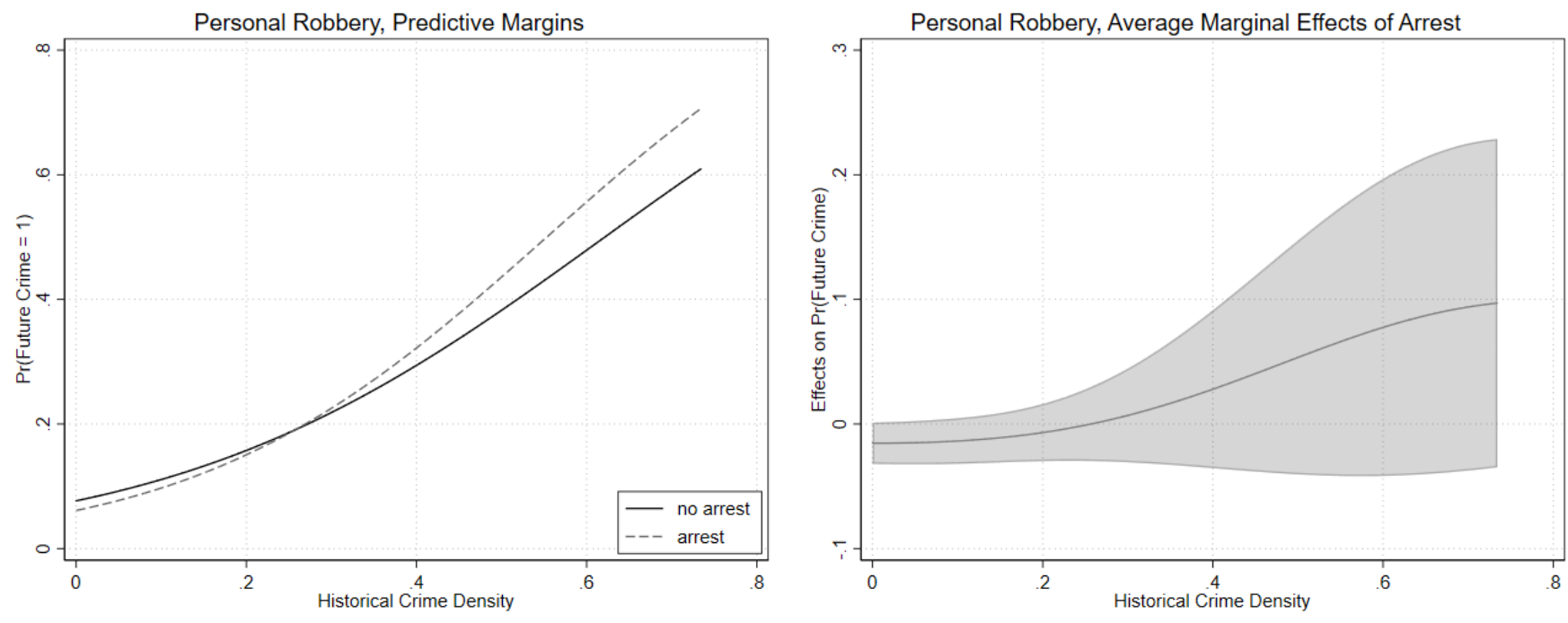

Figure 1: The left hand graph displays the predicted probabilities of a future near repeat robbery (within 1,000 feet and 7 days) from initial event, for events with and without an arrest given different historical crime densities per 7 days (within 1,000 feet). The right hand graph displays the estimated different between those two probabilities with a $95 \%$ confidence interval of the difference. 

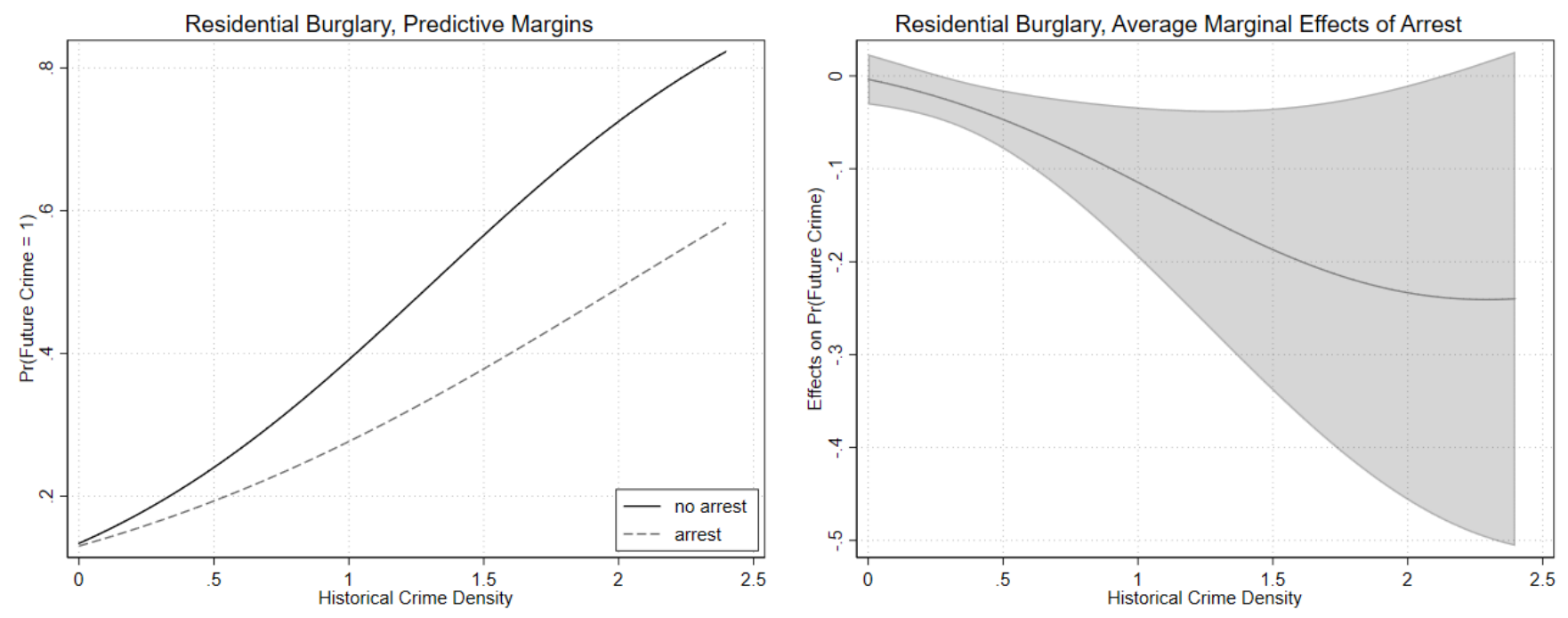

Figure 2: The left hand graph displays the predicted probabilities of a future near repeat burglary (within 1,000 feet and 7 days) from initial event, for events with and without an arrest given different historical crime densities per 7 days (within 1,000 feet). The right hand graph displays the estimated different between those two probabilities with a $95 \%$ confidence interval of the difference. 

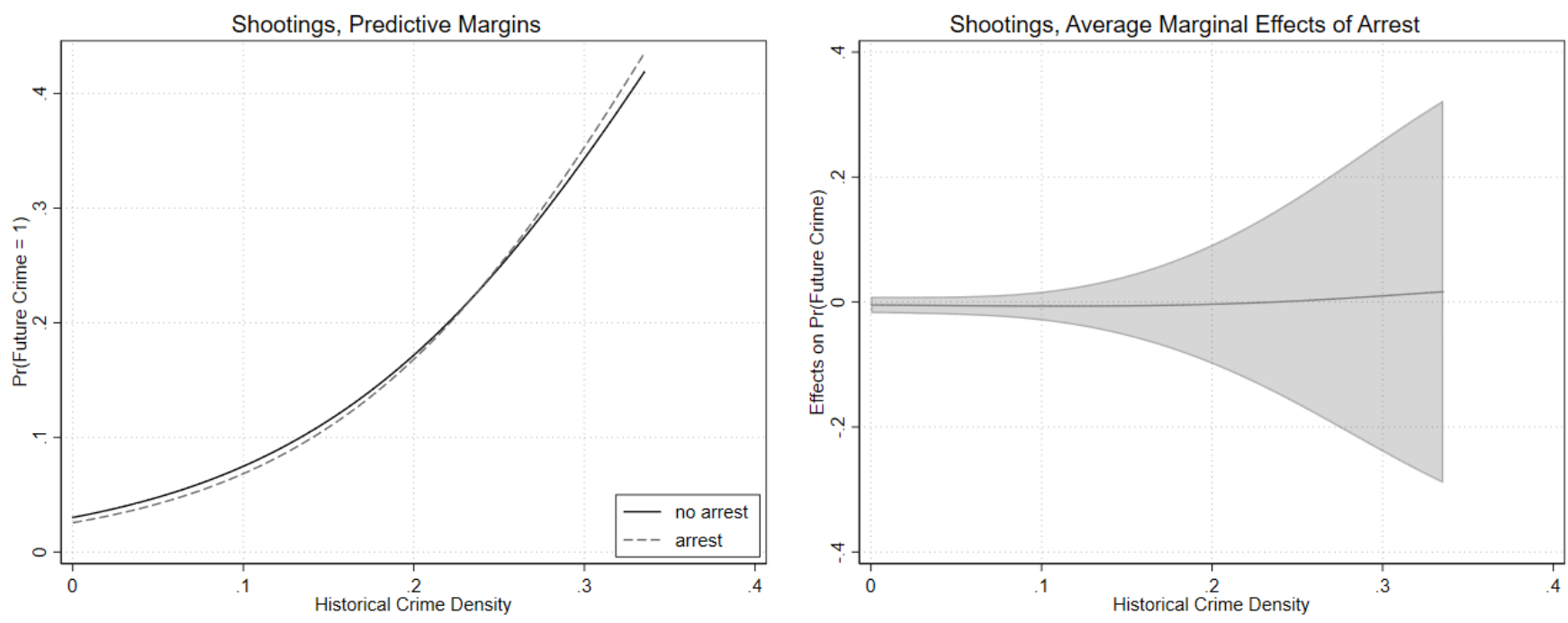

Figure 3: The left hand graph displays the predicted probabilities of a future near repeat shooting (within 1,000 feet and 7 days) from initial event, for events with and without an arrest given different historical crime densities per 7 days (within 1,000 feet). The right hand graph displays the estimated different between those two probabilities with a $95 \%$ confidence interval of the difference. 

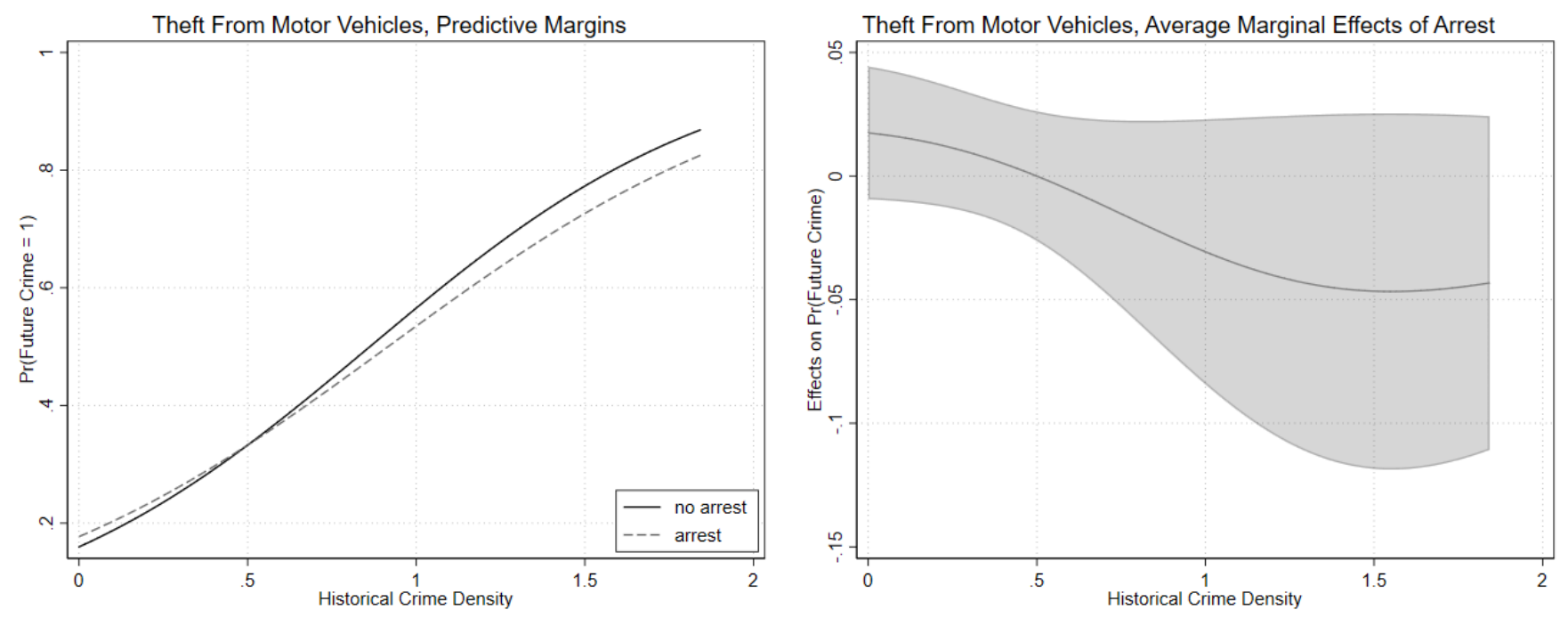

Figure 4: The left hand graph displays the predicted probabilities of a future near repeat theft from motor vehicle (within 1,000 feet and 7 days) from initial event, for events with and without an arrest given different historical crime densities per 7 days (within 1,000 feet). The right hand graph displays the estimated different between those two probabilities with a $95 \%$ confidence interval of the difference. 


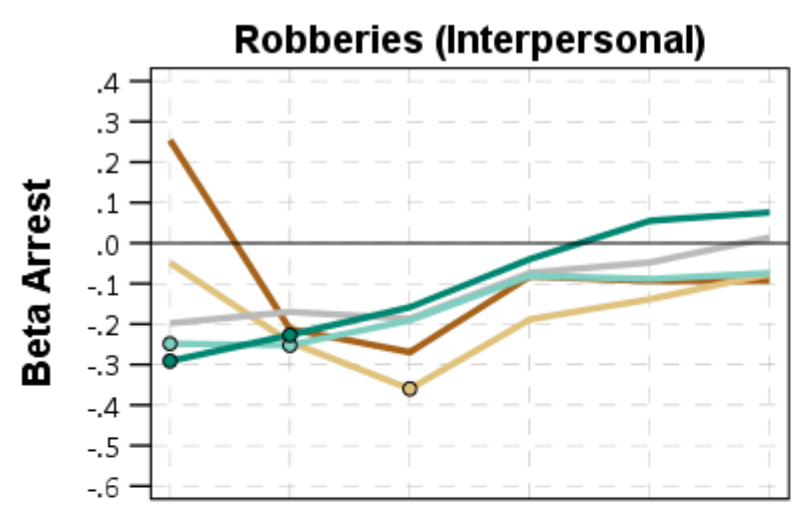

Burglaries (Residential)

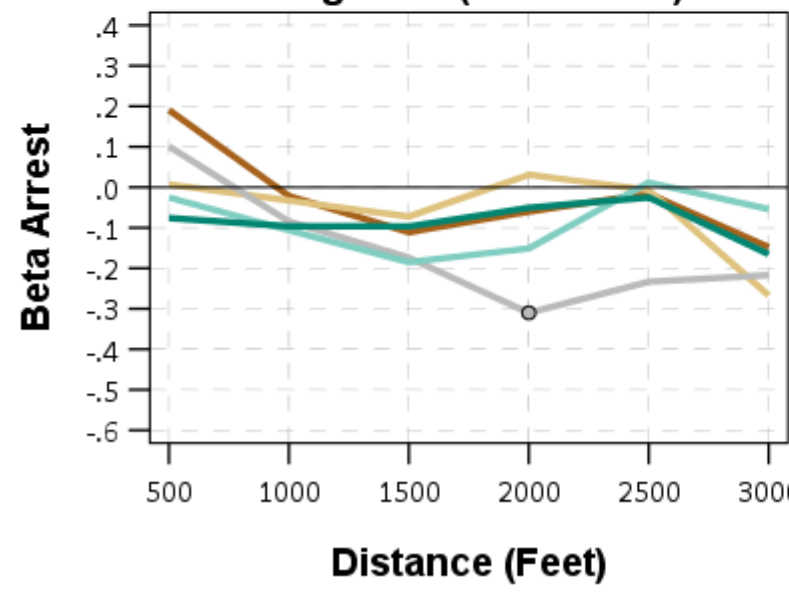

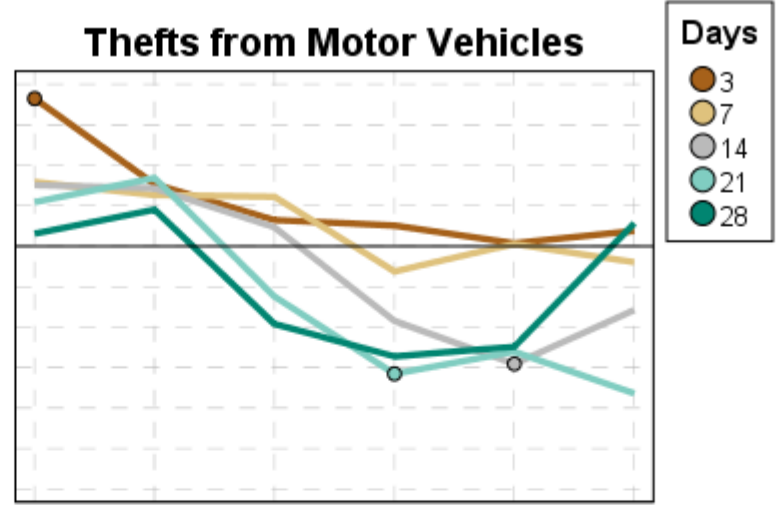

Shootings

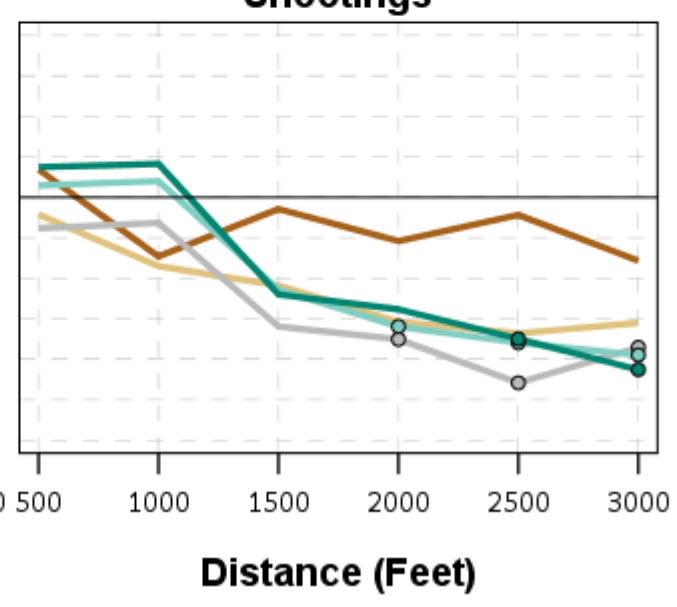

Figure 5: Coefficient for arrest effect, given different distance and time thresholds for examining near-repeats. Coefficients that had a p-value of less than 0.05 are given a dot. 


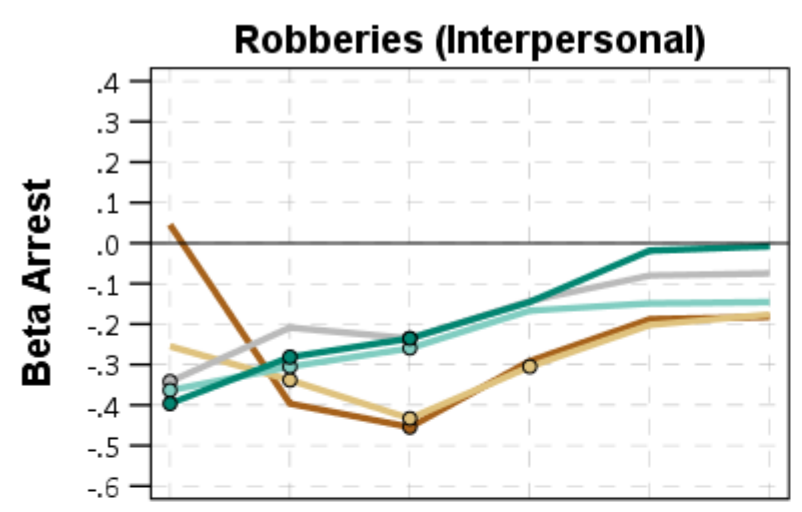

Burglaries (Residential)

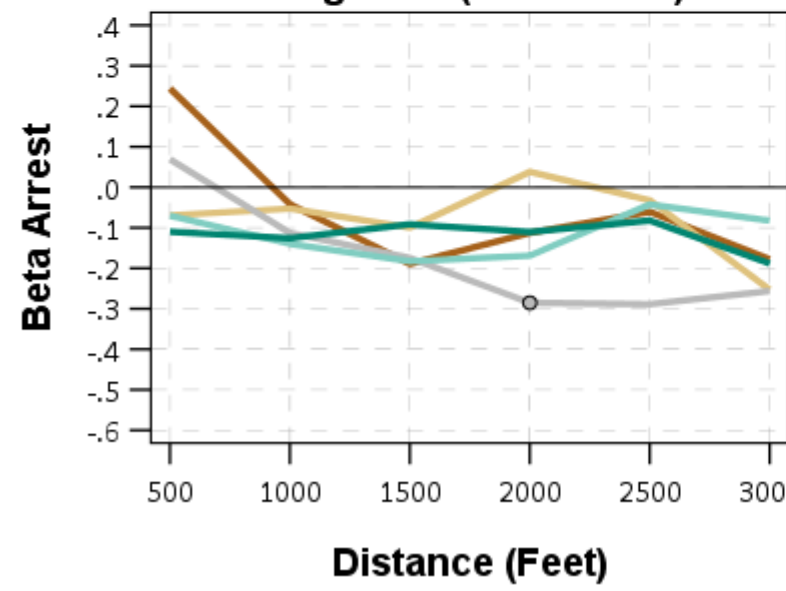

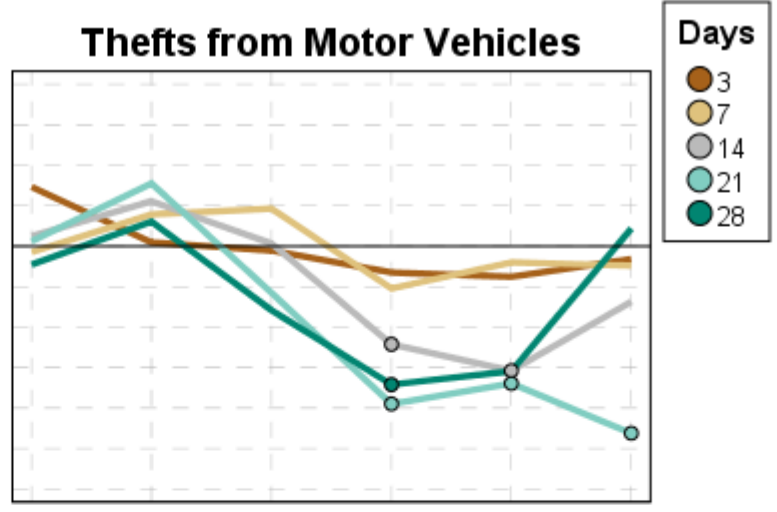

Shootings

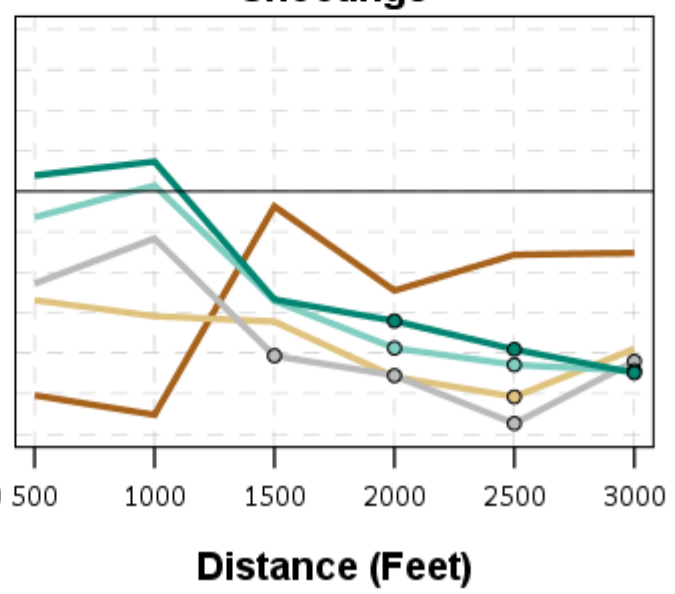

Figure 6: Coefficient for arrest effect, only including future crimes that occurred at least 24 hours after the initiator crime event, given different distance and time thresholds for examining nearrepeats. Coefficients that had a p-value of less than 0.05 are given a dot. 


\section{Appendix A: Supplemental Tables}

Table A.1: Logistic Regression Results (Personal Robbery and Theft from Motor Vehicle)

\begin{tabular}{|c|c|c|c|c|c|c|}
\hline & \multicolumn{6}{|c|}{ Dependent Variable: (Future Crime within 1,000 feet and 7 days) } \\
\hline & \multicolumn{3}{|c|}{ Personal Robbery } & \multicolumn{3}{|c|}{ Theft From $M V$} \\
\hline & Coefficient & Std Error & Sig & Coefficient & Std Error & Sig \\
\hline Arrest & -0.24 & $(0.14)$ & * & 0.13 & $(0.1)$ & \\
\hline Historical Crimes within $1,000 \mathrm{ft}$ & 4.13 & $(0.25)$ & $* * *$ & 1.95 & $(0.04)$ & $* * *$ \\
\hline Arrest*Historical Crimes within $1,000 \mathrm{ft}$ & 0.95 & $(0.59)$ & & -0.25 & $(0.17)$ & \\
\hline Distance in 1.000 Feet to Crime Generators/Attractors & & & & & & \\
\hline Larger Business Retailers & 0.01 & $(0.03)$ & & 0.04 & $(0.01)$ & \\
\hline Smaller food, clothing, drug and item stores & -0.02 & $(0.04)$ & & -0.02 & $(0.01)$ & \\
\hline Gasoline Stations & -0.09 & $(0.03)$ & & -0.03 & $(0.01)$ & \\
\hline Eating and drinking places & -0.01 & $(0.04)$ & & 0.02 & $(0.01)$ & \\
\hline liquor stores & 0.02 & $(0.01)$ & & 0.02 & $(0.00)$ & \\
\hline Movie theaters, amusement and entertainment & -0.01 & $(0.02)$ & & 0.00 & $(0.01)$ & \\
\hline gyms and hair salons & -0.01 & $(0.03)$ & & -0.01 & $(0.01)$ & \\
\hline Motel & -0.02 & $(0.01)$ & & 0.00 & $(0.00)$ & \\
\hline Hotel & 0.00 & $(0.02)$ & & 0.00 & $(0.00)$ & \\
\hline Shopping Mall & 0.01 & $(0.00)$ & & 0.01 & $(0.00)$ & \\
\hline Bank & -0.20 & $(0.03)$ & & -0.08 & $(0.01)$ & \\
\hline Check Cashing & 0.02 & $(0.01)$ & & -0.01 & $(0.00)$ & \\
\hline Libraries & 0.00 & $(0.01)$ & & -0.01 & $(0.00)$ & \\
\hline Middle or High School & -0.01 & $(0.01)$ & & -0.01 & $(0.00)$ & \\
\hline Dart Stations & 0.01 & $(0.01)$ & & 0.00 & $(0.00)$ & \\
\hline Apartment & 0.01 & $(0.00)$ & & 0.00 & $(0.00)$ & \\
\hline Hospital & 0.04 & $(0.02)$ & & 0.02 & $(0.01)$ & \\
\hline Mobile Home Park & -0.03 & $(0.02)$ & & 0.00 & $(0.01)$ & \\
\hline \multicolumn{7}{|l|}{ Demographic Factors } \\
\hline Prop. Non-Hispanic White Population & 0.26 & $(0.33)$ & & -0.23 & $(0.10)$ & $* *$ \\
\hline Prop. Black Population & 0.16 & $(0.26)$ & & -0.40 & $(0.10)$ & $* * *$ \\
\hline Prop. Hispanic & 0.13 & $(0.29)$ & & -0.48 & $(0.10)$ & $* * *$ \\
\hline Prop. Asian & 0.80 & $(0.61)$ & & 0.01 & $(0.21)$ & \\
\hline Total number of population under 17 years old & 0.00 & $(0.00)$ & & 0.00 & $(0.00)$ & \\
\hline Prop. Moved in the last year & 1.02 & $(0.26)$ & $* * *$ & 0.81 & $(0.08)$ & $* * *$ \\
\hline Prop. in Poverty & 0.39 & $(0.32)$ & & 0.33 & $(0.13)$ & $* *$ \\
\hline Prop. of Female Headed Households with Children & 0.15 & $(0.23)$ & & 0.24 & $(0.09)$ & $* *$ \\
\hline Prop. Unemployed & -1.09 & $(0.49)$ & $* *$ & -0.70 & $(0.22)$ & $* * *$ \\
\hline Prop. with some type of govt assistance & 0.79 & $(0.32)$ & $* *$ & -0.24 & $(0.14)$ & $*$ \\
\hline \multicolumn{7}{|l|}{ Month } \\
\hline 2 & -0.04 & $(0.15)$ & & -0.14 & $(0.05)$ & $* * *$ \\
\hline 3 & -0.20 & $(0.15)$ & & -0.05 & $(0.05)$ & \\
\hline 4 & -0.24 & $(0.15)$ & & -0.05 & $(0.05)$ & \\
\hline 5 & -0.22 & $(0.14)$ & & -0.02 & $(0.05)$ & \\
\hline 6 & -0.17 & $(0.14)$ & & -0.09 & $(0.05)$ & * \\
\hline 7 & -0.10 & $(0.13)$ & & -0.02 & $(0.05)$ & \\
\hline 8 & 0.10 & $(0.13)$ & & 0.00 & $(0.05)$ & \\
\hline 9 & -0.01 & $(0.13)$ & & -0.06 & $(0.05)$ & \\
\hline 10 & 0.03 & $(0.13)$ & & -0.04 & $(0.05)$ & \\
\hline 11 & 0.19 & $(0.13)$ & & 0.01 & $(0.05)$ & \\
\hline 12 & -0.06 & $(0.13)$ & & 0.01 & $(0.05)$ & \\
\hline Julian Date $(1 / 1 / 2014$ as 0.00$)$ & 0.00 & $(0.00)$ & & 0.00 & $(0.00)$ & \\
\hline Constant & -3.21 & $(0.35)$ & $* * *$ & -1.35 & $(0.12)$ & $* * *$ \\
\hline
\end{tabular}


Table A.2: Logistic Regression Results (Residential Burglary and Shooting)

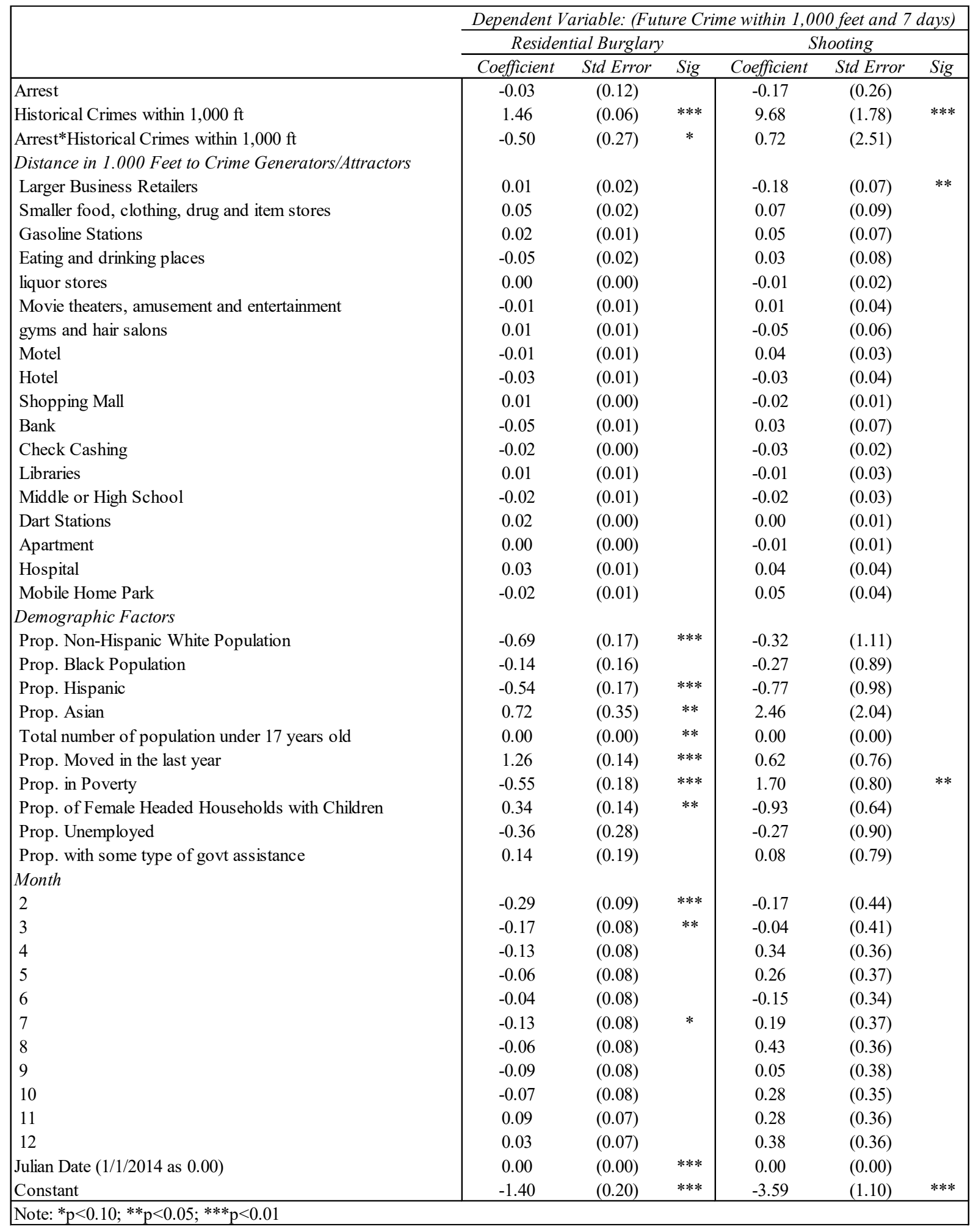


Table B.1: Near Repeat Shootings, P-Value

\section{Appendix B: Knox Tables}

Time (days)

\begin{tabular}{|c|c|c|c|c|c|c|c|c|c|c|c|c|c|c|c|c|c|c|c|c|c|c|c|c|c|c|c|c|c|c|c|}
\hline & & & & & & & & & & & & & & & & & & & & & & & & & & & & & & & \\
\hline & 0 & 1 & 2 & 3 & 4 & 5 & 6 & 7 & 8 & 9 & 10 & 11 & 12 & 13 & 14 & 15 & 16 & 17 & 18 & 19 & 20 & 21 & 22 & 23 & 24 & 25 & $26 \mid$ & 27 & 28 & 29 & 30 \\
\hline 0 & $\mathrm{X}$ & $\mathrm{X}$ & $\ldots$ & $\ldots$ & $\mathrm{X}$ & $\mathrm{X}$ & & $\mathrm{X}$ & $\mathrm{X}$ & & $\ldots$ & $\mathrm{X}$ & \begin{tabular}{|l|}
$\ldots$ \\
\end{tabular} & $\ldots$ & $\ldots$ & \begin{tabular}{|l|}
$\ldots$ \\
\end{tabular} & \begin{tabular}{|l|}
$\ldots$ \\
\end{tabular} & $\ldots$ & $\ldots$ & ... & $X$ & $\ldots$ & ... & $\ldots$ & $\ldots$ & $\ldots$ & $\ldots$ & $\ldots$ & $\ldots$ & $\ldots$ & $\ldots$ \\
\hline 100 & \begin{tabular}{l|l}
$X$ & 2 \\
\end{tabular} & $X$ & & & & & & & & $X$ & & & 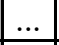 & & & $\ldots$ &. & & & $\ldots$ & & & $\ldots$ & & & & & $\ldots$ & $\ldots$ & & $\ldots$ \\
\hline 200 & & X & & & & & & & & & $X$ & & $\ldots$ & & & $\ldots$ & $\ldots$ & $\mathrm{X}$ & $X$ & & & $\ldots$ & $\ldots$ & &. & $\ldots$ & & $\ldots$ & $\ldots$ & & $\ldots$ \\
\hline 300 & & $X$ & & & & & & $\ldots$ & $\ldots$ & & $\ldots$ & & $\ldots$ & $\ldots$ & $\cdots$ & $\ldots$ & $\ldots$ & $\ldots$ & $\ldots$ & $\ldots$ & $\ldots$ & $\ldots$ & & $\ldots$ & $\ldots$ & & $\ldots$ & $\ldots$ & $\ldots$ & & $\ldots$ \\
\hline 400 & $\mathrm{X}$ & & & & & & & & & & $\ldots$ & & $\ldots$ & $\ldots$ & & $X$ & & & $\ldots$ & $\ldots$ & & $\ldots$ & $\ldots$ & & $\ldots$ & $\ldots$ & & $\ldots$ & $X$ & & $\ldots$ \\
\hline 500 & & & & & & & & & $\ldots$ & & $\ldots$ & & $\ldots$ & $\ldots$ & & $\ldots$ & $\ldots$ & & $\ldots$ & $\ldots$ & 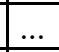 & $\ldots$ & $\ldots$ & 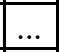 & $\ldots$ & & 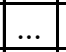 & $\ldots$ & $\ldots$ & & $\ldots$ \\
\hline 600 & &.. &.. & .. & 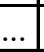 & & & \begin{tabular}{l|l}
$\ldots$ \\
\end{tabular} & $\ldots$ & $\ldots$ & $\ldots$ &. & $\ldots$ & $\ldots$ & $\ldots$ & $\ldots$ & $\ldots$ & $\ldots$ & $\ldots$ & & $\ldots$ & $\ldots$ & & $\ldots$ & $\ldots$ & & $\ldots$ & $\ldots$ & $\ldots$ & & $\ldots$ \\
\hline 700 & & $\bar{X}$ & & $\ldots$ & ... & .. & 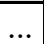 & \begin{tabular}{|l|}
$\ldots$ \\
\end{tabular} & $\ldots$ & $\ldots$ & $\ldots$ & $\ldots$ & $\ldots$ & $\ldots$ & $\ldots$ & $\ldots$ & $\ldots$ & $\ldots$ & $\ldots$ & $\ldots$ & $\ldots$ & $\ldots$ & $\ldots$ & $\ldots$ & $\ldots$ & & $\ldots$ & $\ldots$ & $\ldots$ & & $\ldots$ \\
\hline 800 & & & & & & & & $\ldots$ & $\ldots$ & 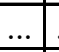 & $\ldots$ & & & 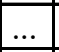 & & $\ldots$ & $\cdots$ & & $\cdots$ & $\ldots$ & & $\ldots$ & - & & $\ldots$ & $\ldots$ & & $\ldots$ & $\ldots$ & & \\
\hline 900 & & & . & $\ldots$ & $\ldots$ & $\ldots$ & & $\ldots$ & $\ldots$ & $\ldots$ & $\ldots$ & $\ldots$ & $\mathrm{X}$ & $\ldots$ & $\ldots$ & $\ldots$ & $\ldots$ & $\cdots$ & $\ldots$ & $\ldots$ & $\ldots$ & $\ldots$ & $X$ & $\cdots$ & $\ldots$ & $\ldots$ & $\ldots$ & $\ldots$ & $\ldots$ & $\ldots$ & $X$ \\
\hline 1000 & &.. & $\ldots$ & $\ldots$ & $\ldots$ & $\ldots$ & $\ldots$ & \begin{tabular}{|l|}
$\ldots$ \\
\end{tabular} & $\mathrm{X}$ & $\ldots$ & $\mathrm{X}$ & $\ldots$ & $\ldots$ & $\ldots$ & $\mathrm{X}$ & $\ldots$ & $\ldots$ & $\ldots$ & $\ldots$ & $\ldots$ & $\ldots$ & $\ldots$ & \begin{tabular}{|l|}
$\ldots$ \\
\end{tabular} & $\ldots$ & $\ldots$ & $\ldots$ & $\ldots$ & $\ldots$ & $\ldots$ & $\ldots$ & $\ldots$ \\
\hline 1100 & &. .12 & $X$ & $\ldots$ & $\ldots$ & $\ldots$ & $X$ & $\ldots$ & $\ldots$ & $\ldots$ & $\ldots$ & $\ldots$ & $X$ & $\ldots$ & $\ldots$ & $\ldots$ & $\mathrm{X}$ & $\ldots$ & $\ldots$ & \begin{tabular}{|l|}
$\ldots$ \\
\end{tabular} & $\ldots$ & $\ldots$ & $\begin{array}{ll}\ldots \\
\end{array}$ & $\ldots$ & $\ldots$ & $\ldots$ & $\ldots$ & $\ldots$ & $\ldots$ & $\ldots$ & $\ldots$ \\
\hline 1200 & 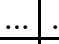 & $\ldots$ & $\ldots$ & $\ldots$ & $\ldots$ & $\ldots$ & $\ldots$ & $\ldots$ & $\ldots$ & $\ldots$ & $\ldots$ & $\ldots$ & $\ldots$ & $\ldots$ & $\ldots$ & $\ldots$ & $\mathrm{X}$ & $\ldots$ & $\ldots$ & $\ldots$ & $\ldots$ & $\ldots$ & $\ldots$ & $\ldots$ & $\ldots$ & $\ldots$ & $\ldots$ & $\ldots$ & $\ldots$ & $\ldots$ & $\ldots$ \\
\hline 1300 & & & & $\ldots$ & $\ldots$ & & & $\ldots$ & $\ldots$ & $\ldots$ & $\ldots$ & $\ldots$ & $\ldots$ & $\ldots$ & $\ldots$ & $\ldots$ & $\ldots$ & $\ldots$ & $\ldots$ & $\ldots$ & $\ldots$ & $\ldots$ & $\ldots$ & $\ldots$ & $\ldots$ & $\ldots$ & $\ldots$ & $\ldots$ & $\ldots$ & $\ldots$ & $\ldots$ \\
\hline 1400 & & $\mathrm{X}$ & & $\ldots$ & $\ldots$ & . & $X$ & $\ldots$ & $\ldots$ & $\ldots$ & $\ldots$ & $X$ & $\ldots$ & $\ldots$ & $\ldots$ & $\ldots$ & $\ldots$ & $\ldots$ & $\ldots$ & $\ldots$ & $\ldots$ & $\ldots$ & $\ldots$ & $\ldots$ & & $\mathrm{X}$ & & $\ldots$ & $\ldots$ & $\ldots$ & $\ldots$ \\
\hline 1500 & & & & $\ldots$ & $\ldots$ & & & $\ldots$ & $\ldots$ & & $\mathrm{X}$ & & $\ldots$ & $\ldots$ & & $\ldots$ & $\ldots$ & & $\ldots$ & $\ldots$ & & $\ldots$ & $\ldots$ & $\ldots$ & & $X$ & & $\ldots$ & $\ldots$ & & $\ldots$ \\
\hline 1600 & & & & & 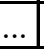 & & & $\cdots$ & $\cdots$ & $\ldots$ & & & $\ldots$ & $\ldots$ & & $\ldots$ & $\ldots$ & & & $\ldots$ &. & & \begin{tabular}{|l|}
$\ldots$ \\
\end{tabular} & $\ldots$ & & & . & $\ldots$ & $\ldots$ & $\mathrm{X}$ & \\
\hline 1700 & & X & & $\ldots$ & $\ldots$ & & & \begin{tabular}{l|}
... \\
\end{tabular} & $\ldots$ & $\ldots$ & $\ldots$ & & $\ldots$ & $\ldots$ & $\cdots$ & $\ldots$ & $\ldots$ & $\ldots$ & $\ldots$ & $\ldots$ & $\ldots$ & $\ldots$ & $\ldots$ & $\ldots$ & $\ldots$ & $\ldots$ & $\ldots$ & $\ldots$ & $\ldots$ & $\ldots$ & $\ldots$ \\
\hline 1800 & 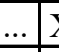 & $\mathrm{X}$ & $\ldots$ & $\ldots$ & $\ldots$ & $\ldots$ &. & \begin{tabular}{|l|}
$\ldots$ \\
\end{tabular} & $\ldots$ & $\ldots$ & $\ldots$ & $\ldots$ & $\ldots$ & $\ldots$ & \begin{tabular}{l|}
$\ldots$ \\
\end{tabular} & $\ldots$ & $\ldots$ & $\ldots$ & $\ldots$ & $\ldots$ & $\ldots$ & $\ldots$ & $\ldots$ & $\ldots$ & $\ldots$ & $\ldots$ & $\ldots$ & $\ldots$ & $\ldots$ & $\ldots$ & $X$ \\
\hline 1900 & & & & & $X$ & & & & 1 & $\ldots$ & & & & & & $\ldots$ & $\ldots$ & & $\ldots$ & $\mathrm{X}$ & & $\ldots$ & \begin{tabular}{l|}
$\ldots$ \\
\end{tabular} & & $\ldots$ & \begin{tabular}{l|}
$\ldots$ \\
\end{tabular} & & $\ldots$ & $\ldots$ & & $\ldots$ \\
\hline 2000 & & $\because$. & $\ldots$ & $\ldots$ & $\ldots$ & & & $\ldots$ & \begin{tabular}{|l|}
$\ldots$ \\
\end{tabular} & $\ldots$ & $\ldots$ &. & $\ldots$ & $\ldots$ & $\ldots$ & $\ldots$ & $\ldots$ & $\ldots$ & $\ldots$ & $\ldots$ & $\ldots$ & $\ldots$ & $\ldots$ & $\ldots$ & $\ldots$ & $\ldots$ & $\ldots$ & $\ldots$ & $\ldots$ & $\ldots$ & $\ldots$ \\
\hline 2100 &.. & $\ldots$ & $\ldots$ & $\ldots$ & $\ldots$ & $\ldots$ & .. & \begin{tabular}{|l|}
$\ldots$ \\
\end{tabular} & $\ldots$ & $\ldots$ & $\ldots$ & $\ldots$ & $\ldots$ & $\ldots$ & $\ldots$ & $\ldots$ & $\ldots$ & $\ldots$ & $\ldots$ & $\ldots$ & $\ldots$ & $\ldots$ & $\ldots$ & $\ldots$ & $\ldots$ & $\ldots$ & $\ldots$ & $\mathrm{X}$ & $\ldots$ & $\ldots$ & $\ldots$ \\
\hline 2200 & & $\ldots$ & $\ldots$ & $\ldots$ & $X$ & $\ldots$ & & \begin{tabular}{|l|}
$\ldots$ \\
\end{tabular} & $\ldots$ & $\ldots$ & $\ldots$ & $\ldots$ & $\ldots$ & $\ldots$ & $\ldots$ & $\ldots$ & $\ldots$ & $\ldots$ & $\ldots$ & \begin{tabular}{|l|}
$\ldots$ \\
\end{tabular} & $\ldots$ & $X$ & $\ldots$ & $\ldots$ & $\ldots$ & $\ldots$ & $\ldots$ & $\ldots$ & $\ldots$ & $\ldots$ & $\mathrm{X}$ \\
\hline 2300 & & $\ldots$ & $\ldots$ & $\ldots$ & $\ldots$ & $\ldots$ & & $\ldots$ & $\ldots$ & $\ldots$ & $\ldots$ & $\ldots$ & $\ldots$ & $\ldots$ & $\ldots$ & $\ldots$ & $\ldots$ & $\ldots$ & $\ldots$ & \begin{tabular}{|l|}
$\ldots$ \\
\end{tabular} & $\ldots$ & $\ldots$ & $\ldots$ & $\ldots$ & $\ldots$ & $\mathrm{X}$ & $\ldots$ & $\ldots$ & $\ldots$ & $\ldots$ & $\ldots$ \\
\hline 2400 & & $\ldots$ & $\ldots$ & $\ldots$ & $\ldots$ & $\ldots$ & & $\ldots$ & $\ldots$ & $\ldots$ & $\ldots$ & $\ldots$ & $\ldots$ & $\ldots$ & $\ldots$ & $\ldots$ & $\ldots$ & $\ldots$ & $\ldots$ & $\ldots$ & $\ldots$ & $\ldots$ & $\ldots$ & $\mathrm{X}$ & $\ldots$ & $\ldots$ & $\ldots$ & $\ldots$ & $\ldots$ & $\ldots$ & $\ldots$ \\
\hline 2500 & & & & & & & & & & . & $\ldots$ & & $\ldots$ & $\ldots$ & & $\ldots$ & $\ldots$ & & $\ldots$ & $\ldots$ & $\ldots$ & & $\ldots$ & $\ldots$ & & $\ldots$ & $\ldots$ & $\ldots$ & $\ldots$ & $\ldots$ & $\ldots$ \\
\hline 2600 & & & $X$ & & $\mathrm{X}$ & & & & & $\ddot{*}$ & $\ldots$ & & $\ldots$ & $\ldots$ & & $\ldots$ & $\ldots$ & & $\ldots$ & $\ldots$ & & & $\ldots$ & $\ldots$ & & $\ldots$ & $\ldots$ & $\ldots$ & $\ldots$ & $\ldots$ & $\ldots$ \\
\hline 2700 & & ... & & 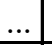 & $\ldots$ & $X$ & & & & $\ldots$ & & & & $\ldots$ & & $\ldots$ & $X$ & & $X$ & ‥ & & & $\cdots$ & & & & & $\ldots$ & $\ldots$ & $\mathrm{X}$ & \\
\hline 2800 & & $\cdots$ & & $\ldots$ & $\ldots$ & 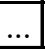 & & $\cdots$ & & $X$ & $\cdots$ & & $\ldots$ & $\ldots$ & & $\ldots$ & & & & $\ldots$ & $\cdots$ & & & $\cdots$ & & & $\cdots$ & $\ldots$ & $\ldots$ & & \\
\hline 2900 & .. & $\ldots$ & $\ldots$ & $\ldots$ & $\mathrm{X}$ & $\cdots$ & & \begin{tabular}{|l|}
$\ldots$ \\
\end{tabular} & \begin{tabular}{|l|}
$\ldots$ \\
\end{tabular} & $\begin{array}{ll}\ldots \\
\end{array}$ & $\ldots$ & $\cdots$ & $\ldots$ & $\ldots$ & $\ldots$ & $\mathrm{X}$ & & $\ldots$ & $\ldots$ & $\ldots$ & $\ldots$ & $\ldots$ & & $\ldots$ & $\ldots$ & & $\ldots$ & $\ldots$ & & $\cdots$ & $\ldots$ \\
\hline 3000 & & $\cdots$ & 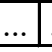 & & $\mathrm{X}$ & & & & & \begin{tabular}{l|l} 
\\
\end{tabular} & & & & & & & & & & & & & & & & & & $\ldots$ & & & - \\
\hline
\end{tabular}

Note: $\mathrm{X}$ indicates $\mathrm{p}$-value of .05 or lower 
Table B.2: Near Repeat Shootings, Knox Ratios

Time (days)

\begin{tabular}{|c|c|c|c|c|c|c|c|c|c|c|c|c|c|c|c|c|c|c|c|c|c|c|c|c|c|c|c|c|c|c|}
\hline & 1 & & 3 & 4 & 5 & 6 & & 8 & 9 & 10 & 11 & 12 & 13 & 14 & 15 & 16 & 17 & 18 & 19 & 20 & 21 & 22 & 23 & 24 & 25 & 26 & 27 & 28 & 29 & 30 \\
\hline 0 & 6.57 & 1.17 & \begin{tabular}{|l}
1.78 \\
\end{tabular} & 3.96 & \begin{tabular}{|l|l|}
3.30 \\
\end{tabular} & $\begin{array}{ll}1.74 \\
\end{array}$ & 3.19 & 3.19 & 2.52 & 1.84 & 2.69 & & & 2.26 & \begin{tabular}{|l|l}
1.71 \\
\end{tabular} & & \begin{tabular}{|l|l}
1.64 \\
\end{tabular} & 1.80 & 1.73 & 2.91 & \begin{tabular}{|l|l|}
1.19 \\
\end{tabular} & \begin{tabular}{|l|}
0.64 \\
\end{tabular} & 2.24 & 0.58 & 1.23 & \begin{tabular}{|l|}
1.92 \\
\end{tabular} & & \begin{tabular}{|l}
1.89 \\
\end{tabular} & 1.08 & 8 \\
\hline 100 & 4.95 & & \begin{tabular}{|l|l} 
\\
\end{tabular} & 0.48 & 1.34 & 1.02 & & 1.47 & 2.90 & 0.94 & 1.35 & & 1. & 0.42 & 0.95 & 1.97 & 0.42 & \begin{tabular}{|l|}
0.99 \\
\end{tabular} & 1.55 & 0.46 & 0.45 & 1.87 & $2.0^{\prime}$ & 0.47 & 0.57 & 2.00 & 0.5 & \begin{tabular}{|l|}
0.98 \\
\end{tabular} & & 0.9 \\
\hline 200 & 4.64 & & 0.77 & 0.67 & 1.42 & \begin{tabular}{|l}
0.72 \\
\end{tabular} & & 1.32 & \begin{tabular}{|l}
0.72 \\
\end{tabular} & 19 & 2.03 & & 0.84 & 0.73 & \begin{tabular}{|l|}
0.72 \\
\end{tabular} & & 1.13 & 2.91 & 0.80 & 3.00 & $\mid 1.98$ & \begin{tabular}{|l|}
0.70 \\
\end{tabular} & 1.3 & 0.89 & & 2.38 & .46 & 1.52 & 2.36 & \\
\hline 300 & .25 & \begin{tabular}{|l|l|}
0.76 \\
\end{tabular} & \begin{tabular}{|l|l|} 
\\
\end{tabular} & 1.45 & \begin{tabular}{|l|l|} 
\\
\end{tabular} & \begin{tabular}{|l}
0.79 \\
\end{tabular} & 1.27 & 0.83 & \begin{tabular}{|l|l}
1.41 \\
\end{tabular} & & & 2.17 & 0.82 & 1.35 & \begin{tabular}{|l|}
0.78 \\
\end{tabular} & 2.20 & \begin{tabular}{|l|l|}
0.75 \\
\end{tabular} & & \begin{tabular}{|l|}
1.36 \\
\end{tabular} & 0.71 & 0.72 & \begin{tabular}{|l|}
0.69 \\
\end{tabular} & 1.60 & \begin{tabular}{|l|l|}
0.69 \\
\end{tabular} & 1.53 & & 0.79 & 0.74 & \begin{tabular}{|l}
0.70 \\
\end{tabular} & \\
\hline 400 & 2.36 & 0.66 & 2.39 & 1.90 & \begin{tabular}{|l|l|} 
\\
\end{tabular} & 2.32 & 1.77 & 1.77 & & 61 & 1.30 & 1.97 & 1.31 & 1.74 & \begin{tabular}{|l|l}
3.32 \\
\end{tabular} & & & 1.17 & 0.61 & \begin{tabular}{|l}
1.83 \\
\end{tabular} & 0.5 & 1.16 & 0.72 & \begin{tabular}{|l|}
1.69 \\
\end{tabular} & & 0.58 & & 3.0 & 1.16 & 0.6 \\
\hline 500 & 1.13 & 1.77 & 1.43 & 1.19 & 1.72 & \begin{tabular}{|l|l|} 
\\
\end{tabular} & 1.70 & 1.09 & \begin{tabular}{|l|l|} 
\\
\end{tabular} & 1.82 & 0.55 & & 1.68 & 1.13 & 0.56 & 2.26 & & 1.27 & 11.33 & \begin{tabular}{|l|l|}
1.70 \\
\end{tabular} & \begin{tabular}{|l|l|} 
\\
\end{tabular} & \begin{tabular}{|l|}
1.79 \\
\end{tabular} & & & 0.57 & & 1.14 & 2.24 & & 1.5 \\
\hline 600 & \begin{tabular}{|l}
1.89 \\
\end{tabular} & 1.23 & & 1.68 & \begin{tabular}{|l|l|} 
\\
\end{tabular} & 0.59 & 0.52 & 0.48 & 1.91 & \begin{tabular}{|l|}
0.49 \\
\end{tabular} & \begin{tabular}{|l|l|}
1.94 \\
\end{tabular} & & 1.93 & \begin{tabular}{|l|l|}
0.52 \\
\end{tabular} & \begin{tabular}{|l|}
0.52 \\
\end{tabular} & 1.54 & \begin{tabular}{|l|l}
0.54 \\
\end{tabular} & 0.57 & \begin{tabular}{|l|}
0.53 \\
\end{tabular} & & & \begin{tabular}{|l|}
0.62 \\
\end{tabular} & 0.93 & \begin{tabular}{|l|l}
1.10 \\
\end{tabular} & 1.09 & 2.01 & 0.5 & 0.54 & 1.0 & 0.9 \\
\hline 700 & 3.35 & 0.49 & 1.06 & 1.44 & \begin{tabular}{|l|}
1.46 \\
\end{tabular} & \begin{tabular}{|l}
0.98 \\
\end{tabular} & 1.45 & 1.07 & 1.45 & \begin{tabular}{|l|l|} 
\\
\end{tabular} & 1.21 & 0.47 & & \begin{tabular}{|l}
0.58 \\
\end{tabular} & 1.80 & 0.51 & & 1.34 & & 0.5 & & \begin{tabular}{|l|}
1.63 \\
\end{tabular} & 2.11 & \begin{tabular}{|l|} 
\\
\end{tabular} & 0.54 & 0.59 & 1.06 & 1.63 & 2.11 & 1.46 \\
\hline 800 & 2.33 & 0.59 & \begin{tabular}{|l}
0.54 \\
\end{tabular} & & 1.14 & 0.61 & & 0.55 & 1.62 & \begin{tabular}{|l|l}
1.41 \\
\end{tabular} & 1.15 & 1.58 & 1.43 & & 2.55 & 1.66 & 1.00 & 2.33 & 1.13 & 1.81 & & & & 0.57 & & \begin{tabular}{|l}
1.49 \\
\end{tabular} & 1.20 & \begin{tabular}{|l}
1.11 \\
\end{tabular} & & 0.5 \\
\hline 900 & 0.74 & \begin{tabular}{|l|}
0.31 \\
\end{tabular} & 1.84 & 2.44 & \begin{tabular}{|l|l|}
1.53 \\
\end{tabular} & 2.06 & 0.71 & 1.27 & 1.08 & 1.74 & \begin{tabular}{|l|}
0.78 \\
\end{tabular} & 2.40 & 0.37 & 0.76 & 1.54 & 1.42 & & 1.05 & \begin{tabular}{|l|}
1.45 \\
\end{tabular} & 0.71 & 1.03 & 2.53 & 0.36 & 0.36 & 1.88 & 1.14 & 1.43 & 0.3 & 0.9 & 2.61 \\
\hline 1000 & & 0.36 & 0.34 & 0.32 & \begin{tabular}{|l|l|}
1.83 \\
\end{tabular} & 0.72 & 1.76 & 3.64 & 1.38 & 2.43 & \begin{tabular}{|l|l|}
1.87 \\
\end{tabular} & 1.75 & 0.35 & 2.44 & 0.39 & 0.35 & 0.34 & 0.32 & \begin{tabular}{|l|l|}
1.67 \\
\end{tabular} & 1.26 & 0.37 & 0.71 & 0.76 & 0.72 & 1.38 & 2.12 & 1.00 & 0.37 & 1.05 & 1.48 \\
\hline 1100 & .69 & 2.36 & 0.36 & 0.36 & 1.08 & 2.48 & 0.73 & 0.33 & 0.72 & \begin{tabular}{|l|l}
0.73 \\
\end{tabular} & 1.41 & 2.33 & 0.37 & 1.97 & & 2.38 & 1.09 & 0.80 & 1.52 & \begin{tabular}{|l} 
\\
\end{tabular} & 0.75 & 1.46 & 0.74 & 1.96 & 1.36 & 1.17 & 0.40 & 0.72 & 1.83 & 1.52 \\
\hline 200 & 1.59 & \begin{tabular}{|l|}
0.66 \\
\end{tabular} & $\mid 1.20$ & 0.37 & \begin{tabular}{|l|}
0.70 \\
\end{tabular} & 1.78 & 0.34 & 1.87 & 1.45 & \begin{tabular}{|l|l|} 
\\
\end{tabular} & 0.68 & 2.17 & 0.30 & 1.01 & 1.25 & 2.86 & \begin{tabular}{|l|l} 
\\
\end{tabular} & 1.43 & \begin{tabular}{|l|}
2.09 \\
\end{tabular} & 0.66 & $\mid 1.55$ & \begin{tabular}{|l|}
0.68 \\
\end{tabular} & 1.01 & 1.05 & 1.37 & \begin{tabular}{|l|l|} 
\\
\end{tabular} & 0.66 & 0.38 & \begin{tabular}{|l}
0.31 \\
\end{tabular} & $1.2^{\prime}$ \\
\hline 300 & 0.55 & 1.81 & 1.54 & 0.29 & 1.16 & & 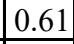 & 0.55 & 1.26 & 0.99 & 0.59 & 1.17 & 0.91 & 0.57 & 0.95 & & 0.63 & 0.30 & 0.85 & 0.61 & 1.06 & \begin{tabular}{|l|}
0.79 \\
\end{tabular} & 0.31 & 0.59 & 1.70 & 1.17 & 1.21 & 1.61 & 1.12 & 1.1 \\
\hline 1400 & 2.23 & 1.45 & 1.85 & 0.28 & 0.87 & 2.34 & 0.58 & 0.55 & 1.16 & 0.30 & 2.34 & 1.23 & 1.40 & 0.53 & 1.18 & 0.57 & 1.36 & 0.87 & $0.29 \mid$ & 0.8 & 1.09 & $0.57 \mid$ & 0.29 & 1.25 & 2.54 & 0.79 & 1.08 & 1.96 & 0.58 & 1.3 \\
\hline 1500 & 1.54 & \begin{tabular}{|l|l|}
0.57 \\
\end{tabular} & 0.89 & \begin{tabular}{|l|l|} 
\\
\end{tabular} & \begin{tabular}{|l|l|}
0.56 \\
\end{tabular} & 1.50 & 1.23 & 0.32 & 1.62 & 2.24 & 1.19 & 1.19 & 1.82 & 0.91 & \begin{tabular}{|l|l|}
0.87 \\
\end{tabular} & 1.79 & 1.48 & 0.28 & $\mid 1.79$ & \begin{tabular}{|l}
1.21 \\
\end{tabular} & 1.50 & $\mid 0.96$ & 0.87 & 0.92 & 2.45 & $\mid 0.67$ & 1.87 & 1.55 & 0.58 & 1.5 \\
\hline 1600 & 0.53 & 0.62 & 1.69 & 0.85 & \begin{tabular}{|l|l|}
1.19 \\
\end{tabular} & 0.59 & 0.29 & 0.61 & 1.72 & 0.58 & 1.42 & 1.82 & 0.88 & 0.54 & 0.58 & 1.57 & 0.59 & 1.94 & \begin{tabular}{|l|l|}
0.89 \\
\end{tabular} & 1.96 & 0.29 & 1.43 & & 1.43 & 0.53 & 1.43 & 0.31 & 2.23 & 2.22 & 1.1 \\
\hline 1700 & 2.43 & 1.16 & \begin{tabular}{|l}
1.48 \\
\end{tabular} & 1.17 & \begin{tabular}{|l|l|}
0.83 \\
\end{tabular} & 2.09 & 1.16 & 0.98 & 1.65 & \begin{tabular}{|l|}
1.59 \\
\end{tabular} & 0.56 & 1.16 & 0.56 & 1.57 & 0.95 & 0.91 & 1.81 & 0.83 & \begin{tabular}{|l|}
0.86 \\
\end{tabular} & 2.00 & 1.43 & 1.30 & 0.98 & 1.85 & 1.26 & 0.87 & 1.83 & 0.29 & 2.09 & 1.6 \\
\hline 1800 & 2.35 & \begin{tabular}{|l|l|}
0.90 \\
\end{tabular} & \begin{tabular}{|l|l|}
0.92 \\
\end{tabular} & 2.08 & \begin{tabular}{|l|}
1.49 \\
\end{tabular} & & 1.37 & 1.31 & 0.59 & 1.14 & 0.84 & 0.90 & 0.57 & 1.20 & 1.57 & 0.83 & 1.13 & \begin{tabular}{|l|l|}
1.62 \\
\end{tabular} & 0.5 & 0.30 & 0.82 & 1.28 & 0.28 & 1.41 & 1.42 & 0.60 & 0.61 & 0.88 & 1.38 & 2.3 \\
\hline 1900 & 1.40 & 1.91 & 0.90 & 2.99 & 0.86 & 1.89 & 1.06 & 0.87 & 1.41 & 1.23 & 1.07 & 0.30 & 1.11 & 0.57 & 1.63 & 1.72 & 1.21 & 0.77 & 2.11 & 0.94 & 1.58 & 0.77 & 1.78 & 1.21 & 1.99 & 0.59 & $0.5^{5}$ & 0.30 & $\mid 0.27$ & 0.8 \\
\hline 2000 & 1.14 & 1.50 & 0.84 & 1.57 & \begin{tabular}{|l|l|} 
\\
\end{tabular} & 0.56 & 1.66 & 2.11 & 0.62 & 0.92 & 0.54 & 1.42 & 0.79 & 1.43 & 1.65 & 0.93 & 1.39 & 0.31 & 0.54 & 2.06 & 1.18 & 0.87 & 0.27 & 0.5 & 1.0 & 0.93 & 0.85 & 1.07 & 0.29 & 1.2 \\
\hline 2100 & \begin{tabular}{|l|}
1.03 \\
\end{tabular} & \begin{tabular}{|l|l}
1.67 \\
\end{tabular} & \begin{tabular}{|l|l}
1.41 \\
\end{tabular} & 1.48 & \begin{tabular}{|l|}
0.78 \\
\end{tabular} & 1.04 & 2.10 & 1.27 & 1.72 & 0.51 & \begin{tabular}{|l|}
1.89 \\
\end{tabular} & 1.27 & 1.52 & 1.0 & 0.78 & 0.79 & 0.79 & 0.88 & 1.87 & 0.5 & 1.0 & 1.43 & 1.0 & 0.8 & 0.8 & 0.52 & 2.78 & 1.36 & 1.18 & 1.0 \\
\hline 2200 & 1.45 & 1.50 & 0.98 & 2.30 & \begin{tabular}{|l|l|} 
\\
\end{tabular} & \begin{tabular}{|l|} 
\\
\end{tabular} & 1.14 & 1.18 & 1.30 & 1.18 & 2.20 & 1.94 & 0.51 & 0.79 & 0.93 & 0.94 & 0.78 & 0.81 & 0.5 & 0.69 & 2.10 & 1.26 & 0.94 & 1.72 & 1.0 & 0.5 & 0.5 & 1.4 & 1.33 & 2.00 \\
\hline 2300 & 1.79 & 0.80 & 0.7 & 0.26 & 0.24 & 2.08 & 0.24 & 1.26 & 0.95 & & 1.21 & 1.14 & 0.49 & \begin{tabular}{|l|l}
1.77 \\
\end{tabular} & 1.08 & 1.31 & \begin{tabular}{|l|l}
1.47 \\
\end{tabular} & & 1.74 & 0.80 & \begin{tabular}{|l|l}
1.46 \\
\end{tabular} & 1.16 & 1.39 & 1.31 & 2.53 & \begin{tabular}{|l}
0.73 \\
\end{tabular} & 1.0 & 1.55 & 0.51 & 1.2 \\
\hline 2400 & 1.15 & \begin{tabular}{|l|l|} 
\\
\end{tabular} & 1.65 & \begin{tabular}{|l|l|}
1.72 \\
\end{tabular} & \begin{tabular}{|l|l|}
1.15 \\
\end{tabular} & 1.15 & 0.92 & 0.64 & 1.64 & 1.50 & 1.60 & 0.76 & 1.46 & \begin{tabular}{|l|}
1.24 \\
\end{tabular} & \begin{tabular}{|l|l}
1.21 \\
\end{tabular} & 0.72 & \begin{tabular}{|l|l|}
0.72 \\
\end{tabular} & 1.13 & \begin{tabular}{|l|l|}
1.02 \\
\end{tabular} & 1.69 & 1.62 & \begin{tabular}{|l|}
1.09 \\
\end{tabular} & 2.08 & 0.71 & 1.86 & 1.21 & 0.50 & 1.21 & \begin{tabular}{|l}
1.13 \\
\end{tabular} & $0.4^{7}$ \\
\hline 2500 & 0.45 & 0.24 & 0.89 & 0.24 & 0.66 & 0.23 & 1.49 & 1.70 & 1.44 & 0.95 & 1.20 & & 0.47 & 0.70 & 1.20 & 0.25 & 0.83 & 0.72 & 0.25 & 1.3 & 0.48 & 1.60 & 0.89 & 1.38 & 1.62 & 0.47 & 1.22 & & 0.49 & \\
\hline 2600 & 1.50 & 2.32 & 1.09 & 1.92 & 0.19 & 0.95 & 1.16 & 1.13 & 1.35 & 0.44 & 1.07 & & 0.86 & 0.90 & 1.62 & 1.47 & 0.70 & 1.18 & 0.72 & 0.47 & 0.62 & 0.62 & 0.90 & 1.80 & 1.13 & 1.18 & 0.76 & 0.66 & 0.63 & $0.6^{\circ}$ \\
\hline 2700 & \begin{tabular}{|l|}
1.25 \\
\end{tabular} & 0.23 & 1.18 & 0.92 & 2.24 & 1.60 & 1.05 & 1.41 & 0.65 & \begin{tabular}{|l|l|}
1.62 \\
\end{tabular} & \begin{tabular}{|l|}
0.46 \\
\end{tabular} & 1.07 & 1.83 & 0.42 & 1.60 & 2.06 & \begin{tabular}{|l|l}
0.64 \\
\end{tabular} & \begin{tabular}{|l|l|}
1.89 \\
\end{tabular} & \begin{tabular}{|l|}
0.50 \\
\end{tabular} & 0.85 & 1.11 & 1.59 & 0.70 & \begin{tabular}{|l}
0.93 \\
\end{tabular} & 0.81 & 2.02 & 1.18 & 1.77 & 2.29 & 1.54 \\
\hline 2800 & \begin{tabular}{|l|l} 
\\
\end{tabular} & 0.87 & 0.85 & 0.21 & 0.23 & 1.16 & 0.87 & 0.44 & 2.07 & 0.86 & 0.86 & 1.51 & 1.07 & 1.65 & 1.42 & 0.47 & 1.06 & 1.56 & \begin{tabular}{|l|}
0.88 \\
\end{tabular} & 0.66 & 1.9 & \begin{tabular}{|l|}
1.72 \\
\end{tabular} & 1.08 & 0.22 & 1.37 & 1.8 & 0.45 & 0.43 & 1.55 & 1.06 \\
\hline 2900 & \begin{tabular}{|l|l}
1.32 \\
\end{tabular} & \begin{tabular}{|l|l}
1.70 \\
\end{tabular} & 0.66 & 2.00 & 1.12 & 0.68 & 0.24 & 0.66 & \begin{tabular}{|l}
0.90 \\
\end{tabular} & 0.97 & 0.68 & 0.70 & 0.91 & 1.28 & 2.14 & & \begin{tabular}{|l|l}
0.91 \\
\end{tabular} & 1.47 & 1.01 & 0.72 & 1.3 & \begin{tabular}{|l|}
0.99 \\
\end{tabular} & 1.43 & \begin{tabular}{|l}
0.88 \\
\end{tabular} & 0.99 & 1.92 & $0.4^{\prime}$ & 0.22 & 0.23 & 1.42 \\
\hline 000 & 87 & 56 & & .5 & 0.46 & 44 & & 1.46 & 2.1 & .87 & 0.20 & & 9 & $0.7^{7}$ & 1.18 & 0.2 & 0.6 & 0.64 & .46 & .86 & & & 0.6 & 1.3 & 0.6 & 0.9 & & 0.9 & 0.72 & 0.46 \\
\hline
\end{tabular}


Table B.3: Near Repeat Interpersonal Robberies, P-Values

Time (days)

\begin{tabular}{|c|c|c|c|c|c|c|c|c|c|c|c|c|c|c|c|c|c|c|c|c|c|c|c|c|c|c|c|c|c|c|c|}
\hline & 0 & 1 & 2 & & 4 & 5 & 6 & & 8 & 9 & \begin{tabular}{|l|}
10 \\
\end{tabular} & 11 & 12 & 13 & \begin{tabular}{|l|}
14 \\
\end{tabular} & 15 & 16 & 17 & 18 & 19 & $\mid 20$ & & 22 & 23 & 24 & 25 & 26 & & 28 & & 30 \\
\hline 0 & $\mathrm{X}$ & $X$ & $\mathrm{X}$ & $\mathrm{X}$ & $\mathrm{X}$ & $\mathrm{X}$ & $X$ & $X$ & $\mathrm{X}$ & $\mathrm{X}$ & $\mathrm{X}$ & $X$ & $X$ & $\mathrm{X}$ & $\mathrm{X}$ & $\mathrm{X}$ & $\mathrm{X}$ & & .. & $\ldots$ & \begin{tabular}{|l|}
$\ldots$ \\
\end{tabular} & $X$ & $\mathrm{X}$ & $\mathrm{X}$ & $\mathrm{X}$ & $\mathrm{X}$ & $\ldots$ & $X$ & $\ldots$ & $X$ & \\
\hline 100 & $\mathrm{X}$ & $\mathrm{X}$ & $\mathrm{X}$ & & X & & & $\mathrm{X}$ & X & & & & $\mathrm{X}$ & & & & $X$ & & & $\ldots$ & & & $\ldots$ & & & $\ldots$ & & & $\ldots$ & & $X$ \\
\hline 200 & & $X$ & $X$ & & & $X$ & & $X$ & & $\mathrm{X}$ & $X$ & & & & $\ldots$ & & 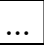 & & 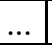 & $\ldots$ & $\ldots$ & $X$ & $\ldots$ & $\ldots$ & $X$ & 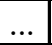 & $\ldots$ & & $\ldots$ & $\ldots$ & $\ldots$ \\
\hline 300 & 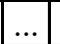 & $X$ & $\mathrm{X}$ & $X$ & 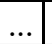 & $\ldots$ & $\mathrm{X}$ & $\ldots$ & $\mathrm{X}$ & $\mathrm{X}$ & $\ldots$ & $\ldots$ & $X$ & 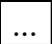 & $\ldots$ & $X$ & $\ldots$ & $\ldots$ & $\ldots$ & $\ldots$ & $\ldots$ & $\ldots$ & $\ldots$ & $\ldots$ & $\ldots$ & $X$ & $\ldots$ & 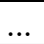 & $\ldots$ & $\ldots$ & $\ldots$ \\
\hline 400 & & 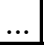 & & $X$ & & $\mathrm{X}$ & $\ldots$ & $\ldots$ & & & $\ldots$ & $\ldots$ & $X$ & $\mathrm{X}$ & $\ldots$ & $\ldots$ & $\ldots$ & $\ldots$ & $\ldots$ & $\ldots$ & $\ldots$ & $\ldots$ & $\ldots$ & $\ldots$ & $\ldots$ & $\ldots$ & $\ldots$ & 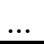 & $\ldots$ & $\mathrm{X}$ & \\
\hline 500 & & $X$ & $X$ & $X$ & & X & $\ldots$ & $\ldots$ & $X$ & & $\ldots$ & $\ldots$ & .. & $\ldots$ & $\ldots$ & $\ldots$ & $\ldots$ & $X$ & $\ldots$ & $\ldots$ & $\ldots$ & $\ldots$ & $X$ & $\ldots$ & $\ldots$ & $\ldots$ & $\ldots$ & $\ldots$ & $\ldots$ & $\ldots$ & $\cdots$ \\
\hline 600 & & $\mathrm{X}$ & & & & & $\ldots$ &. & & & . & $X$ & & $\ldots$ & $\ldots$ & & & .. & & ... & $\ldots$ & &.. & $\ldots$ & $\mathrm{X}$ & & $\ldots$ & & $\ldots$ & .. & \\
\hline 700 & & $X$ & X & & & & . & $\ldots$ & $X$ & & & & . & $\cdots$ & $\ldots$ & .. & & & .. & $\cdots$ & ... & & $\ldots$ & $\cdots$ & $\ldots$ & . & $\ldots$ & & $X$ & & \\
\hline 800 & & $\ldots$ & $X$ & & .. & $X$ & $X$ & $\ldots$ & $\ldots$ & . & $X$ & $\cdots$ & $\ldots$ &.. & $\ldots$ & $\ldots$ & $\ldots$ & $X$ & $\ldots$ & $\ldots$ & $X$ & & $X$ & $\ldots$ & $X$ & & $\ldots$ & ... & $\ldots$ & .. & $\ldots$ \\
\hline 900 & 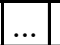 & $\ldots$ & $\ldots$ & $X$ & $\ldots$ & $\mathrm{X}$ & $\ldots$ & $\ldots$ & $\ldots$ & $\ldots$ & $\ldots$ & $\ldots$ & $\ldots$ & $\mathrm{X}$ & $\ldots$ & $\ldots$ & $\ldots$ & $\mathrm{X}$ & $\ldots$ & $\ldots$ & $\ldots$ & $\mathrm{X}$ & $\ldots$ & $X$ & $\ldots$ & $\ldots$ & $\ldots$ & $\ldots$ & $\mathrm{X}$ & $\ldots$ & $\ldots$ \\
\hline 1000 & $X$ & $X$ & & & & & 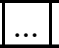 & $\ldots$ & .. & & $\ldots$ & $\ldots$ & . & $\cdots$ & $\ldots$ & .. & $\ldots$ & $\ldots$ & $\ldots$ & $\ldots$ & \begin{tabular}{|l}
$\ldots$ \\
\end{tabular} & $\ldots$ & $\ldots$ & $\ldots$ & $\ldots$ & $\ldots$ & $\ldots$ & $\ldots$ & $\ldots$ & $\ldots$ & \\
\hline 1100 & & $X$ & $X$ & .. & $\ldots$ & .. & $\mathrm{X}$ & $\ldots$ & $\ldots$ & $\ldots$ & $\ldots$ & $\ldots$ & $\ldots$ & $\ldots$ & $X$ & $\ldots$ & $\ldots$ & $\ldots$ & $\ldots$ & $\ldots$ & $\ldots$ & $\ldots$ & $\ldots$ & $\ldots$ & $\ldots$ & $\ldots$ & $\ldots$ & 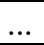 & $\ldots$ & $\ldots$ & $\ldots$ \\
\hline 1200 & & & & & $\mathrm{X}$ & & & $\mathrm{X}$ & & & 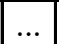 & & & & 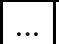 & & $\ldots$ & 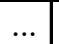 & $\ldots$ & $\ldots$ & ... & 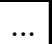 & $\ldots$ & 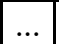 & 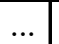 & $\ldots$ & 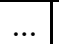 & $X$ & 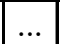 & & \\
\hline 1300 & & & $X$ & & & & $\mathrm{X}$ & & .. & & . & $X$ & &.. & $\ldots$ & $\ldots$ & $\ldots$ & $\ldots$ & $\ldots$ & $\ldots$ & $\ldots$ & $\ldots$ & $\ldots$ & $X$ & & $\ldots$ & $\ldots$ & & $\ldots$ & ... & $\ldots$ \\
\hline 1400 & & .. & $\ldots$ & $\ldots$ & $X$ & & $\ldots$ & $X$ & $\ldots$ &.. & $\ldots$ & $\ldots$ & $\ldots$ & $\ldots$ & $\ldots$ & $\ldots$ & $\ldots$ & $\ldots$ & $\ldots$ & $\ldots$ & $\ldots$ & $\ldots$ & $\ldots$ & $\ldots$ & $\ldots$ & $\ldots$ & $\ldots$ & X & $X$ & $\ldots$ & $\ldots$ \\
\hline 150 & & $X$ & & & & & $\cdots$ & & $\ldots$ & & ... & $\ldots$ & & $\ldots$ & $\ldots$ & $\ldots$ & $\ldots$ & $\ldots$ & $\ldots$ & $\ldots$ & $\ldots$ & $\ldots$ & $\ldots$ & $\ldots$ & $\ldots$ & $\ldots$ & $\ldots$ & ... & $\ldots$ & $\ldots$ & $\ldots$ \\
\hline 1600 & & . & $X$ & $\ldots$ & $\mathrm{X}$ & & $\ldots$ & $\ldots$ & $\ldots$ & & $\ldots$ & $\ldots$ & $X$ & ... & $\ldots$ & $\ldots$ & $\ldots$ & $\ldots$ & $\ldots$ & $\ldots$ & $X$ & $\ldots$ & $\ldots$ & $\ldots$ & $\ldots$ & $\ldots$ & $\ldots$ & $\ldots$ & $\ldots$ & $\mathrm{X}$ &.. \\
\hline 1700 & & $\ldots$ & $\ldots$ & $\ldots$ & .. & & $\ldots$ & $\ldots$ & $X$ & & $\ldots$ & $\ldots$ & $\ldots$ & $\ldots$ & $\ldots$ & $\ldots$ & $\ldots$ & $\ldots$ & $\ldots$ & $\ldots$ & $\ldots$ & $\ldots$ & $\ldots$ & $\ldots$ & $\ldots$ & & $\ldots$ & $X$ & $\ldots$ & $\ldots$ & $\ldots$ \\
\hline 1800 & & $\ldots$ & $\ldots$ & $\ldots$ & $\mathrm{X}$ & & $\ldots$ & $\begin{array}{ll}\ldots \\
\end{array}$ & $\ldots$ & .. & $\ldots$ & $\ldots$ & $\ldots$ & $\ldots$ & $\ldots$ & $\ldots$ & $\ldots$ & $\ldots$ & $\ldots$ & $\ldots$ & $\ldots$ & $\ldots$ & $\ldots$ & $\ldots$ & $\ldots$ & $\ldots$ & $\ldots$ & $\ldots$ & $\ldots$ & $\ldots$ & $\ldots$ \\
\hline 1900 & & $X$ & $\ldots$ & X & & & $\ldots$ & $\ldots$ & $\ldots$ & & $\ldots$ & $\ldots$ & .. & $\ldots$ & $X$ & & $\ldots$ & $\ldots$ & $\ldots$ & $\ldots$ & $\mathrm{X}$ & $\ldots$ & $\ldots$ & $\mathrm{X}$ & $\ldots$ & $\ldots$ & $\ldots$ & $\ldots$ & $\ldots$ & $\ldots$ & $\ldots$ \\
\hline 2000 & & $X$ & $\ldots$ & $\cdots$ & $\ldots$ & &.. & $\ldots$ & $X$ & & $\ldots$ & $\ldots$ & $\ldots$ & $\ldots$ & 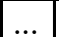 & $\ldots$ & $\ldots$ & $\ldots$ & $X$ & $\ldots$ & $\ldots$ & $\ldots$ & $\ldots$ & $\ldots$ & $\ldots$ & $\ldots$ & $\ldots$ &.. & $X$ & .. & $\ldots$ \\
\hline 2100 & $\mathrm{X}$ & $X$ & $\ldots$ & $\ldots$ &.. & $\mathrm{X}$ & $\ldots$ & ... & $\mathrm{X}$ & & $\ldots$ & $\ldots$ &.. & $\ldots$ & $X$ & & $\ldots$ & $\ldots$ & $\ldots$ & $\ldots$ & $X$ & $\ldots$ & $\ldots$ & $X$ & . & $\ldots$ & $\ldots$ & $\ldots$ & $\ldots$ & $\ldots$ & $\ldots$ \\
\hline 2200 & & $\bar{X}$ & $\ldots$ & $\ldots$ & $\bar{X}$ & X & $\ldots$ & $\ldots$ &.. &.. & $\ldots$ & $\ldots$ & $\ldots$ & $\ldots$ & $\ldots$ & $X$ & $\ldots$ & $\ldots$ & $\ldots$ & $\ldots$ & $\ldots$ & $\ldots$ & $\ldots$ & $\ldots$ & $\ldots$ & $\ldots$ & $\ldots$ & $\ldots$ & $\ldots$ & ... & $\mathrm{X}$ \\
\hline 2300 & $X$ & $\ldots$ & $\bar{X}$ & $X$ & $\ldots$ &.. & $\ldots$ & $\ldots$ & $\ldots$ & ... & $\ldots$ & $\ldots$ & $\ldots$ & $\ldots$ & $\mathrm{X}$ & $\ldots$ & $\ldots$ & $\ldots$ & $\ldots$ & $\ldots$ & $\ldots$ & $\ldots$ & $\ldots$ & $\ldots$ & $\ldots$ & $\ldots$ & $\ldots$ & $\ldots$ & $\ldots$ & $\ldots$ & $\ldots$ \\
\hline 2400 & $\mathrm{X}$ & $\mathrm{X}$ & 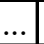 & 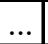 & $\mathrm{X}$ & & 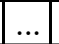 & 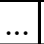 & .. & & $\ldots$ & $\ldots$ & $\ldots$ & .. & $X$ & & $\ldots$ & $\ldots$ & $\ldots$ & $\ldots$ & $\ldots$ & $\ldots$ & $\ldots$ & $\ldots$ & $\mathrm{X}$ & & $\ldots$ & & $\ldots$ & $\ldots$ & $X$ \\
\hline 2500 & & $\mathrm{X}$ & & & & & & & 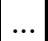 & &. & &.. & .. & $\ldots$ & & $\ldots$ & $\ldots$ & $\ldots$ & $\ldots$ &.. & $\ldots$ & & & $\ldots$ & & & & $\ldots$ & $\ldots$ & $\ldots$ \\
\hline 2600 & .. & $\mathrm{X}$ & $\ldots$ & $\ldots$ & $\ldots$ & $\ldots$ & 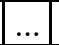 & $\ldots$ & $\ldots$ & $\ldots$ & $\ldots$ & $\mathrm{X}$ & $\ldots$ & $\ldots$ & $\ldots$ & $\ldots$ & $X$ & $\mathrm{X}$ & $\ldots$ & $\ldots$ & $\ldots$ & $\ldots$ & $\ldots$ & $\ldots$ & $\ldots$ & $\ldots$ & $\ldots$ & $\ldots$ & $\ldots$ & $\ldots$ & $\ldots$ \\
\hline 2700 & ... & $\mathrm{X}$ & $\ldots$ & ... & $\ldots$ & $\ldots$ & $\mathrm{X}$ & $\ldots$ & $\ldots$ & $\ldots$ & $\ldots$ & $\ldots$ & $\ldots$ & $\ldots$ & $\mathrm{X}$ & $\ldots$ & $\ldots$ & $\ldots$ & $\ldots$ & $\ldots$ & $\ldots$ & $\ldots$ & $\ldots$ & $\ldots$ & $\ldots$ & $\ldots$ & $\ldots$ & $\ldots$ & $\ldots$ & $\ldots$ & $\ldots$ \\
\hline 2800 & & .. & .. & $\ldots$ & $\ldots$ & .. & & $\ldots$ & $\ldots$ & & $\ldots$ & $\ldots$ & $\ldots$ & $\ldots$ & $X$ & $\ldots$ & $\ldots$ & $\ldots$ & $\ldots$ & X & $\ldots$ & $\cdots$ & $\ldots$ & $\ldots$ & $\ldots$ & & $\ldots$ & $\ldots$ & $\mathrm{X}$ & $\ldots$ & $\ldots$ \\
\hline 2900 & .. & .. & $\ldots$ & $\mathrm{X}$ & $\ldots$ & .. & $\mathrm{X}$ & $\ldots$ & $\ldots$ & $X$ & $\ldots$ & $\ldots$ & $\ldots$ & $\ldots$ & $\ldots$ & $\ldots$ & $\ldots$ & $\ldots$ & $\ldots$ & $\ldots$ & $\ldots$ & & $\ldots$ & $\ldots$ & $\mathrm{X}$ & & $\ldots$ & & & $\ldots$ & $\ldots$ \\
\hline 3000 & & $X$ & & & & & & & & & & & & & & & & & & & $\mathrm{X}$ & & $X$ & & & & & & & & \\
\hline
\end{tabular}

Note: $\mathrm{X}$ indicates $\mathrm{p}$-value of .05 or lower 
Table B.4: Near Repeat Interpersonal Robberies, Knox Ratios

Time (days)

\begin{tabular}{|c|c|c|c|c|c|c|c|c|c|c|c|c|c|c|c|c|c|c|c|c|c|c|c|c|c|c|c|c|c|c|c|}
\hline & & & & & 4 & & & & & & 10 & & 12 & & & & & & & & & & 22 & 23 & 24 & & & & & & \\
\hline & .00 & & 3.11 & 2.85 & $\mid 2.51$ & 1.85 & 2.24 & 2.04 & 2.80 & 2.43 & 1.97 & & & & & & & & 1.37 & & 1.45 & 2.12 & & 1.49 & 1.63 & & & 2.01 & 32 & & \\
\hline 100 & .00 & & & & & & 142 & & & \begin{tabular}{|l|l|}
1.06 \\
\end{tabular} & & & & & & & & & & & & & & & & & & & & & \\
\hline 200 & & & & & & & & & & & & & & & & & & & & & & & & & & & & & & & \\
\hline & & & & & & 14 & & & & & & & & & & & & & & & & & & & & & & & & & \\
\hline 40 & & & & & & & & & & & & & & & & & & & & & & & & & & & & & & & \\
\hline 500 & & & \begin{tabular}{|l|l|}
1.44 \\
\end{tabular} & .60 & 25 & 1.41 & 1.11 & 38 & 1.45 & 1.21 & 07 & & \begin{tabular}{|l|}
0.79 \\
\end{tabular} & & & \begin{tabular}{|l|}
1.25 \\
\end{tabular} & 16 & 72 & & & 8 & & 37 & & & & & & & & .2 \\
\hline 600 & & & 1.19 & 13 & 14 & 0.91 & \begin{tabular}{|l|}
1.02 \\
\end{tabular} & 22 & 1.21 & 1.22 & & 53 & 1.21 & & & 0.92 & 25 & 1.11 & & 34 & & & 1 & & & 0.7 & . & & & & 1 \\
\hline 700 & & & & 21 & 11 & \begin{tabular}{|l|}
0.99 \\
\end{tabular} & \begin{tabular}{|l|}
1.19 \\
\end{tabular} & 34 & 1. & \begin{tabular}{|l|l|}
1.41 \\
\end{tabular} & & 28 & 0. & & 1.19 & 1.42 & 38 & & 1 & .97 & 97 & 29 & 30 & & 1.0 & 1.16 & & & 1.61 & & 0.7 \\
\hline 800 & & & & 22 & & & 1.43 & & & 31 & & & & & & 0.77 & & & & & \begin{tabular}{|l|l}
1.41 \\
\end{tabular} & & & & 1.4 & 1.29 & 1.2 & & .0 & & 0.9 \\
\hline 900 & & & 0.95 & 1.34 & & \begin{tabular}{|l|l|}
1.57 \\
\end{tabular} & \begin{tabular}{|l|}
1.11 \\
\end{tabular} & 16 & 1.0 & 0.88 & 07 & 12 & 1. & & 0 & \begin{tabular}{|l|}
1.02 \\
\end{tabular} & 95 & & 0.81 & 1.02 & & & 1.2 & $\begin{array}{ll}1.3 \\
\end{array}$ & & 0.86 & & & & & \\
\hline & .00 & & 0.74 & 1.07 & & \begin{tabular}{|l|l|}
0.98 \\
\end{tabular} & 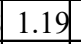 & & 0.97 & \begin{tabular}{|l|}
1.24 \\
\end{tabular} & 30 & 27 & \begin{tabular}{|l|}
1.22 \\
\end{tabular} & & 0.79 & 1.11 & 88 & & & .20 & & & .14 & 4 & & 1.2 & & & & & \\
\hline & & & & 1.26 & & & 1.76 & & 0.91 & 1.13 & & & & & 1.44 & 1.08 & 20 & & & & 08 & & & & & & & 15 & & & \\
\hline & & & & & & & 1.14 & & & 02 & & & & & & 1.21 & & & & 14 & 10 & & & & 13 & & & & 3 & & .05 \\
\hline & & & 1.47 & 27 & & 1.05 & 54 & & & .08 & & & & & & & & & & & & & 0.75 & & & 1.0 & & & .7 & & 1.8 \\
\hline 40 & & & 96 & & & & 0.97 & & & $2]$ & & & & & & & & & & & & & & & & $1 .($ & & & & & \\
\hline 1500 & & 43 & 1.05 & .99 & & \begin{tabular}{|l|l|} 
\\
\end{tabular} & 0.78 & 19 & 1.01 & 1.15 & 04 & 20 & 1.17 & 63 & & 1.25 & 59 & 1 & 65 & 1.22 & & 1. & 1.09 & 0.98 & & 0.91 & 1.3 & & 0.97 & 1. & 1.9 \\
\hline 1600 & & & 1.62 & & & \begin{tabular}{|l|l|}
0.79 \\
\end{tabular} & \begin{tabular}{|l|}
0.91 \\
\end{tabular} & & 17 & 97 & & 13 & 1 & & & & 08 & & & .19 & & & .0 & & & 1.0 & & & & & \\
\hline 1700 & & & .83 & & & 0.96 & 1.07 & & & 25 & 00 & 09 & 12 & & & 1.11 & 14 & 12 & & .02 & & & 0.77 & & & 1.0 & & & & .8 & .0 \\
\hline & & & & & & & \begin{tabular}{|l|}
0.89 \\
\end{tabular} & & & .07 & & & & & & & 25 & & & & & & & & & 1. & & & & & 88 \\
\hline 190 & & & .85 & 31 & & 1.24 & \begin{tabular}{|l|l|} 
\\
\end{tabular} & & & 1.03 & 96 & 0.77 & 0.95 & 83 & 1.36 & 1.11 & .07 & & 1 & 1.06 & 1.3 & & 0.97 & 1.41 & & 0.8 & 0.9 & 02 & 1.2 & 1.12 & 10 \\
\hline 2000 & & & 0.85 & 05 & & \begin{tabular}{|l|l|}
0.76 \\
\end{tabular} & \begin{tabular}{|l|l|}
1.31 \\
\end{tabular} & & & 0.91 & 21 & & 0. & 0.92 & & 1 & .00 & & & 09 & & & 113 & & ( & 0.8 & 13 & 98 & 132 & 0.7 & 29 \\
\hline 2100 & & & 0.94 & & & 1.44 & \begin{tabular}{|l|} 
\\
\end{tabular} & 27 & & & 08 & 09 & & & & & & & & & & & & & & & & & & & \\
\hline 2200 & & & 1.12 & & & 1.41 & \begin{tabular}{|l|l|}
0.87 \\
\end{tabular} & 11 & 1. & 0.79 & 0.99 & 0.96 & 0. & & 1.01 & 1.43 & .31 & & & & & 02 & & & & 1.2 & & 97 & 0.84 & 1.1 & \begin{tabular}{|l|l}
1.3 \\
\end{tabular} \\
\hline 2300 & & & 1.32 & & & \begin{tabular}{|c|}
1.10 \\
\end{tabular} & 0.83 & 0.97 & 1.07 & 0.98 & .01 & 1.20 & 1.27 & 0 & 1.41 & 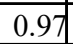 & 0.95 & 1.11 & \begin{tabular}{|l|}
0.69 \\
\end{tabular} & 0.9 & 86 & \begin{tabular}{|l|}
1.11 \\
\end{tabular} & 0.96 & 1.21 & 1.08 & 1.1 & & .23 & 0.9 & 0.6 & 1.1 \\
\hline & & & & & & & 87 & & & 17 & & 1.01 & & & & & 0.97 & & 91 & & & & & & & & 1.12 & & & & \\
\hline 2 & & & & & & & & & & & & & & & & & & & & & & & & & & & & & & & \\
\hline 600 & & & 1.19 & & & \begin{tabular}{|l|}
0.96 \\
\end{tabular} & 1.15 & 98 & 1. & 0.88 & & 1.4 & 0.90 & & & & 38 & & & 0.88 & 14 & & 1.18 & & & 1. & & & & & \\
\hline 2700 & & 1.3 & 1.13 & .16 & \begin{tabular}{|l|l|}
1.12 \\
\end{tabular} & 1.03 & 1.45 & 0 & 0.8 & 0.61 & 10 & 1.23 & 1.12 & 1.06 & 1. & 1.15 & 1.06 & 1.12 & 1.02 & 1.02 & 1.01 & 1.15 & 1.22 & 1.20 & 0.76 & & & .30 & 1.18 & & \\
\hline 800 & & 1.22 & 1.19 & 0.92 & 1.07 & 0.86 & 1.15 & 1.14 & 0.82 & \begin{tabular}{|l|l|} 
\\
\end{tabular} & 0.77 & 1.08 & \begin{tabular}{|l|l|}
0.67 \\
\end{tabular} & 1.01 & 1.43 & 0.84 & 1.22 & 1.04 & 0.87 & & 0.81 & \begin{tabular}{|l}
0.99 \\
\end{tabular} & 1.05 & 1.20 & 1.03 & & 0.93 & 1.13 & 1.32 & & .79 \\
\hline 90 & & & 0.93 & 1.33 & & \begin{tabular}{|l|l|} 
\\
\end{tabular} & 1.36 & & 1.11 & \begin{tabular}{|l|l|}
1.36 \\
\end{tabular} & 1. & 0.84 & 1.22 & 1.1 & 0. & 0.92 & 1.15 & & & 0. & & & & & 1.340 & 0.5 & 1.15 & 91 & & $\varepsilon$ & 1.9 \\
\hline 000 & & & & & & & & & & & & & & & & & & & & & & & & & & & & & & & \\
\hline
\end{tabular}


Table B.5: Near Repeat Residential Burglaries, P-Values

Time (days)

\begin{tabular}{|c|c|c|c|c|c|c|c|c|c|c|c|c|c|c|c|c|c|c|c|c|c|c|c|c|c|c|c|c|c|c|c|}
\hline & 0 & & 2 & 3 & & & & & & & 10 & 11 & 12 & 13 & 14 & 15 & 16 & 17 & 18 & \begin{tabular}{|l|}
19 \\
\end{tabular} & 20 & 21 & 22 & 23 & 24 & & & & & & \\
\hline 0 & $\mathrm{X}$ & X & $\mathrm{X}$ & $\mathrm{X}$ & $\mathrm{X}$ & X & $\mathrm{X}$ & $\mathrm{X}$ & $\mathrm{X}$ & $X$ & $\mathrm{X}$ & $\mathrm{X}$ & $\mathrm{X}$ & $\mathrm{X}$ & $X$ & $\mathrm{X}$ & $\mathrm{X}$ & $X$ & $\mathrm{X}$ & $\mathrm{X}$ & $\mathrm{X}$ & $\mathrm{X}$ & $\mathrm{X}$ & $\mathrm{X}$ & $\mathrm{X}$ & $\mathrm{X}$ & $\mathrm{X}$ & $\mathrm{X}$ & $\mathrm{X}$ & $\mathrm{X}$ & $X$ \\
\hline 100 & $X$ & X & & .. & & & & $\mathrm{X}$ & ... & & $\ldots$ & $\ldots$ & $\ldots$ & ... & $\ldots$ & &. & $\ldots$ & $\ldots$ & ... & $\ldots$ & $\ldots$ & .. & $\ldots$ & $\ldots$ & $\ldots$ & $\ldots$ & $\ldots$ & & & \\
\hline 200 & & X & $\mathrm{X}$ & $X$ & & & $X$ & $\mathrm{X}$ & $X$ & & & & & & & & & & & & & $\ldots$ & .. & ... & $\ldots$ & $\mathrm{X}$ & $X$ & $\cdots$ & & 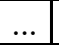 & \\
\hline 300 & & & & & $X$ & $\mathrm{X}$ & & $\mathrm{X}$ & $X$ & & $\mathrm{X}$ & & $X$ & & & $X$ & & $X$ & $\mathrm{X}$ & & $X$ & ... & $\ldots$ & $\ldots$ & $\ldots$ & $\ldots$ & .. & $\ldots$ & $\mathrm{X}$ & $\mathrm{X}$ & $\ldots$ \\
\hline 400 & & X & $\mathrm{X}$ & $\mathrm{X}$ & $\bar{X}$ & X & $X$ & $\mathrm{X}$ & $\mathrm{X}$ & ... & $\mathrm{X}$ & $\ldots$ & $\mathrm{X}$ & $\mathrm{X}$ & $X$ & $\mathrm{X}$ & $\ldots$ & $\ldots$ & $\mathrm{X}$ & $\mathrm{X}$ & $\ldots$ & $\ldots$ & $\ldots$ & $\ldots$ & $\ldots$ & $\mathrm{X}$ & $\ldots$ & $\ldots$ & & $\ldots$ & $\ldots$ \\
\hline 500 & & $\mathrm{X}$ & $\mathrm{X}$ & $\mathrm{X}$ & & $\mathrm{X}$ & $\bar{X}$ & & & $\mathrm{X}$ & & & $\mathrm{X}$ & & & $\mathrm{X}$ & $\mathrm{X}$ & $X$ & & $\mathrm{X}$ & & $\ldots$ & & & 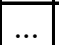 & & 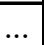 & 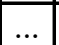 & & 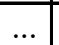 & 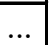 \\
\hline 600 & $\mathrm{X}$ & X & $\bar{X}$ & & X & X & X & $\mathrm{X}$ & $\mathrm{X}$ & $\bar{X}$ & $\mathrm{X}$ & .. & . & $\mathrm{X}$ & 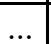 & & & & $\ldots$ & 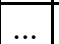 & X & $\ldots$ & $\mathrm{X}$ & $\mathrm{X}$ & $\mathrm{X}$ & . & 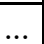 & $\ldots$ & $\mathrm{X}$ & $\ldots$ & ... \\
\hline 700 & & $\mathrm{X}$ & $\bar{X}$ & $\mathrm{X}$ & $\bar{X}$ & & X & $\bar{X}$ & $\ldots$ & & $\mathrm{X}$ & ... & $\bar{X}$ & .. & $\ldots$ & $\ldots$ & $\ldots$ & $\ldots$ & $\ldots$ & $\mathrm{X}$ & $\ldots$ & $\ldots$ & $\ldots$ & $\ldots$ & $\ldots$ & $\ldots$ & $\mathrm{X}$ & $\ldots$ & $\mathrm{X}$ & $\ldots$ & $\ldots$ \\
\hline 800 & & $\mathrm{X}$ & & & $\mathrm{X}$ & X & $\mathrm{X}$ & $X$ & $\ldots$ & & $\mathrm{X}$ & $X$ & $X$ & $X$ & & $\ldots$ & $X$ & $X$ & $\ldots$ & & $X$ & $\mathrm{X}$ & X & $X$ & $X$ & $X$ & $\ldots$ & $X$ & & $X$ & \\
\hline 900 & $X$ & $\bar{X}$ & $X$ & & & & X & $X$ & . & & $\mathrm{X}$ & $\mathrm{X}$ & $X$ & & X & $\ldots$ & & $\mathrm{X}$ & $\ldots$ & ... & $X$ & .. & ... & ... & $\ldots$ & .. & $\ldots$ & $\ldots$ & $X$ & .. & \\
\hline 1000 & & $X$ & $\mathrm{X}$ & $X$ &.. & $X$ & $\bar{X}$ & $\ldots$ & $\ldots$ &.. & $\mathrm{X}$ & $\ldots$ & $\mathrm{X}$ & & $\mathrm{X}$ & $\ldots$ & $\ldots$ & $\ldots$ & $\ldots$ & $\ldots$ & $\ldots$ & $\ldots$ & $\mathrm{X}$ & $X$ & $\ldots$ & $X$ & $\ldots$ & $\ldots$ & $\ldots$ & $\ldots$ & $\mathrm{X}$ \\
\hline 1100 & .. & $X$ & $\mathrm{X}$ & $\ldots$ & $\ldots$ & $X$ & $X$ & $X$ & $\ldots$ & $\ldots$ & $\ldots$ & $\mathrm{X}$ & $\ldots$ & $\ldots$ & $\mathrm{X}$ & $\ldots$ & $\ldots$ & $\ldots$ & $\ldots$ & $\ldots$ & $\ldots$ & $X$ & $\ldots$ & $\ldots$ & $\ldots$ & $\ldots$ & $\ldots$ & $\ldots$ & $\ldots$ & $\ldots$ & $\mathrm{X}$ \\
\hline 1200 & & $\mathrm{X}$ & $X$ & 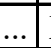 & $\bar{X}$ & $\mathrm{X}$ & $\mathrm{X}$ & & $\ldots$ & $X$ & & $\ldots$ & $X$ & & $\mathrm{X}$ & 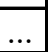 & .. & $\ldots$ & $\mathrm{X}$ & 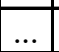 & $\ldots$ & ... & $\mathrm{X}$ & ... & $\ldots$ & .. & ... & $\ldots$ & 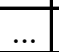 & 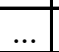 & \\
\hline 1300 & & $\mathrm{X}$ & $\mathrm{X}$ & $\bar{X}$ & $\ldots$ & & $\ldots$ & $\bar{X}$ & $\bar{X}$ & ... & $\ldots$ & $\ldots$ & $\ldots$ & $\ldots$ & $\ldots$ & $\bar{X}$ & $\ldots$ & $\ldots$ & $\ldots$ & $\mathrm{X}$ & $\mathrm{X}$ & $\ldots$ & $\ldots$ & $\ldots$ & $\mathrm{X}$ & $\ldots$ & $\ldots$ & $\ldots$ & $\ldots$ & $\ldots$ & $\ldots$ \\
\hline 1400 & .. & $\mathrm{X}$ & \begin{tabular}{l|l}
$\ldots$ & \\
\end{tabular} & $\mathrm{X}$ & $\mathrm{X}$ & $X$ & $\ldots$ & \begin{tabular}{l|l}
$\ldots$ & \\
\end{tabular} & $\mathrm{X}$ & $\mathrm{X}$ & $\ldots$ & $\ldots$ & $\ldots$ & $\ldots$ & $\ldots$ & $\ldots$ & $\ldots$ & $\mathrm{X}$ & $\mathrm{X}$ & $\ldots$ & $\ldots$ & $\mathrm{X}$ & $\mathrm{X}$ & $\ldots$ & $\ldots$ & $\ldots$ & $\ldots$ & $\ldots$ & $\ldots$ & $\mathrm{X}$ & $\ldots$ \\
\hline 150 & & $\mathrm{X}$ & $\mathrm{X}$ & $X$ & & & $\mathrm{X}$ & & & & $\mathrm{X}$ & & .. & $\mathrm{X}$ & & $X$ & & .. & $\ldots$ & & $\ldots$ & $\ldots$ & $\ldots$ & $\ldots$ & $\ldots$ & & $\ldots$ & $\ldots$ & & $\ldots$ & $\ldots$ \\
\hline 160 & & $X$ & \begin{tabular}{|c|}
$x$ \\
\end{tabular} & $\mathrm{X}$ & $X$ & $X$ & & .. & $\mathrm{X}$ & $\mathrm{X}$ & $\mathrm{X}$ & ... & $X$ & & & & & ... & ... & & $\ldots$ & & $\ldots$ & $\ldots$ & & & $\ldots$ & $\ldots$ & $\mathrm{X}$ & & \\
\hline 1700 & & $\bar{X}$ & $\mathrm{X}$ & & & & $X$ & $\mathrm{X}$ & & & . & $\ldots$ & $\ldots$ & & $\mathrm{X}$ & $\mathrm{X}$ & & & $\bar{X}$ & & $\ldots$ & & \begin{tabular}{|l|}
$\mathrm{X}$ \\
\end{tabular} & $\ldots$ & & & & $\ldots$ & & & \\
\hline 1800 & & $\bar{X}$ & & $\ldots$ & 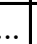 & $X$ & 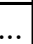 & $\mathrm{X}$ & $\mathrm{X}$ & $\bar{X}$ & ... & $\ldots$ & $\ldots$ & $\bar{X}$ & $\ldots$ & $\ldots$ & $\ldots$ & $\mathrm{X}$ & $\mathrm{X}$ & $\ldots$ & $\ldots$ & $\ldots$ & $\mathrm{X}$ & $\ldots$ & $\ldots$ & $\ldots$ & $\ldots$ & $\ldots$ & $\mathrm{X}$ & $\ldots$ & \\
\hline 1900 & & & &.. & & & 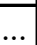 & ... & \begin{tabular}{l|}
$\ldots$ \\
\end{tabular} & ... & $\ldots$ & $\ldots$ & $\ldots$ & $\ldots$ & $\ldots$ & $\ldots$ & $\mathrm{X}$ & 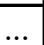 & $\mathrm{X}$ & $\ldots$ & $\ldots$ & $\ldots$ & $\mathrm{X}$ & 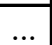 & $\ldots$ & $\ldots$ & $\ldots$ & $\ldots$ & $\ldots$ & $\ldots$ & \\
\hline 2000 & & . & $\mathrm{X}$ & $\bar{X}$ & 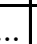 & $\mathrm{X}$ & & $\mathrm{X}$ & $\mathrm{X}$ & $\bar{X}$ & $\mathrm{X}$ & $\ldots$ & $\bar{X}$ & ... & $\ldots$ & $\bar{X}$ & $\mathrm{X}$ & $\mathrm{X}$ & $\bar{X}$ & 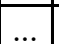 & $\ldots$ & $\ldots$ & $\ldots$ & $\mathrm{X}$ & $\mathrm{X}$ & $\mathrm{X}$ & $\ldots$ & $\ldots$ & $\ldots$ & $\ldots$ & $\ldots$ \\
\hline 2100 & .. & $\bar{X}$ & & $\ldots$ &. & $\bar{X}$ & & $\ldots$ & $\ldots$ & $\bar{X}$ & $\ldots$ & $\bar{X}$ & $\bar{X}$ & 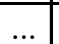 & $\ldots$ & $\ldots$ & $\ldots$ & $\ldots$ & $\ldots$ & $\mathrm{X}$ & $\ldots$ & $\ldots$ & $\ldots$ & $\ldots$ & $\bar{X}$ & $\ldots$ & $\ldots$ & $\ldots$ & $\ldots$ & $\ldots$ & $\ldots$ \\
\hline 2200 & . & $\mathrm{X}$ & $\mathrm{X}$ & $\mathrm{X}$ & & & X & & $\ldots$ & ... & .. & $\ldots$ & $X$ & $\mathrm{X}$ & ... & $\ldots$ & $\ldots$ & $\ldots$ & $\ldots$ & $\ldots$ & 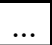 & $\ldots$ & .. & $\ldots$ & $\ldots$ & 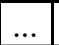 & $\ldots$ & $\ldots$ & $\ldots$ & $\ldots$ & $\ldots$ \\
\hline 2300 & & & $\mathrm{X}$ & & $X$ & & . & $\mathrm{X}$ & $\ldots$ & $\ldots$ & . & $\ldots$ & $\mathrm{X}$ & & $\ldots$ & $X$ & & $\ldots$ & $\mathrm{X}$ & & $X$ & $\ldots$ & & $\ldots$ & $\ldots$ & & ... & $\ldots$ & $\mathrm{X}$ & & $\ldots$ \\
\hline 2400 & $\mathrm{X}$ & $\mathrm{X}$ & \begin{tabular}{|l|}
$x$ \\
\end{tabular} & $\mathrm{X}$ & & 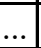 & 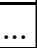 & $\ldots$ & $\ldots$ & $\ldots$ & .. & $\ldots$ & $\ldots$ & 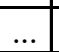 & $\ldots$ & $\ldots$ & $\mathrm{X}$ & $\ldots$ & $\ldots$ & . & $\ldots$ & $\ldots$ & $\mathrm{X}$ & $\ldots$ & $\ldots$ & $\mathrm{X}$ & $\ldots$ & $\ldots$ & .. & $\ldots$ & $\ldots$ \\
\hline 2500 & & 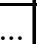 & ... & $\mathrm{X}$ & & 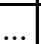 & 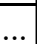 & $\ldots$ & .. & $\ldots$ & 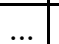 & $\bar{X}$ & $\bar{X}$ & 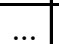 & $\ldots$ & $\ldots$ & $\ldots$ & $\ldots$ & $\ldots$ & $\mathrm{X}$ & $\ldots$ & $\ldots$ & $\ldots$ & $\ldots$ & $\ldots$ & $\ldots$ & $\ldots$ & $\ldots$ & .. & ... & $\ldots$ \\
\hline 2600 & 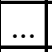 & $\ldots$ & $\mathrm{X}$ & $\ldots$ & $X$ & $\ldots$ & $\mathrm{X}$ & $\begin{array}{ll}\ldots . \\
\end{array}$ & $\mathrm{X}$ & $\ldots$ & $\ldots$ & $\mathrm{X}$ & $\mathrm{X}$ & $\mathrm{X}$ & $\ldots$ & $\ldots$ & $\ldots$ & $\ldots$ & $\ldots$ & $\mathrm{X}$ & $\ldots$ & $\ldots$ & $\ldots$ & $\ldots$ & $\ldots$ & $\ldots$ & $\ldots$ & $\mathrm{X}$ & & $\mathrm{X}$ & $\mathrm{X}$ \\
\hline 2700 & & & & & & & 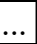 & $\mathrm{X}$ & 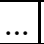 & $\ldots$ & .. & $\ldots$ & $\ldots$ & $\ldots$ & $X$ & $\ldots$ & $X$ & $\ldots$ & $\ldots$ & & $\ldots$ & $\ldots$ & & $\mathrm{X}$ & $\ldots$ & $\mathrm{X}$ & $\ldots$ & $\ldots$ & & $\ldots$ & \\
\hline 2800 & & & & & & $\mathrm{X}$ & & & & & & $\mathrm{X}$ & & & ... & $X$ & $X$ & & & & $\ldots$ & 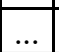 & & & $\ldots$ & & $\ldots$ & $X$ & & & \\
\hline 2900 & & .. & ... & $\ldots$ & . & ... & & ... & $\ldots$ & $\mathrm{X}$ & $\mathrm{X}$ & $\ldots$ & $\bar{X}$ & & $\ldots$ & $\ldots$ & & X & & & & $\bar{X}$ & & $\ldots$ & $\ldots$ & & $\bar{X}$ & & & $\ldots$ & \\
\hline 3000 & & & & & & & & & $\mathrm{X}$ & & & & & & & & & & & & & & & & $\mathrm{X}$ & & & & & & \\
\hline
\end{tabular}

Note: $\mathrm{X}$ indicates $\mathrm{p}$-value of .05 or lower 
Table B.6: Near Repeat Residential Burglaries, Knox Ratios

Time (days)

\begin{tabular}{|c|c|c|c|c|c|c|c|c|c|c|c|c|c|c|c|c|c|c|c|c|c|c|c|c|c|c|c|c|c|c|c|}
\hline & & & & & & & & \\
\hline & & & & & & & & & 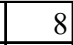 & & 10 & 11 & 12 & 13 & 14 & 15 & 16 & 17 & 18 & 19 & 20 & 21 & 22 & 23 & 24 & 25 & 26 & 27 & 28 & 29 & \\
\hline & 5.50 & & & & & & & & & & & & & & & & & & & & & & & & & & & & & & \\
\hline 100 & 7.50 & 91 & & \begin{tabular}{|l}
1.14 \\
\end{tabular} & 0.95 & & 1.11 & 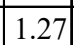 & & & & & & & & & & & & & & & & & 0.8 & 079 & & & & & \\
\hline 200 & 7.07 & & & & 25 & 4 & & & & & & & & & & & & & & & 22 & & & & & & & & & & 17 \\
\hline 300 & & & & & & & & 17 & & & & & & 1.19 & & & & & & & 1.35 & & 01 & 12 & & & & & .4 & & .17 \\
\hline 400 & 5.82 & & & & & & & & & & & & & & & & & & & & & & & & & & & & & & \\
\hline 500 & & & & & & & & & & & & & & & & & & & & & & & & & & & & & & & \\
\hline 600 & 9.80 & & \begin{tabular}{|l|l}
1.35 \\
\end{tabular} & .17 & 27 & & 24 & \begin{tabular}{|l|l|} 
\\
\end{tabular} & 29 & \begin{tabular}{|l|l}
1.22 \\
\end{tabular} & \begin{tabular}{|l|}
1.2 \\
\end{tabular} & & & 40 & & & & & & & & & & & & 91 & & & & & \\
\hline 700 & 9.00 & & 1.46 & \begin{tabular}{|l|l|} 
\\
\end{tabular} & 1. & 27 & 27 & 1.48 & 55 & \begin{tabular}{|l|l|}
1.12 \\
\end{tabular} & \begin{tabular}{|l|}
1.36 \\
\end{tabular} & 03 & & 12 & 02 & & 21 & 96 & & & 04 & & & & & & 31 & & & & .10 \\
\hline 800 & 3.67 & & 1.00 & \begin{tabular}{|l|l|}
1.12 \\
\end{tabular} & & 24 & & 1.30 & 19 & \begin{tabular}{|l|l|}
1.21 \\
\end{tabular} & 1.20 & 4 & 25 & 31 & 03 & 1.14 & 33 & 37 & 19 & 1.13 & 36 & 1.23 & & 30 & 1.23 & & 19 & 1.22 & & & \begin{tabular}{|l|l} 
\\
\end{tabular} \\
\hline 900 & .00 & & & \begin{tabular}{|l|}
1.1 \\
\end{tabular} & & & & 1.26 & 00 & \begin{tabular}{|l|l}
1.18 \\
\end{tabular} & . & & & .17 & 1.44 & 1.09 & 10 & 1 & & & 1.2 & 1.07 & & & & 99 & & .14 & & & 1.0 \\
\hline & & & 1.28 & 1.3 & 1.18 & 46 & & 1.18 & 13 & \begin{tabular}{|l|}
1.05 \\
\end{tabular} & 1.34 & 05 & \begin{tabular}{|l|}
1.22 \\
\end{tabular} & 1.15 & 1.38 & 1.09 & 1.20 & 11 & \begin{tabular}{|l|}
1.09 \\
\end{tabular} & 1.06 & 1.11 & 1.1 & & & & .36 & & & 1.0 & & 1.2 \\
\hline & & & 1.30 & & 1.05 & & 1.33 & 1.21 & $\overline{06}$ & & 1.08 & 25 & & 10 & 1.35 & 0.97 & 1.12 & & 06 & 10 & 96 & 1.25 & & & & 12 & & & & & \\
\hline & 67 & & 1.31 & & 1.27 & & & 1.05 & & & & & & & 19 & & & & & & & & & & & & & & & & 12 \\
\hline 0 & & & 1.24 & 18 & 84 & & 19 & 1.31 & 43 & & \begin{tabular}{|l|l|}
1.10 \\
\end{tabular} & & \begin{tabular}{|l|l|} 
\\
\end{tabular} & \begin{tabular}{|l|l|}
1.01 \\
\end{tabular} & 94 & 1.17 & $\begin{array}{ll}0.98 \\
\end{array}$ & 12 & 17 & 1.19 & 1.23 & 0.91 & & 1.05 & & 82 & & & & 91 & $\mid \begin{array}{l}1.12 \\
\end{array}$ \\
\hline 0 & & & 04 & & 25 & & 05 & 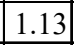 & & & \begin{tabular}{|l|}
0.99 \\
\end{tabular} & & & 05 & 26 & & .02 & & 27 & & 1.17 & \begin{tabular}{|l}
1.17 \\
\end{tabular} & & & & 97 & & & & 17 & 1.0 \\
\hline 1500 & .75 & & 1.22 & 24 & d & & .15 & 1.10 & 84 & .14 & 1.18 & & 1. & 18 & & & & ]1 & & 10 & & & & & & 94 & & & & & \\
\hline 160 & & & 1.15 & 42 & 24 & & & 1.14 & & & 1.22 & & 1. & .13 & & & 0.99 & & & & 07 & & & & & & & & & & \\
\hline & 2.61 & & 1.30 & & & & & 1.34 & & & 1.03 & & & 13 & & & & & & & & & & & & & & & 94 & & .05 \\
\hline 1800 & & & & & & & 9.93 & 1.26 & & \begin{tabular}{|l|}
1.19 \\
\end{tabular} & \begin{tabular}{|l|l|}
1.10 \\
\end{tabular} & & 0. & \begin{tabular}{|l|l|}
1.22 \\
\end{tabular} & 1.00 & 1.01 & .05 & & 1. & 01 & & \begin{tabular}{|l|l|} 
\\
\end{tabular} & & 1.08 & & 25 & & & & 1.03 & .9 \\
\hline 1900 & 15 & & 0.96 & & 0.98 & & & 1.14 & & 1.05 & \begin{tabular}{|l|l|} 
\\
\end{tabular} & & 1.14 & 113 & 0.95 & & .16 & & & & & \begin{tabular}{|l|l|}
1.01 \\
\end{tabular} & & 0.97 & & & & 11 & & 1.13 & 1.1 \\
\hline 2000 & & & 1.18 & \begin{tabular}{|l|l|} 
\\
\end{tabular} & 1.11 & & 0.99 & 1.15 & & \begin{tabular}{|l|l}
1.31 \\
\end{tabular} & \begin{tabular}{|l|}
1.25 \\
\end{tabular} & & \begin{tabular}{|l|}
1.17 \\
\end{tabular} & \begin{tabular}{|l|}
1.07 \\
\end{tabular} & 1.11 & & .17 & & 117 & & 12 & 1. & & & & & & & .9 & 00 & $\overline{1.0}$ \\
\hline 2100 & & & 1.11 & & 1.09 & & 1.10 & 1.11 & & 1.28 & 1.01 & & \begin{tabular}{|l|l|} 
\\
\end{tabular} & .05 & 05 & & 96 & & & & & & & 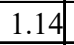 & & & 1 & & & 99 & 1.0 \\
\hline 200 & & & 1.16 & 1.15 & 1.09 & \begin{tabular}{|l|}
0.96 \\
\end{tabular} & 1.15 & $\begin{array}{ll} \\
\end{array}$ & & \begin{tabular}{|l|}
0.96 \\
\end{tabular} & 1.03 & & \begin{tabular}{|l|}
1.20 \\
\end{tabular} & \begin{tabular}{|l|}
1.22 \\
\end{tabular} & 1.10 & 1.06 & .10 & & \begin{tabular}{|l|}
1.15 \\
\end{tabular} & 1.04 & \begin{tabular}{|l|}
1.06 \\
\end{tabular} & 1.13 & 94 & 1.08 & 1.01 & & 1.05 & 1.07 & 1.0 & 0.95 & 0.8 \\
\hline & & & & & 1.18 & & & 1.18 & & 1.09 & 1.12 & & 1.23 & .12 & 1.02 & & & & & & & & & & & & & & & & .9 \\
\hline & & & & & 1.09 & & & & & & 0.98 & & & \begin{tabular}{|l|l|} 
\\
\end{tabular} & 1.00 & 0. & & & & & & & & & & & & & 0 & & \\
\hline 00 & & & 0.95 & .21 & \begin{tabular}{|l|l}
1.07 \\
\end{tabular} & & .05 & \begin{tabular}{|l|l|}
1.13 \\
\end{tabular} & & \begin{tabular}{|l|l|}
0.94 \\
\end{tabular} & 1.00 & & 1.15 & 1.08 & 03 & 1.01 & $\begin{array}{ll}1.09 \\
\end{array}$ & & & & & & & & & & & 0.99 & 10 & & 80 \\
\hline 2600 & & & 1.19 & 1.02 & 1.16 & 11 & 1.19 & \begin{tabular}{|l}
1.09 \\
\end{tabular} & & \begin{tabular}{|l|l|}
1.09 \\
\end{tabular} & 1.05 & & \begin{tabular}{|l|l|}
1.20 \\
\end{tabular} & 1.23 & 0.98 & & 1.13 & 1.04 & 12 & & \begin{tabular}{|l|}
0.98 \\
\end{tabular} & & & 1.03 & 1.06 & \begin{tabular}{|l|}
1.02 \\
\end{tabular} & & 1.21 & & 16 & .1 \\
\hline 00 & & & 1.12 & 1. & 1.09 & & 1.01 & \begin{tabular}{|l|l|}
1.19 \\
\end{tabular} & & \begin{tabular}{|l|l|}
1.03 \\
\end{tabular} & \begin{tabular}{|l|}
0.95 \\
\end{tabular} & & 1.06 & \begin{tabular}{|l|}
0.94 \\
\end{tabular} & 1.20 & 0.8 & 1.14 & & \begin{tabular}{|l|l|}
1.01 \\
\end{tabular} & \begin{tabular}{l|l}
0.98 \\
\end{tabular} & 1.15 & \begin{tabular}{|l}
1.00 \\
\end{tabular} & & 1.27 & $\begin{array}{ll}1.02 \\
\end{array}$ & 1.2 & 0.97 & & 0.9 & 07 & .0 \\
\hline & & & & & \begin{tabular}{|l}
0.98 \\
\end{tabular} & & & \begin{tabular}{|l|l|} 
\\
\end{tabular} & & \begin{tabular}{|l|l|}
0.90 \\
\end{tabular} & 1.04 & & \begin{tabular}{|l|}
1.04 \\
\end{tabular} & $E$ & 0.91 & 1. & & & 0.91 & 1.0 & & \begin{tabular}{|l}
1.03 \\
\end{tabular} & & & & & 891 & & & 95 & .1 \\
\hline & & & 1.00 & & 1.10 & 1.09 & & 1.10 & & & \begin{tabular}{|l|l|} 
\\
\end{tabular} & & 1.19 & 1.10 & 1.11 & 0.87 & 0.98 & 1.20 & 1.07 & & & 1.1 & & & 0.5 & & 1.20 & 0.93 &. & .95 & \\
\hline 000 & & 08 & 0.92 & 1.10 & \begin{tabular}{|l|l}
1.07 \\
\end{tabular} & \begin{tabular}{|l|l|} 
\\
\end{tabular} & \begin{tabular}{|l|l}
0.97 \\
\end{tabular} & \begin{tabular}{|l|l}
1.03 \\
\end{tabular} & $\mid$ & \begin{tabular}{|l|l|}
0.90 \\
\end{tabular} & \begin{tabular}{|l|l|}
1.10 \\
\end{tabular} & & $\mid 1.09$ & \begin{tabular}{|l|}
0.96 \\
\end{tabular} & & 1.03 & 1.09 & & act & 1.08 & \begin{tabular}{|l|}
1.08 \\
\end{tabular} & \begin{tabular}{|l|}
1.01 \\
\end{tabular} & \begin{tabular}{|l|}
0.95 \\
\end{tabular} & 0.94 & 1.13 & \begin{tabular}{|l|}
0.93 \\
\end{tabular} & \begin{tabular}{|l|l|}
1.02 \\
\end{tabular} & 0.97 & 1.13 & 11 & \\
\hline
\end{tabular}


Table B.7: Near Repeat Thefts From Motor Vehicles, P-Values

\section{Time (days)}

\begin{tabular}{|c|c|c|c|c|c|c|c|c|c|c|c|c|c|c|c|c|c|c|c|c|c|c|c|c|c|c|c|c|c|c|c|}
\hline & 0 & 1 & 2 & & 4 & 5 & 6 & 7 & 8 & 9 & 10 & 11 & 12 & 13 & 14 & 15 & 16 & 17 & 18 & 19 & 20 & 21 & 22 & 23 & 24 & & $26 \mid$ & 27 & & & \\
\hline & $\mathrm{X}$ & $\mathrm{X}$ & $\mathrm{X}$ & $\mathrm{X}$ & $\mathrm{X}$ & $\mathrm{X}$ & $\mathrm{X}$ & $\mathrm{X}$ & $\mathrm{X}$ & $\mathrm{X}$ & $\mathrm{X}$ & $X$ & $\mathrm{X}$ & $\mathrm{X}$ & $\mathrm{X}$ & $X$ & $\mathrm{X}$ & $\mathrm{X}$ & $X$ & $\mathrm{X}$ & $\mathrm{X}$ & $X$ & $X$ & $X$ & $\mathrm{X}$ & X & $\mathrm{X}$ & $X$ & $X$ & $X$ & $X$ \\
\hline 100 & $X$ & $\mathrm{X}$ & $\mathrm{X}$ & & & & & & & & & & & & & & & & & & & & & & & & & & & & \\
\hline 200 & $\mathrm{X}$ & $X$ & $\bar{X}$ & $X$ & & & & $\mathrm{X}$ & $X$ & & 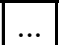 & & & & & $X$ & $X$ & & $\mathrm{X}$ & & $X$ & $X$ & & & & & & & & & \\
\hline 300 & & $\mathrm{X}$ & $\bar{X}$ & & $X$ & & $X$ & & $\mathrm{X}$ & & $\ldots$ & $\ldots$ & & ... & X & $\mathrm{X}$ & & $\ldots$ & $\bar{X}$ & 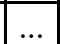 & $\ldots$ & ... & . & $X$ & 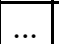 & . & $\ldots$ & $\ldots$ & $\ldots$ & $\ldots$ & .. \\
\hline 400 & $X$ & $\mathrm{X}$ & & X & & & $X$ & & X & & $X$ & & & 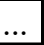 & & & $X$ & $\ldots$ & & ... & $\mathrm{X}$ & $X$ & $X$ & & $X$ & & 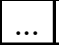 & 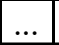 & $\mathrm{X}$ & $X$ & \\
\hline 500 & & $\mathrm{X}$ & $\mathrm{X}$ & X & & $X$ & & & $\mathrm{X}$ & & & & & X & $\mathrm{X}$ & & X & & & & & & $X$ & & $X$ & & & & $X$ & & $\underline{X}$ \\
\hline 600 & $X$ & $\mathrm{X}$ & $X$ & & X & & $X$ & $\mathrm{X}$ & $X$ & X & $X$ & $X$ & & & & & X & $X$ & $X$ & & $X$ & $X$ & $X$ & $X$ & & & $X$ & $X$ & & $X$ & X \\
\hline 700 & & $X$ & $X$ & ... & $\mathrm{X}$ & $\ldots$ & $\mathrm{X}$ & $X$ & $\ldots$ & $\mathrm{X}$ & $\ldots$ & $\mathrm{X}$ & $\mathrm{X}$ & X & $\ldots$ & $\ldots$ & $\ldots$ & $X$ & $X$ & $X$ & $\ldots$ & $X$ & $X$ & $\ldots$ & $\ldots$ & $\ldots$ & $\ldots$ & $\mathrm{X}$ & $X$ & $\ldots$ & $\mathrm{X}$ \\
\hline 800 & $X$ & $\mathrm{X}$ & $\mathrm{X}$ & $\mathrm{X}$ & & $\mathrm{X}$ & $\mathrm{X}$ & & .. & $\mathrm{X}$ &. & & & & $\mathrm{X}$ & & $\ldots$ & $\ldots$ & 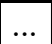 & ... & $\mathrm{X}$ & $X$ & $X$ & & $\mathrm{X}$ & $\mathrm{X}$ & & $\ldots$ & .. & & \\
\hline 900 & & $\mathrm{X}$ & $\mathrm{X}$ & $\bar{X}$ & & $\mathrm{X}$ & $\ldots$ & ... & X & & $\ldots$ & $\ldots$ & $\ldots$ & $X$ & $X$ & $X$ & $\ldots$ & $X$ & $X$ & $\ldots$ & $\ldots$ & $\ldots$ & $\ldots$ & $\ldots$ & $X$ & ... & $\mathrm{X}$ & .. & ... & $X$ & X \\
\hline 1000 & $X$ & $\mathrm{X}$ & $\begin{array}{l}. . \\
\end{array}$ & $\mathrm{X}$ & X & $\ldots$ & $\mathrm{X}$ & $\mathrm{X}$ & $\ldots$ & $\ldots$ & $\ldots$ & $\ldots$ & $\ldots$ & $\ldots$ & $\ldots$ & $\ldots$ & $\ldots$ & $\mid \ldots$ & $\ldots$ & $\ldots$ & $\ldots$ & $\ldots$ & $\mathrm{X}$ & $\ldots$ & $\ldots$ & $\ldots$ & $\mathrm{X}$ & $\ldots$ & $\mathrm{X}$ & $\bar{X}$ & ... \\
\hline 1100 & & $\mathrm{X}$ & $X$ & $\mathrm{X}$ & $X$ & $\ldots$ & $\ldots$ & $X$ & $\ldots$ & & $\ldots$ & $X$ & $\ldots$ & $X$ & ... & $X$ & & $\ldots$ & $\ldots$ & $\ldots$ & $\ldots$ & $X$ & $\mathrm{X}$ & $\ldots$ & $\ldots$ & $\ldots$ & $\ldots$ & $X$ & $X$ & & $\ddot{.}$ \\
\hline 1200 & & $\mathrm{X}$ & $\mathrm{X}$ & $X$ & & & $\mathrm{X}$ & & & & & & & $X$ & . & & $X$ & $X$ & $\mathrm{X}$ & & $X$ & & $\mathrm{X}$ & & $\mathrm{X}$ & & & & & & \\
\hline 1300 & & $\mathrm{X}$ & $\mathrm{X}$ & $\mathrm{X}$ & & & \begin{tabular}{|l|}
$\ldots$ \\
\end{tabular} & $X$ & & $\mathrm{X}$ & X & & $X$ & .. & & & $\ldots$ & $\ldots$ & & $\ldots$ & $\ldots$ & $\mathrm{X}$ & $\ldots$ & $\mathrm{X}$ & & $\ldots$ & $\ldots$ & $\ldots$ & $\mathrm{X}$ & & $X$ \\
\hline 1400 & & $X$ & $\bar{X}$ & $\ldots$ & $\mathrm{X}$ & $X$ & $\ldots$ & $\ldots$ & $\ldots$ & $\ldots$ & $\mathrm{X}$ & $\ldots$ & $\mathrm{X}$ & $\ldots$ & $\mathrm{X}$ & $X$ & ... & $\ldots$ & $X$ & $\ldots$ & $\ldots$ & $\ldots$ & $\ldots$ & $\ldots$ & $\ldots$ & $\ldots$ & $\ldots$ & $\ldots$ & $\ldots$ & $\cdots$ & .. \\
\hline 1500 & & $\mathrm{X}$ & $\mathrm{X}$ & $\mathrm{X}$ & & & $\ldots$ & $\ldots$ & $\mathrm{X}$ & $X$ & $\ldots$ & $X$ & & $\ldots$ & $\ldots$ & $\mathrm{X}$ & $\mathrm{X}$ & $\ldots$ & $\ldots$ & $\ldots$ & $\ldots$ & $\mathrm{X}$ & . & $\mathrm{X}$ & $\mathrm{X}$ & .. & $\ldots$ & $\mathrm{X}$ & $\ldots$ & & $\bar{X}$ \\
\hline 1600 & & $\mathrm{X}$ & & $\mathrm{X}$ & & & $\ldots$ & $\mathrm{X}$ & X & $X$ & $\ldots$ & $\ldots$ & $\ldots$ & $\ldots$ & $\ldots$ & 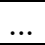 & $X$ & $\ldots$ & ... & $\ldots$ & $\ldots$ & $\ldots$ & $\mathrm{X}$ & $\mathrm{X}$ & $\ldots$ & .. & $\ldots$ & $\ldots$ & $X$ & &. \\
\hline 1700 & & $X$ & 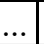 & $\mathrm{X}$ & . & 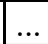 & $\mathrm{X}$ & $X$ & & $X$ & $\ldots$ & $\ldots$ & $\ldots$ & $\ldots$ & $\ldots$ & $X$ & $X$ & $\ldots$ & $\ldots$ & $\mathrm{X}$ & $\mathrm{X}$ & $\ldots$ & $\ldots$ & $\mathrm{X}$ & $\ldots$ & $\ldots$ & $\ldots$ & $\mathrm{X}$ & $\ldots$ & $\ldots$ & .. \\
\hline 1800 & $X$ & $\mathrm{X}$ & $\mathrm{X}$ & $\mathrm{X}$ & $X$ & & 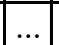 & $\bar{X}$ & & $X$ & 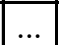 & & $\bar{X}$ & $\ldots$ & $X$ & & $\mathrm{X}$ & $\ldots$ & & 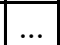 & $\ldots$ & ... & $\mathrm{X}$ & $\ldots$ & . & $\ldots$ & $\mathrm{X}$ & $\ldots$ & 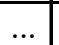 & & \\
\hline 1900 & & $X$ & & $\mathrm{X}$ & $\mathrm{X}$ & $X$ & $X$ & $\theta$ & .. & $X$ & $X$ & $X$ & & X & $X$ & & $X$ & ... & & $\ldots$ & $\ldots$ & .. & $\ldots$ & $\ldots$ & $X$ & ... & ... & $X$ & 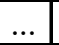 & & .. \\
\hline 2000 & $\mathrm{X}$ & $X$ & & & $\mathrm{X}$ & & .. & & .. & • & $\ldots$ & $\ldots$ & $\ldots$ & $\ldots$ & .. & .. &.. & $\ldots$ & .. & $X$ & $\ldots$ & $\ldots$ & $\ldots$ & ... & $\mathrm{X}$ & .. & $\ldots$ & ... & . & & .. \\
\hline 2100 & & $\ldots$ & $\mathrm{X}$ & $\bar{X}$ & $\ldots$ & $\mathrm{X}$ & . & $X$ & .. & .. & $\ldots$ & $\ldots$ & $\ldots$ & $\ldots$ & $\ldots$ & $\ldots$ & $\ldots$ & $\ldots$ & $\ldots$ & $\ldots$ & $\ldots$ & $\ldots$ & $\ldots$ & $\ldots$ & $\ldots$ & $\ldots$ & $\ldots$ & .. & $\mathrm{X}$ & $X$ & ... \\
\hline 2200 & & $\mathrm{X}$ & ... & ... & ... & $\ldots$ & $\ldots$ & $\mathrm{X}$ & $\mathrm{X}$ & 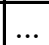 & $\ldots$ & $\ldots$ & $\ldots$ & $\ldots$ & $X$ & ... & $\ldots$ & $\ldots$ & $\ldots$ & $\ldots$ & $\ldots$ & $\ldots$ & $\ldots$ & $\mathrm{X}$ & $\ldots$ & $\ldots$ & $\ldots$ & $\mathrm{X}$ & $\mathrm{X}$ & $\ldots$ & ... \\
\hline 2300 & & $\mathrm{X}$ & $\mathrm{X}$ & $\ldots$ & $x$ & $X$ & $X$ & . . & .. & & .. & $\ldots$ & $\ldots$ & $\ldots$ & $\ldots$ & $\mathrm{X}$ & ... & $\ldots$ & $\ldots$ & $\ldots$ & $\ldots$ & $\mathrm{X}$ & $\ldots$ & $\ldots$ & $\ldots$ & $\ldots$ & $\ldots$ & & $\ldots$ & & $\ldots$ \\
\hline 2400 & & $\mathrm{X}$ & $\ldots$ & $\ldots$ & $\ldots$ & $\mathrm{X}$ & $\mathrm{X}$ & $\ldots$ & $\ldots$ & . & $\ldots$ & $\ldots$ & $\ldots$ & $\ldots$ & $\ldots$ & $\ldots$ & $\ldots$ & $\ldots$ & $\ldots$ & $\ldots$ & $\ldots$ & $\ldots$ & $\ldots$ & $\ldots$ & $\ldots$ & $\ldots$ & $\ldots$ & $\ldots$ & $\ldots$ & & $\bar{X}$ \\
\hline 2500 & & $\mathrm{X}$ & $\mathrm{X}$ & $\ldots$ & $\ldots$ & & 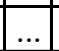 & 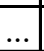 & $\mathrm{X}$ & & $\ldots$ & $\ldots$ & & $\ldots$ & $\ldots$ & & $\mathrm{X}$ & $\ldots$ & $\ldots$ & $\ldots$ & $\ldots$ & $\mathrm{X}$ & & $\ldots$ & $\ldots$ & $\ldots$ & $\ldots$ & $\ldots$ & $\ldots$ & & $\mathrm{X}$ \\
\hline 2600 & & $\mathrm{X}$ & $\ldots$ & $\ldots$ & $\ldots$ & $\ldots$ & $\ldots$ & $\mathrm{X}$ & $\ldots$ & $\ldots$ & $\ldots$ & $\ldots$ & $X$ & $\ldots$ & $\ldots$ & $X$ & $\ldots$ & $\ldots$ & $\ldots$ & $\ldots$ & $\ldots$ & $\ldots$ & $\ldots$ & $\ldots$ & $\ldots$ & $\ldots$ & $\ldots$ & $\ldots$ & $\ldots$ & $\ldots$ & $\ldots$ \\
\hline 2700 & & $x$ & & $\cdots$ & . & & & & & & $\ldots$ & $\ldots$ & & .. & $\ldots$ & & & $\ldots$ & & $\cdots$ & $\ldots$ & $\ldots$ & $\cdots$ & $\ldots$ & & .. & .. & & .. & & \\
\hline 2800 & & $X$ & .. & .. & $X$ & & $\mathrm{X}$ & $\mathrm{X}$ & .. & & $\ldots$ & .. & .. & ... & ... & $X$ & & $\ldots$ & $X$ & . & $\ldots$ & .. & ... & $\ldots$ & $X$ & & ... & $X$ & & ... & .. \\
\hline 2900 & $X$ & $X$ & .. & ... & ... & & $\ldots$ & $X$ & $\ldots$ & & $\ldots$ & $\ldots$ & ... & $\ldots$ & $\ldots$ & $\ldots$ & $\ldots$ & $\ldots$ & ... & $\ldots$ & $\ldots$ & ... & $\ldots$ & & & & & $\ldots$ & $\mathrm{X}$ & $\ldots$ & \\
\hline 3000 & & $\mathrm{X}$ & $\mathrm{X}$ & & & & $\mathrm{X}$ & $\mathrm{X}$ & & & & & & & & & & & & & & $\bar{X}$ & & & & & & $\mathrm{X}$ & & $\bar{X}$ & \\
\hline
\end{tabular}

Note: $\mathrm{X}$ indicates $\mathrm{p}$-value of .05 or lower 
Table B.8: Near Repeat Thefts From Motor Vehicles, Knox Ratios

Time (days)

\begin{tabular}{|c|c|c|c|c|c|c|c|c|c|c|c|c|c|c|c|c|c|c|c|c|c|c|c|c|c|c|c|c|c|c|c|}
\hline & & & & & & & & & & & 10 & 11 & 12 & 13 & 14 & 15 & 16 & 17 & 18 & 19 & 20 & 21 & 22 & 23 & 24 & 25 & 26 & 27 & 28 & 29 & \\
\hline 0 & & 24 & 2.32 & 1.84 & $\mid 1.73$ & 1.871 & \begin{tabular}{|l|l}
1.93 \\
\end{tabular} & 1.88 & 1.77 & & \begin{tabular}{l|l}
1.75 & 1 \\
\end{tabular} & 1.52 & & 1.61 & 1.82 & 1.75 & & & & 1.50 & 1.64 & 1.631 & 1.691 & 1.51 & $1.51 \quad 1$ & 1.60 & 1.46 & 1.55 & 162 & 1.72 & \\
\hline 100 & 16 & & 1.17 & & & 920 & & & & & & & & & & & & & & & & & & & & & & & & & \\
\hline 200 & & & 1.27 & & & & & & & & & & & & & & & & & & & & & & & & & & & & \\
\hline 00 & & & & & & & & & & & & & & & & & & & & & & & & & & & & & & & \\
\hline 400 & & & & & & & & & & & & & & & & & & & & & & & & & & & & & & & \\
\hline 500 & 2.96 & $\begin{array}{ll}1.87 \\
\end{array}$ & \begin{tabular}{|l|l|}
1.24 \\
\end{tabular} & 25 & 1.08 & 1.13 & & 1.12 & .18 & 09 & 1.05 & 1.07 & & & 1.12 & 1.02 & 1.12 & 1.0 & & & & & & & & & 10 & & & & .17 \\
\hline 600 & 4.95 & 1.91 & \begin{tabular}{|l|}
1.31 \\
\end{tabular} & 1.13 & 1.17 & .05 & 1.29 & 1.14 & 26 & 15 & 1.221 & 1.15 & 96 & 0.5 & 1.08 & 1.09 & 1.18 & 1.16 & 13 & 1.07 & 1.22 & .13 & 1.15 & 1.14 & .99 & & 1.27 & 15 & 0 & 1.1 & .1 \\
\hline 700 & 2.20 & 1.64 & \begin{tabular}{|l|l|} 
\\
\end{tabular} & 1.06 & 1.16 & 1.00 & 1.25 & \begin{tabular}{|l|l|}
1.18 \\
\end{tabular} & 07 & 0 & 1.04 & 1.13 & 16 & & 1.04 & 1( & 1.05 & 1.14 & 13 & 1.10 & 1.10 & 1.18 & 1.21 & 1.04 & 1.021 & 1.02 & 1.024 & 16 & .14 & 1.1 & 1.1 \\
\hline 800 & 6.42 & .75 & \begin{tabular}{|l|l|} 
\\
\end{tabular} & 1.17 & \begin{tabular}{|l|}
1.04 \\
\end{tabular} & 1.12 & 1.19 & 1.09 & 1.12 & 1.11 & 0.98 & 1.00 & 99 & 1.06 & 1.12 & 1.07 & 1.07 & 1.08 & .06 & 1.01 & 1.16 & 1.16 & 1.14 & 1.04 & 1.17 & 1.12 & 0.98 & .01 & .09 & 0.93 & 1.0 \\
\hline 900 & 52 & 63 & \begin{tabular}{|l|l|}
1.22 \\
\end{tabular} & 14 & \begin{tabular}{|l|}
1.05 \\
\end{tabular} & 1.12 & 1.09 & 1.09 & .11 & 1.0 & 1.05 & 1.06 & 1.06 & 1.15 & 1.12 & 1.12 & 0.99 & 1.16 & .12 & 1.03 & 1.10 & 1.05 & 1.05 & 0.98 & 1.11 & & 1.1 & & 1.0 & 1.1 & .1 \\
\hline & 38 & 1.46 & 1.08 & 1.12 & 1.20 & 1.06 & 1.10 & 1.15 & 1.04 & 1.04 & 0.94 & 1.08 & 1.01 & 1.01 & 1.06 & 1.07 & 1.0 & 1.03 & .03 & 0.92 & 1.04 & 1.04 & .14 & 1.02 & 0.91 & 1.0 & 1.13 & & & & \\
\hline & 35 & 1.58 & 1.12 & & 11 & 0.96 & & 1.12 & 0.97 & & 1.08 & 1.12 & 03 & 1. & 1.03 & 1.11 & 0.92 & 0.94 & 34 & & $1.10[1$ & \begin{tabular}{l|l}
15 & 1 \\
\end{tabular} & & & $\begin{array}{lll}98 & 1\end{array}$ & & & & & & \\
\hline & 1.39 & & 1.14 & & 1.05 & \begin{tabular}{l|l}
1.02 & 1 \\
\end{tabular} & 1.12 & & \begin{tabular}{l|l}
0.98 & 1 \\
\end{tabular} & 1.08 & & & & & 1.04 & & 1.08 & & & & & & & 0.98 & \begin{tabular}{l|l}
1.12 & 0 \\
\end{tabular} & & & & 00 & & 1.0 \\
\hline 300 & 1.92 & 41 & 1.13 & & 05 & 1.050 & 0.99 & 1.11 & \begin{tabular}{l|l}
1.05 & 1 \\
\end{tabular} & 1.12 & .11 & 1.03 & $\begin{array}{ll}12 \\
\end{array}$ & 0.96 & 1.02 & 1.07 & 1.00 & 1.09 & .99 & 1.05 & 1.08 & \begin{tabular}{l|l}
1.10 \\
\end{tabular} & \begin{tabular}{l|l}
06 & 1 \\
\end{tabular} & 1.17 & 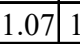 & 1.06 & 0.95 & 1.051 & 1.11 & & 1.2 \\
\hline 400 & 2.46 & 39 & 1.17 & & 08 & .11 & 0.96 & 08 & \begin{tabular}{l|l}
06 & 0 \\
\end{tabular} & & 10 & \begin{tabular}{|c|}
0.98 \\
\end{tabular} & 08 & & .08 & .12 & 1.00 & 1.05 & 08 & 1.05 & 0.98 & \begin{tabular}{l|l}
.03 & 1
\end{tabular} & $06 \mid 1$ & 1.05 & 103 & 0.9 & 1.0 & .98 & 0 & & .0 \\
\hline 1500 & 0.99 & \begin{tabular}{|l|}
1.33 \\
\end{tabular} & $\mid 1.15$ & .12 & 0.99 & 0.99 & $\begin{array}{ll}1.06 \\
\end{array}$ & 1.07 & .07 & 12 & \begin{tabular}{|l|l}
.04 & 1 \\
\end{tabular} & 1.08 & & & .05 & & & .06 & & & 10 & 11 & $\begin{array}{l}06 \\
6\end{array}$ & 1.0 & & 1.0 & & .11 & & & .1 \\
\hline 1600 & 0.51 & 1.24 & \begin{tabular}{|l|l}
1.07 \\
\end{tabular} & 1.07 & 1.06 & \begin{tabular}{l|l|l}
1.04 \\
\end{tabular} & 1.01 & 1.10 & .11 & 1.08 & 0.99 & 1.01 & 99 & 0.99 & (.07) & .99 & 1.13 & \begin{tabular}{c|}
0.98 \\
\end{tabular} & .01 & 1.01 & 0.99 & $1.06\left[\begin{array}{l}1.1 \\
\end{array}\right.$ & 1.09 & 1.11 & $1.00[1$ & 1.0 & 1.05 & .05 & & & .9 \\
\hline 1700 & 2.13 & 22 & .05 & & 1.07 & 0.99 & 1.09 & 1.17 & 1.03 & 1.13 & 0.98 & 1.00 & .00 & 97 & 1.02 & 17 & & 0.98 & & & 1.09 & 1.02 & 03 & 1.11 & 1.03 & .0 & 1.01 & 1.099 & $.0 t$ & & .05 \\
\hline 1800 & 45 & 28 & & & 1.07 & 99 & 1.01 & 1.09 & $\begin{array}{ll}02 & \\
\end{array}$ & 1. & 1.011 & 05 & 07 & 1.01 & .08 & 1.0 & & 1.02 & & 06 & 0.95 & 1.01 & 1.12 & 1.02 & 1.010 & & 1.08 & 1.01 & 0.9 & & 1.0 \\
\hline 1900 & & & & & 13 & & & 1.05 & 00 & & 1.14 & 10 & & & 09 & 02 & & 1. & & & 011 & & & 0.99 & 1.08 & & 70 & & 1.01 & 1.02 & .0 \\
\hline 2000 & 3.19 & 1.17 & 1.04 & 1.04 & \begin{tabular}{ll|}
1.09 \\
\end{tabular} & .04 & 1.06 & 1.01 & 1.00 & 1.00 & 1.01 & 1.03 & 1.06 & 1.00 & 1.03 & 1.0 & 1.02 & $\begin{array}{ll}1.03 \\
\end{array}$ & & 1.11 & 0.96 & 1.04 & 1.04 & 1.04 & 1.11 & 0.95 & 0.99 & .01 & 1.02 & 0.98 & 1.0 \\
\hline 2100 & 1.78 & 1.08 & 1.10 & 1.08 & 1.05 & 1.09 & 1.05 & 1.07 & 1.02 & 1.02 & 1.050 & 0.97 & 0.99 & 0.96 & 1.01 & 1.02 & 1.00 & 1.06 & 0.98 & 0.96 & 1.04 & 0.97 & 1.03 & 0.98 & 1.03 & 1.0 & 1.05 & 1.04 & 1.0 & 1.10 & 1.0 \\
\hline 2200 & 1.62 & 1.20 & \begin{tabular}{|l|}
1.03 \\
\end{tabular} & 1.06 & .00 & 1.05 & 1.04 & 1.10 & 1.07 & 0.99 & 0.92 & 1.02 & 0.98 & 1. & 1.10 & 1.07 & 1.0 & 1.01 & & & 1.00 & 0.98 & 1 & 1.09 & 1.04 & 1.01 & 1.04 & 1.11 & 1.10 & 1.03 & 1.0 \\
\hline 2300 & 0.40 & 1.18 & 10 & 1.04 & 1.09 & 1.08 & 1.10 & 1.02 & 1.06 & 1.06 & 1.04 & 0.98 & 0.97 & 0. & 0.99 & 1.06 & 1.04 & 1.03 & 1.0 & 0.9 & 0.94 & 1.07 & 1.02 & 1.06 & 0.99 & 0.9 & 0.94 & & 0.9 & 0.97 & 1.0 \\
\hline 240 & 0.84 & \begin{tabular}{l|l}
15 & 1 \\
\end{tabular} & \begin{tabular}{|l|l|} 
& \\
\end{tabular} & 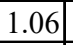 & \begin{tabular}{|l|l}
04 & 1 \\
\end{tabular} & \begin{tabular}{l|l}
08 & 1 \\
\end{tabular} & 1.08 & 1.04 & \begin{tabular}{l|l}
00 & 1 \\
\end{tabular} & 1.04 & \begin{tabular}{l|l}
1.00 & 1
\end{tabular} & 1.05 & $1.06 \mathrm{C}$ & 0. & 1.051 & 1.06 & 1.02 & 1.0 & 1.02 & 0.99 & 1.0 & \begin{tabular}{|l|l|l}
0.98 & 1 \\
\end{tabular} & \begin{tabular}{l|l}
1.05 & 1 \\
\end{tabular} & 1.04 & \begin{tabular}{l|l|l}
1.00 \\
\end{tabular} & 0.9 & 1.03 & & 1.0 & 1.07 & .0 \\
\hline & & & & & & & & & & & & & & 1. & & & 1. & & & & & & & & & & & & & & \\
\hline 00 & 0.38 & & & & & $\begin{array}{lll}3 & 0 \\
\end{array}$ & 0.96 & 1.08 & & & \begin{tabular}{l|l}
0.92 & 1 \\
\end{tabular} & & 1.10 & 1. & 0.96 & 1.0 & 1.00 & 9 & & 0. & 0.98 & & 1.051 & 1.00 & & & & & & 102 & \\
\hline 2700 & 2.29 & 131 & .02 & .02 & 03 & \begin{tabular}{l|l}
0.98 & 1
\end{tabular} & 1.00 & 1.05 & 1.01 & 0.99 & $1.06 \mathrm{C}$ & 99 & 0.97 & 1.05 & 1.01 & 1.0 & 1.02 & 1.00 & 1.01 & 1.04 & 1.00 & 1.021 & \begin{tabular}{l|l}
1.01 & 1
\end{tabular} & 1.04 & \begin{tabular}{l|l}
1.00 & 1
\end{tabular} & & & & 106 & 1.03 & \\
\hline 300 & 0.64 & 1.12 & 1.01 & 1.00 & 1.07 & 0.94 & 1.06 & 1.11 & 1.00 & 0.98 & \begin{tabular}{l|l}
1.00 & 1 \\
\end{tabular} & 1.00 & 1.03 & 1.01 & 1.00 & 1.0 & 1.03 & 1.04 & 1.08 & 0.96 & & 0.96 & 1.05 & 1.00 & \begin{tabular}{l|l}
1.12 & 1 \\
\end{tabular} & & & & 0.98 & 1.05 & \\
\hline 100 & 3.25 & 5 & .03 & .01 & (.04) & 0.9 & & 1.07 & 1.0 & 1.01 & 1.051 & & & 0.9 & 1.0 & 1.02 & 1.05 & 1.05 & & & & 1.01 & 1.04 & 1.01 & & & 0.95 & & 07 & 1.02 & .0 \\
\hline 000 & .00 & & & & & & & & & & & & & & & & & & & & & & & 1.01 & & & & & & & \\
\hline
\end{tabular}

